Universidad Politécnica de Madrid Departamento de Economía Agraria,

Estadistica y Gestión de Empresas

Escuela Técnica Superior de Ingeniería Agronómica, Alimentaria y de Biosistemas

\title{
Economic effects of climate change on agriculture: multi-scale assessment through regional mathematical programming models
}

\author{
Tesis Doctoral \\ Francisco Fernández Jorquera \\ Ingeniero Agrónomo
}

Madrid 2017 

Universidad Politécnica de Madrid Departamento de Economía Agraria, Estadística y Gestión de Empresas Escuela Técnica Superior de Ingeniería Agronómica, Alimentaria y de Biosistemas

\title{
Economic effects of climate change on agriculture: multi-scale assessment through regional mathematical programming models
}

\author{
Tesis Doctoral \\ Francisco Fernández Jorquera \\ Ingeniero Agrónomo \\ Directores \\ Maria Blanco Fonseca \\ Dra. Ingeniero Agrónomo \\ Roberto Ponce Oliva \\ Dr. Economista
}

Madrid 2017 



\section{CAMPUS}

DE EXCELENCIA

POLITÉCNICA

INTERNACIONAL

"Ingeniamos el futuro"

Tribunal nombrado por el Sr. Rector Magfco. de la Universidad Politécnica de Madrid, el día de de $201 \ldots$

Presidente:

Vocal:

Vocal:

Vocal:

Secretario:

Suplente:

Suplente:

Realizado el acto de defensa y lectura de la Tesis el día de de $201 \ldots$ en la E.T.S.I./Facultad

Calificación

EL PRESIDENTE

LOS VOCALES

EL SECRETARIO 

A mis fieles compañeras de viaje Francisca y Matilda 



\section{Agradecimientos}

Cumplir este desafío propuesto hace 5 años atrás, ha significado recorrer un camino difícil, de mucho esfuerzo, un reto constante a la perseverancia y a la capacidad de enfrentar diversas frustraciones y adversidades. Sin embargo, ya estamos acá, en el último tramo de este camino. Y digo "estamos" ya que todo este proceso hubiera sido imposible de llevar sin el apoyo, la confianza, el ánimo y porque no decir, la paciencia de muchas personas. A todas ellas quiero dedicar este trabajo.

Quiero expresar mi más sincero agradecimiento a mis dos tutores de tesis, Maria Blanco y Roberto Ponce. Sin su apoyo y paciencia este trabajo probablemente no hubiera concluido. Muchas gracias Maria por la confianza que pusiste en mi durante los primeros años de este proceso, me enseñaste la importancia de la rigurosidad en el trabajo realizado, y me empujaste a creer en mis capacidades más allá de lo que yo creía poder lograr. Gracias por todo lo aprendido y por tu enorme paciencia. Muchas gracias Roberto, por todo lo que has aportado a este trabajo. Por haber confiado en mí cuando regresé a Chile y darme la oportunidad de seguir trabajando en el mundo académico sin abandonar este proyecto. Además de un excelente tutor has sido un gran amigo, que, en aquellos momentos de flaqueza, siempre te diste el tiempo de escucharme y decirme las palabras claves para continuar.

También agradecer sinceramente a Felipe Vásquez, quien junto a Roberto me acogieron como parte de su equipo de trabajo en diversos proyectos, dándome la oportunidad y la confianza de trabajar en la academia y continuar el proceso de desarrollo de mi tesis doctoral. Gracias por tus aportes a las investigaciones que componen esta tesis.

Sin duda, este trabajo no hubiera sido posible de realizar sin la existencia de diversos proyectos en España y Chile. Quiero agradecer al proyecto ULYSSES, en cual tuve la suerte de trabajar junto a Maria Blanco y un gran equipo de investigadores. Gracias por el financiamiento durante la primera etapa de desarrollo de mi tesis y por la oportunidad de conocer y compartir con investigadores de primer nivel. Gracias a todos los compañeros de este proyecto por la experiencia académica y profesional que me han brindado. En especial gracias a los miembros del equipo UPM, Alberto Garrido, coordinador del proyecto, Isabel Bardají, José M. Sumpsi, Sol García-Germán, Esperanza Luque y Ana Felis. 
La segunda etapa de este proceso fue posible de realizar gracias al financiamiento de los proyectos eec 2 y CRHIAM. En este sentido, quiero volver a agradecer a Felipe y Roberto por integrarme a estos proyectos y confiar en mis capacidades.

Agradezco también al Departamento de Economía Agraria, Estadística y Gestión de Empresas especialmente al grupo de Investigación de Economía Agraria y Gestión de los Recursos Naturales. En especial agradecer a todos los profesores del Master en Economía Agraria por todo lo aprendido.

Gracias a todos mis compañeros y amigos de la ETSI Agrónomos y del CEIGRAM. A mis amigos del Master Jorge, Tere, Tamara, Andrés con quienes compartimos muy gratos momentos. A mis compañeros y amigos de oficina cuando trabajé en España, Berta, Ruth, Paloma, Gema, Irene, Rhys, Silvestre, Pili. A todos ustedes, aunque insistan que el vino español es mejor que el chileno, me hicieron sentir a mí y a mi familia como en casa, y por eso estoy eternamente agradecido y los perdono.

Por último, quiero agradecer a mi familia. A mis padres por sus palabras de aliento y apoyo y por siempre creer en mí, especialmente a mi madre quien grabó en mí el valor y las recompensas de la paciencia, el esfuerzo y la perseverancia. A Francisca, mi compañera de vida, quien ha vivido cada uno de los momentos de este proceso, los buenos y los malos. Gracias por estar junto a mi todo este tiempo, por apoyarme y soportarme, por darme el tiempo y espacio necesario para cumplir con este objetivo, muchas veces haciendo el trabajo que alguna vez prometimos que haríamos como equipo. Finalmente, agradecer a mi querida Matilda, quien sin sospecharlo ha sido una fuente de energía inagotable.

Gracias a todos!!! 


\section{Contents}

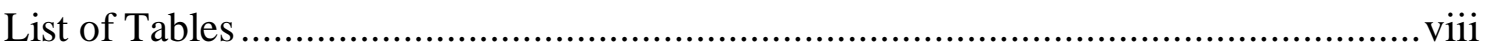

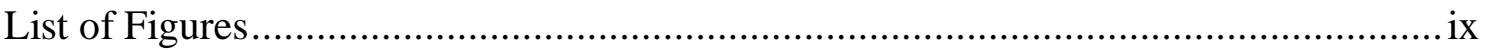

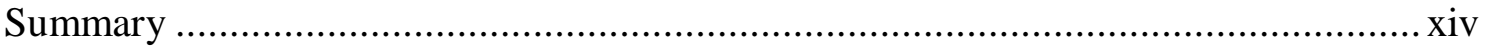

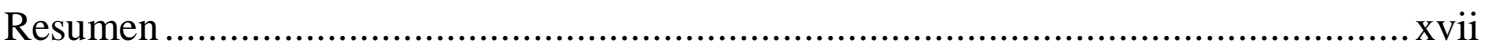

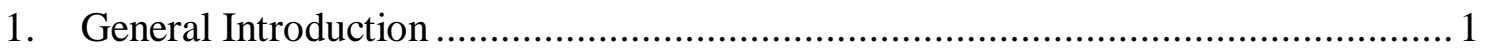

1.1. Research context .............................................................................. 1

1.1.1. Agriculture and Climate Change ..................................................... 1

1.1.2. Modelling the Economic Impacts of Climate Change on Agriculture ....... 2

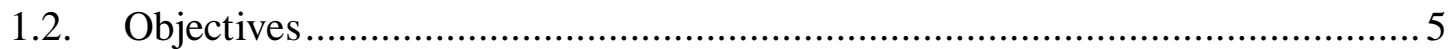

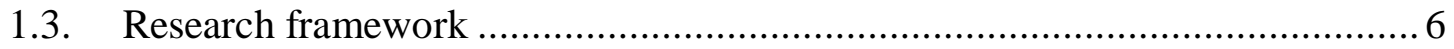

2. Modelling the Economic Impact of Climate Change on Agriculture: A Review of

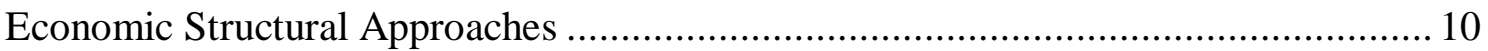

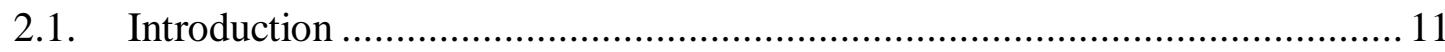

2.2. Overview of Economic Assessment methods ............................................. 12

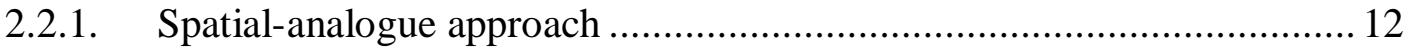

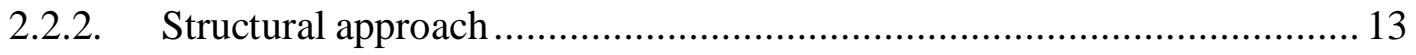

2.3. Global and Regional economic assessments .......................................... 16

2.3.1. Global Economic Impact assessments .......................................... 16

2.3.2. Regional Economic Impact Assessments ........................................... 27

2.4. Common findings and future research directions ..................................... 35

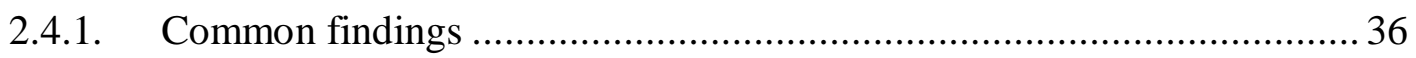

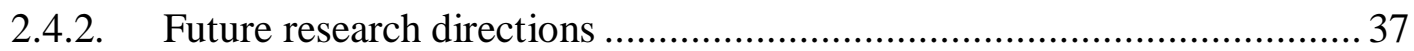

3. Water Variability and the Economic Impacts on Small-Scale Farmers. A Farm Risk-Based Integrated Modelling Approach ................................................... 42

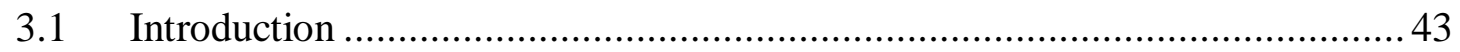

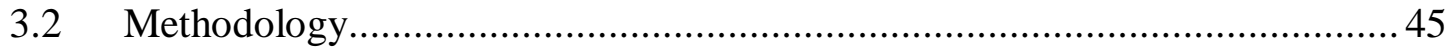


3.2.1 Hydrological model .............................................................. 45

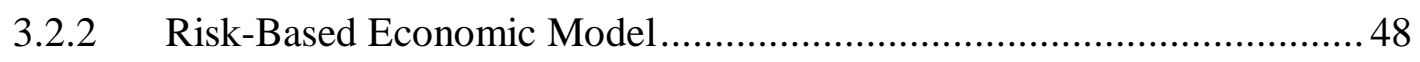

3.2.3 Modelling Integration and Water Scenarios....................................... 51

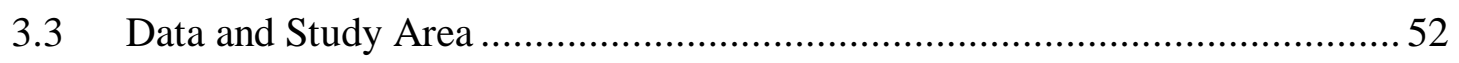

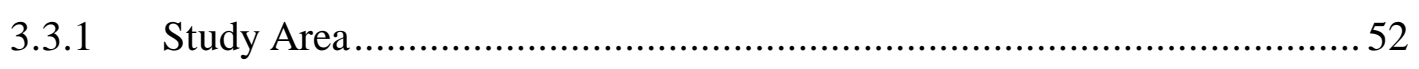

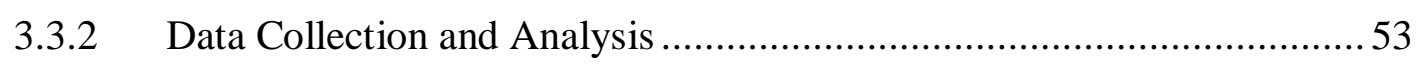

3.4 Socio-economic effects of water shocks on smallholders in the Vergara River Basin 56

3.5 Policy implications and future paths for research 60

4. Adaptation assessment to climate change for dualistic agricultural sectors: a case

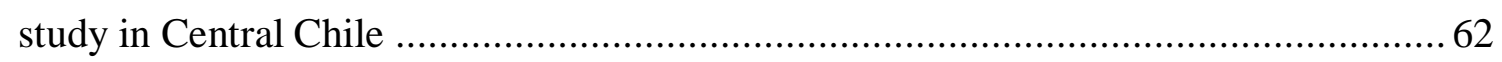

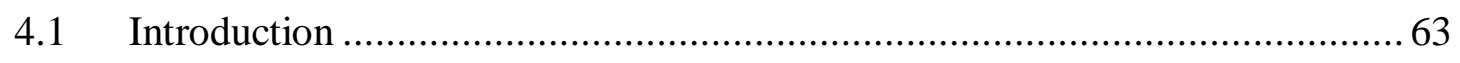

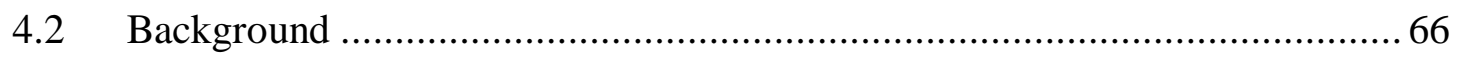

4.2.1 Climate change and irrigated agriculture in dryland regions ..................66 66

4.2.2 Regional context for farm household modelling framework applications 67

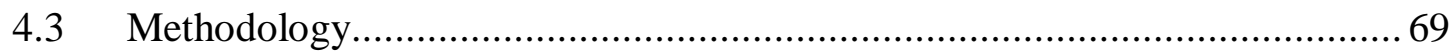

4.3.1 Farm Household Modelling Framework........................................... 69

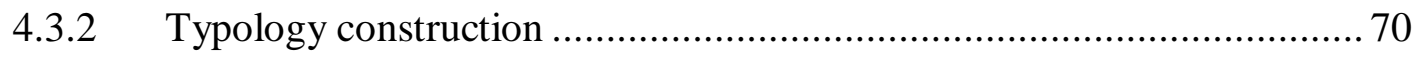

4.3.3 Application of assessments of climate impacts ................................ 73

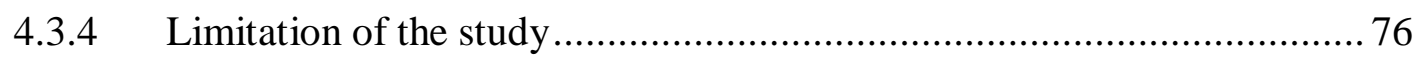

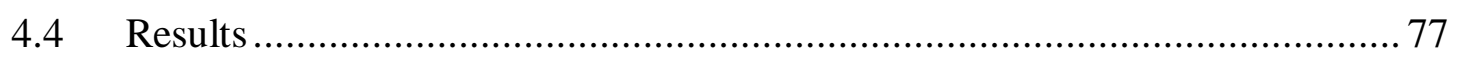

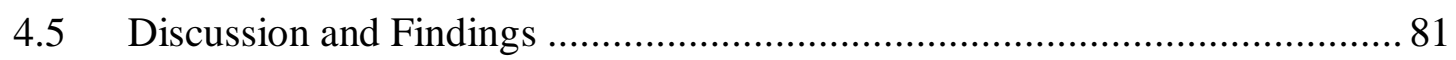

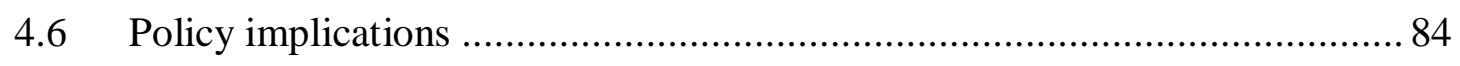

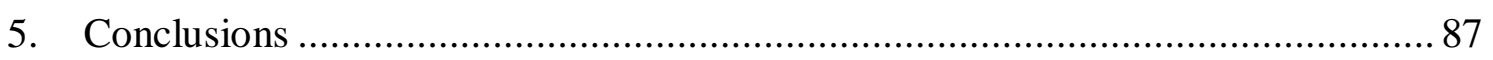

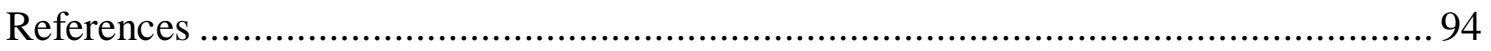

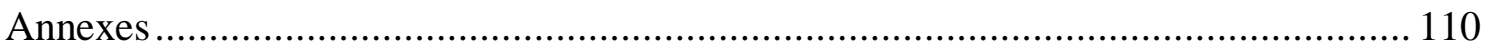

Annex 1. Global and EU regional economic assessments previous to RCPs and SSPs

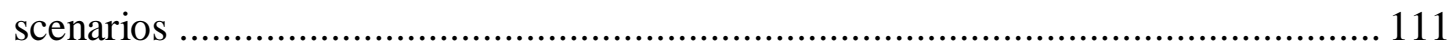


Annex 2. Global and EU regional economic assessments post RCPs and SSPs scenarios

Annex 3. Main features and differences between market models used for the assessment of climate change impact on agriculture......................................... 117

Annex 4. National Institute for Agricultural Development Survey ....................... 118

Annex 5. Survey of farmers in Central Chile ........................................................ 124

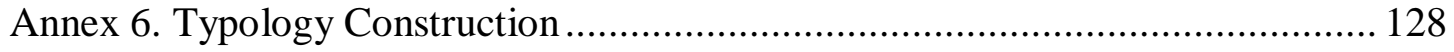

Annex 7. Household Model, Mathematical Description ....................................... 136 


\section{List of Tables}

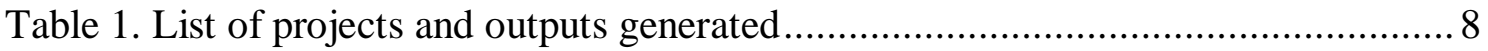

Table 2. Percentage range of changes on global cereal production and prices. ............. 17

Table 3. Global and regional cereal production (\% change) ..................................... 19

Table 4. Global cereal production and prices (\% change) for different averages of As $(\mathrm{A} 1 \mathrm{Fl} ; \mathrm{A} 2 \mathrm{a}-\mathrm{c})$ and $\mathrm{Bs}(\mathrm{B} 1 \mathrm{a} ; \mathrm{B} 2 \mathrm{a}-\mathrm{b})$ scenarios, with and without $\mathrm{CO} 2$ fertilization by

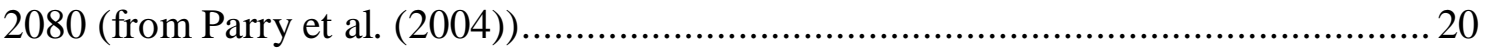

Table 5. Price changes comparison between different studies after AR4 .................... 23

Table 6. Range of price percent change between climate scenarios by 2050 for coarse

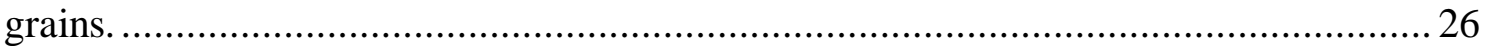

Table 7. Economic results comparison between EU-regional assessments ................... 30

Table 8 Expected change in water availability for the $50^{\text {th }}$ percentile by commune (\%)52

Table 9 Summary of representative farm types in the Vergara River Basin................. 55

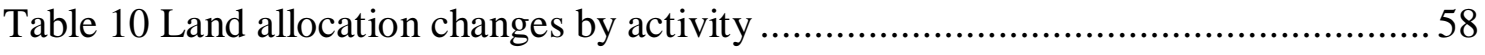

Table 11. Variables chosen for typology construction after data control ${ }^{\mathrm{a}}$..................... 70

Table 12. Principal components loading vectors for the survey data .......................... 71

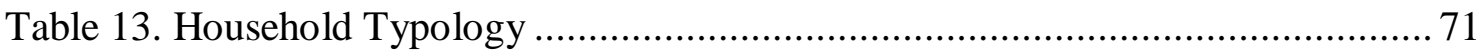

Table 14. Summary of scenarios, effects of climate change and key assumptions ........ 76 


\section{List of Figures}

Figure 1. Climate change impact chain to the agricultural sector. ............................... 1

Figure 2. Scheme of the different methodologies within the structural approach.......... 15

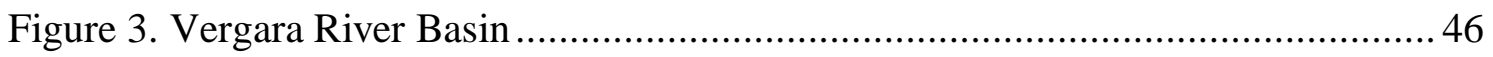

Figure 4. Wealth and EU change (\%) after water shock scenario ............................. 57

Figure 5. Wealth and EU level by Percentile of climate change ................................59

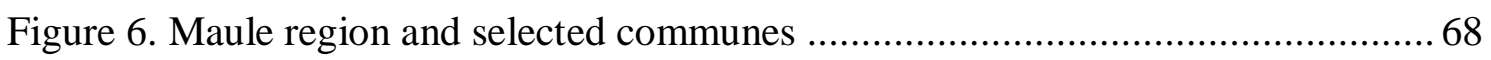

Figure 7. Regional crop distribution and cultivated land change ............................. 78

Figure 8. Regional income and labour change compared to the baseline ..................... 79

Figure 9. Agricultural Income and Farm household expected income change. ............. 80

Figure 10. Labour requirements change by household compared with the baseline ...... 81 


\section{List of Abbreviations}

AEZ: Agro-Ecological Zones model

AgMIP: Agricultural Model Intercomparison and Improvement Project

AR4: Fourth Assessment Report

AR5: Fifth Assessment Report

BEFM: Bio-economic Farm Model

BIOMA: Biophysical Models Application

BLS: Basic Linked System

CAPRI: Common Agricultural Policy Regionalised Impact Modelling System

CGE: Computable General Equilibrium

CRHIHAM: Water Research Center for Agriculture and Mining

DARA: Decreasing Absolute Risk Aversion

DSSAT: Decision Support System for Agrotechnology Transfer

EC: European Commission

eec2: Environmental Economics and Climate Change

EU: European Union

FAR: First Assessment Report

FSSIM: Farm System Simulator bio-economic model

GCM: Global Circulation Model

GGCMs: Global Gridded crop models

GLOBIOM: Global Biosphere Management Model

GTAP: Global Trade Analysis Project

HRUs: Hydrologic Response Units

IA: Integrated Assessment

IDRC: International Development Research Center

IMPACT: International Model for Policy Analysis of Agricultural Commodities and Trade 
IPCC: Intergovernmental Panel on Climate Change

ISIMIP: Inter-Sectoral Impacts Model Intercomparison Project

JRC: Joint Research Centre

NUTS: Nomenclature of Territorial Units for Statistics

PAD: Percentage Absolute Deviation

PE: Partial Equilibrium

PMP: Positive Mathematical Programming

RCM: Regional Climate Model

RCP: Representative Concentration Pathways

SAR: Second Assessment Report

SRES: Spetial Report on Emission Scenarios

SSPs: Shared Socio-economic Pathways

SWAT: Soil and Water Assessment Tool

SWOPSIM: Static World Policy Simulation Model

TAR: Third Assessment Report

UdeC: Universidad de Concepción

Ulysses: Understanding and coping with food markets volatility towards more Stable World and EU food SystEmS

UNEP: United Nations Environmental Programme

UPM: Technical University of Madrid

UDD: Universidad del Desarrollo

VRB: Vergara River Basin

WG2: Working Group II

WOFOST: World Food Studies crop model 


\section{Summary}

The strong nexus between climate and agriculture has determined that agriculture is one of the sectors most vulnerable to climate change. Higher concentrations of greenhouse gases will directly affect climatic factors such as temperature and precipitation, significantly impacting agricultural productivity. This impact will yield several socioeconomic responses at different scales, affecting markets and food prices at the global level and farm income and household consumption at the local level.

The complexities of socio-economic responses that may arise due to the impacts of climate change on agriculture have spurred the development of several quantitative modelling tools that allow one to disentangle these reactions at different scales. Although such tools have been continuously improved and have helped better determine the potential socio-economic effects of climate change, gaps and uncertainties that require further research remain, especially at sub-national levels. Several modelling tools have been developed at scales that do not allow one to explicitly reflect on the responses of affected farms or to capture the heterogeneities of several agricultural systems that may co-exist within the same region, thus resulting in overestimations of the capacities of more vulnerable farmers.

Further, adaptation policies, and especially those applied in developing countries, require ex-ante assessments regarding local responses to future impacts of climate change. These assessments could support donors in developing an ex-ante comprehensive understanding of micro-level responses to adaptation strategies, in turn allowing them to allocate resources more efficiently. Moreover, these assessments could support the development of adaptation plans, providing relevant information that can strengthen the link between local adaptation needs and national adaptation initiatives.

The scope of this research is to assess the economic effects of climate change on agriculture at different sub-national scales through the use of mathematical programming models. These models allow for one to capture the most vulnerable farmer's socio-economic responses and the heterogeneities of different agricultural systems within the same region based on their different responses to the impacts of climate change and adaptation measures. Two modelling frameworks are applied to two regions of Chile. First, a hydro-economic model is developed for the Vergara River 
Basin in the Bío Bío region to capture the socio-economic effects of changes in water availability on small-scale agriculture irrigation. Second, a household model is applied to the Maule region in central Chile to assess the impacts of climate change and adaptation patterns at the micro scale while considering the heterogeneity of household level responses.

The overall results of the study highlight the importance of economic assessments of the impacts of climate change conducted at sub-national scales as a complement to global and national assessments. The results show that economic impacts found at the basin scale for the Vergara River and at the household level for the Maule region mainly compromise to the poorest farmers. The hydro-economic model applied to the Vergara River Basin illustrates the relevance of analyses conducted at disaggregated levels, revealing different impacts among different farm types. Further, from a methodological perspective, this study offers an alternative quantitative analysis that considers the farmer as a risk-averse agent and that takes into account levels of wealth as a factor shaping climate change effects on profitability. For the modelling framework applied to the Maule region, we illustrate the irrigated semi-arid region's vulnerability to climate change effects and especially to changes in water availability. Moreover, this study allows for a stronger understanding of how farm households' agricultural and economic features affect their responses to climate change and likely adaptation measures. 


\section{Resumen}

El fuerte nexo existente entre el clima y la agricultura ha determinado que este sector sea uno de los más vulnerables al cambio climático. Altas concentraciones de gases efecto invernadero afectarán directamente a factores climáticos como la temperatura o las precipitaciones, impactando significativamente a la productividad agrícola. Esto generará diversas respuestas socio-económicas a diferentes escalas, afectando los precios y el mercado de los alimentos a nivel mundial, como también los ingresos de las explotaciones y el consumo de los hogares a nivel local.

La complejidad de las respuestas socio-económicas que pueden generarse debido al impacto del cambio climático en la agricultura, ha llevado al desarrollo de diversos instrumentos de modelización cuantitativa que permitan desentrañar estas respuestas a diferentes escalas. Si bien este desarrollo ha sido continuo, mejorado y ha ayudado al mejor entendimiento de la comunidad científica respecto a los posibles efectos económicos del cambio climático, aún quedan brechas e incertezas que faltan por investigar, especialmente a nivel sub-nacional. Varias herramientas de modelización se han desarrollado a escalas que no permiten reflejar explícitamente las respuestas de las explotaciones afectadas o capturar las heterogeneidades de diversos sistemas agrícolas que pueden existir en una misma región, muchas veces sobre-estimando la capacidad de respuesta de los agricultores más vulnerables.

Así mismo, las políticas de adaptación, especialmente aquellas aplicadas en países en desarrollo, requieren de evaluaciones ex ante respecto de las respuestas locales a futuros impactos del cambio climático. Estas evaluaciones podrían apoyar a los contribuyentes a comprender de manera ex ante las respuestas a nivel micro a estrategias de adaptación, ayudándoles así a asignar los recursos de manera más eficiente. Además, estas evaluaciones podrían apoyar el desarrollo de planes de adaptación, proporcionando información relevante para fortalecer el vínculo entre las necesidades locales de adaptación y las iniciativas de adaptación nacionales.

El objetivo de la presente investigación es analizar los efectos del cambio climático en la agricultura bajo diferentes escalas sub-nacionales a través del uso de modelos de programación matemática. Estos, permiten capturar tanto las respuestas socioeconómicas de los agricultores más vulnerables como también la heterogeneidad de 
sistemas agrícolas existente en una misma región y sus diferentes respuestas al cambio climático y a posibles medidas de adaptación. Dos marcos de modelización son aplicados en dos regiones diferentes de Chile. Primero, un modelo hidroeconómico es desarrollado para la cuenca del río Vergara en la región del Bío Bío, para capturar los efectos socio-económicos de cambios en la disponibilidad de agua en la pequeña agricultura bajo riego. En segundo lugar, un modelo a nivel de hogares es aplicado en la región del Maule, zona central de Chile, para evaluar el impacto y la adaptación al cambio climático a nivel de micro escala, considerando la heterogeneidad de las respuestas a nivel de hogar.

Los resultados generales del estudio destacan la importancia de las evaluaciones económicas del cambio climático a escalas sub-nacionales, como complemento a las evaluaciones globales y nacionales. Los resultados muestran que los impactos del cambio climático revelados a nivel de cuenca en el río Vergara y a nivel de hogar en la región del Maule comprometen principalmente a los agricultores más pobres. El modelo hidroeconómico aplicado en la cuenca del río Vergara resalta la necesidad de análisis de resultados a niveles desagregados, revelando impactos diferenciados entre los distintos actores. Así mismo, desde el punto de vista metodológico, el estudio ofrece una alternativa de análisis cuantitativo que considera a los agricultores como agentes aversos al riesgo y toma en cuenta el patrimonio como factor influyente sobre los efectos del cambio climático en la rentabilidad. En el caso del marco de modelización aplicado para la región del Maule, se resalta la vulnerabilidad de esta zona a los efectos del cambio climático, especialmente a los cambios en la disponibilidad de agua. Así mismo, este estudio permite comprender de mejor manera como las características agrícolas y económicas de los diversos hogares agrícolas influyen sobre sus respuestas al cambio climático y a posibles medidas de adaptación 


\section{General Introduction}

\subsection{Research context}

\subsubsection{Agriculture and Climate Change}

Agriculture is one of the most important human economic activities. It remains as a key economic sector in many developing countries and makes fundamental contributions to the socioeconomic development of developed countries. Accordingly, given its role in human welfare, any future challenges to the agricultural sector are of scientific, political and public concern.

Among these challenges, climate change is already affecting the agricultural sector with uneven effects across the world (Tol et al., 2004). The climate is one of the main determinants of agricultural productivity, and therefore any change in weather patterns will have direct biophysical effects on agricultural production (Adams et al., 1998). Changes in climatic factors such as temperature, precipitation and the frequency and severity of extreme weather events are expected to directly influence crop yields, hydrologic balances, input supplies and other components of agricultural systems. Moreover, the impact chain is expected to continue to exhibit different socio-economic responses resulting from the effects of climate change from the farm level to the global economic level (Figure 1).

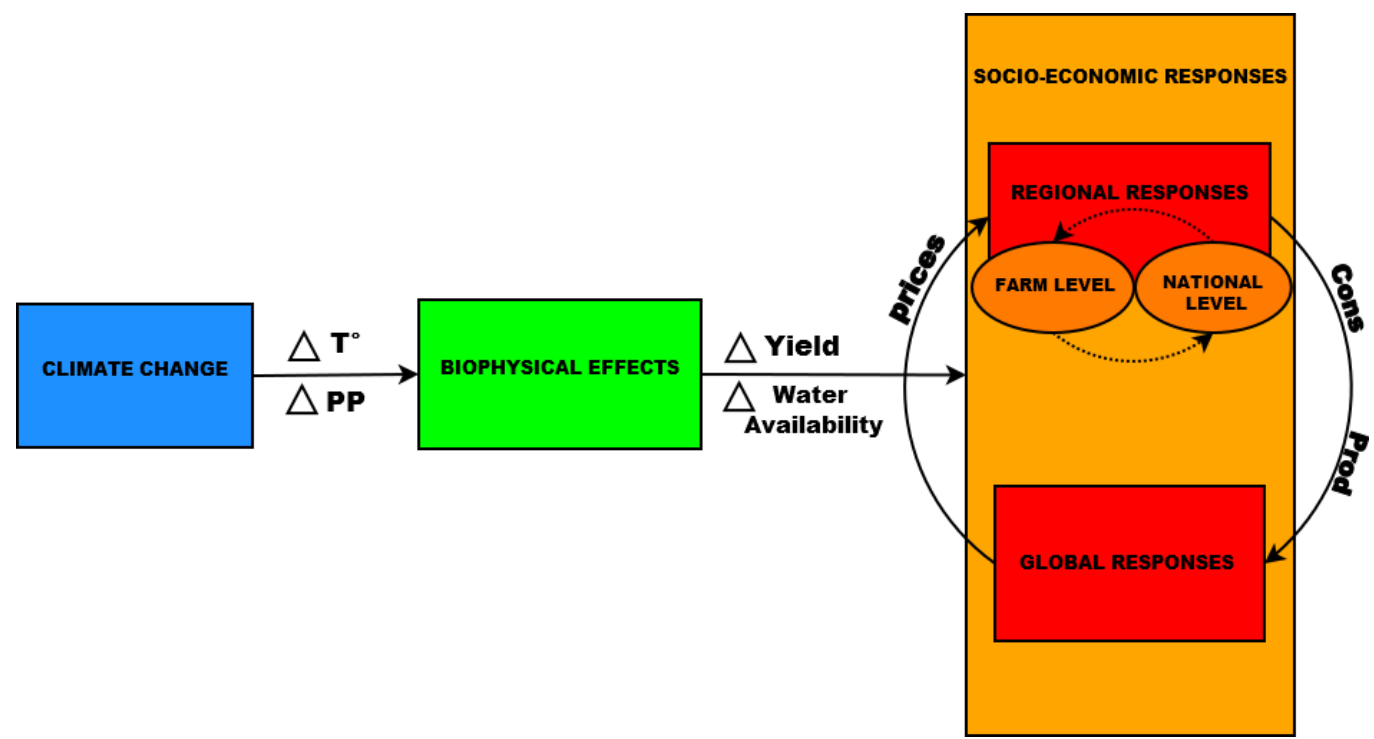

Figure 1. Climate change impact chain to the agricultural sector.Abbreviations. Cons: Consumption of goods; Prod: Production of goods; $\Delta \mathrm{T}^{\circ}$ : changes in temperature; $\Delta \mathrm{pp}$ : changes in precipitation 
Bosello and Zhang (2005) describe potential socio-economic system responses to the effects of climate change on agriculture. These responses include adaptation processes and autonomous responses to new climatic conditions. At the farm level, responses are translated into different decisions regarding production, management, and adaptation. These decisions influence the final economic impacts of climate change and are in turn influenced by technological development, policies, markets and the availability of information. At the national level, climate change can induce changes in agricultural inputs such as water availability for irrigation or changes in the quantity and quality of crop production. Further, national responses are shaped by the adaptation capacities of each farmers and national adaptation strategies that can strengthen autonomous responses observed at the farm level. A nation's level of vulnerability will depend on its degree of flexibility in terms of substituting between input factors and produced and demanded goods. At the global level, international flows of production and goods link all countries and their agricultural sectors. Climate change will generate both winners and losers in the world, and shifts in domestic and international supply and demand will affect the prices of production and goods factors, which will in turn likely affect socioeconomic responses at the regional level.

Given the complexities of the economic impacts of climate change on the agricultural sector, there is a growing need to use methods that can disentangle these different socioeconomic responses. In this sense, mathematical programming models have emerged as a reliable tool to further understand the socio-economic responses of all constituencies involved from the farm level to the global level.

\subsubsection{Modelling the Economic Impacts of Climate Change on Agriculture}

Socio-economic responses of the agricultural sector to climate change have been modelled for more than 40 years (Bosello and Zhang, 2005). The acknowledgement of a global climate change issue at the start of the 1980s and the establishment of the Intergovernmental Panel on Climate Change (IPCC) by the United Nations Environmental Programme (UNEP) at the end of the same decade have led to a steady growth of the modelling literature. Modelling exercises have mainly been employed to assess the impacts of climate change on food production and their consequences for socio-economic development. 
Modelling approaches used to assess the socio-economic impacts of climate change on agriculture cover a broad range of tools. Each one of these tools and methods employs a specific perspective and therefore consequent outputs are limited by their scope and underlying assumptions. Some of these tools have been categorised as spatial analogue models, which are mainly based on econometric techniques that analyse changes in spatial production patterns. Other tools are categorised as structural approaches, which simulate crop and farmer responses based on economic structural relationships proposed by theories that are specified rather than estimated (Adams, 1999).

The spatial analogue approach is a powerful tool used to capture the effects of data used for analyses. Amongst methods used within this category, the most frequently mentioned in the literature include 1) the Ricardian approach, which estimates adaptation using cross-sectional statistics and econometric techniques (Mendelsohn et al., 1996; Mendelsohn et al., 1994) and 2) the duality based model, which uses geographic information systems combined with an economic model (Darwin, 1999; Darwin et al., 1995). One of their main advantages is that there is no need to estimate possible adaptations, as these models are embedded in information collected on farmer behaviours. However, there are several limitations related to the use of spatial analogue approaches. Among these limitations, the most frequently mentioned in the literature on economic assessments of the impacts of climate change include 1) their abstraction from the costs of changes in structural characteristics (Field et al., 2014); 2) their underlying assumptions that ignore the future impacts of price changes on supply and demand (Bosello and Zhang, 2005); and 3) their plausibility for long-term projections, as such approaches capture only effects observed in data (Nelson et al., 2014a).

The structural approach, unlike the spatial analogue, considers the responses of all economic agents explicitly as well as the direct effects of specific farm-level adaptation measures. When it is applied to assess the impacts of climate change, it is considered an inherently interdisciplinary method due to its common use of related models drawn from several disciplines (Freeman, 1993). From the farm level to the global level, economic models developed through mathematical programming have been related to models drawn from different disciplines that mostly simulate the effects of climate change on crops and water balance. Such simulation is carried out with the aim to understand the socio-economic responses of the agricultural sector to two likely climate 
change's effects: crop yield changes and changes in levels of water available for irrigation.

Several studies have assessed the economic impacts of climate change through the use of various tools that fall within the category of structural approaches. At the global level, since the 1990s, most of these tools have been based on market equilibrium models, which have used information drawn from crop models or have been directly related to such models, in turn assessing the impacts of climate change on production, consumption, trade and prices (Kane et al., 1992; Nelson et al., 2014a; Parry et al., 2004). At the regional level, market equilibrium models have also played an important role. As examples for specific locations, to name a few, several assessments have been conducted on the effects of climate change on agricultural sectors of the EU (Blanco et al., 2014b; Ciscar et al., 2009; Shrestha et al., 2013), Sub-Saharan Africa (Calzadilla et al., 2013b), Egypt (Yates and Strzepek, 1998), Latin American countries (Andersen et al., 2016), among others. These assessments represent important contributions to our understanding of the likely economic impacts of climate change on agriculture at global or regional level. However, these approaches do not explicitly consider the farm level even though several decisions are made at this level (Reidsma et al., 2015).

To overcome this shortcoming, several authors have assessed farm-level socioeconomic responses to climate change. Recent studies have combined farm-based economic optimisation models with hydrological models to assess the potential effects of climate change on irrigated agriculture (D’Agostino et al., 2014; Esteve et al., 2015). On the other hand, several authors have also used integrated assessments (IAs) in conjunction with bio-economic farm models (Bobojonov and Aw-Hassan, 2014; Kanellopoulos et al., 2014; Reidsma et al., 2015). These approaches simultaneously consider biophysical changes and farm decisions, thus enabling to understand how farm-level socio-economic responses influence the impacts of climate change. Despite the positive effects of farm-level assessment in terms of complementing knowledge of climate change effects at lower scales, further assessments of the poverty-climate nexus and additional climate impact assessments with a focus on smallholders in developing countries are still needed.

The latest IPCC Working Group II (WG2) report has identified a need to understand how climate change may affect poor people from developing and developed countries 
where agricultural sectors are characterised by heterogeneity and by large proportions of small-scale farmers. Several studies have already recognised small-scale farmers as the most vulnerable to climate change effects on agriculture (Bellon et al., 2011; Easterling et al., 2007; Kurukulasuriya and Rosenthal, 2013), and they thus require special attention in future research. The latter underscores the need for tools capable of improving understanding of small-scale farmer decisions made at sub-national scales, and especially for areas that share a common region with large commercial farms. Such co-existence between small- and large-scale farmers may bias the final outputs of aggregated socio-economic assessments. Therefore, studies focusing on smallholders or that are capable of differentiating between socio-economic responses among a heterogeneous group of farmers are still required.

\subsection{Objectives}

The general objectives of this thesis are twofold: first, to develop different modelling frameworks capable of capturing farm and household responses to climate change scenarios at a subnational scale and second, to analyse the economic effects of climate change on two cases of different subnational scales to identify heterogeneous responses among different constituencies within a common agricultural region.

The specific objectives of the study can be summarised as follows:

- To provide a thorough literature review of economic structural approaches used to model the economic impacts of climate change on agriculture at the global, regional and local scales.

- To quantitatively assess the socio-economic impacts of future climate change scenarios of the agricultural sector at the regional, basin, commune and household levels.

- To identify economic impacts of changes in water availability levels resulting from climate change at the basin, commune and farm levels.

- To propose a framework for assessing impacts of and adaptation to climate change at the household level in consideration of heterogeneous farm-household responses and to provide a micro-scale understanding that reflects how the impacts of climate change are experienced differently depending on household features and how adaptation decisions vary in the same context. 
- To explore and compare different regional modelling approaches used to assess socio-economic impacts of climate change on agriculture while identifying their main strengths and weaknesses and their most suitable scopes of application.

The literature review analyses the evolution of mathematical programming modelling approaches used to understand socio-economic responses of the agricultural sector to future climate change scenarios. It frames approaches used in the context of assessments of the impacts of climate change and reviews empirical studies conducted at the global and regional levels. The review identifies common findings of global and regional assessments and challenges to be addressed in future research. Amongst these challenges, the review highlights the need to develop modelling tools that are capable of representing small-scale farmers' behaviours and of addressing farm level decisions and adaptation measures applied with likely stresses generated by future climate conditions.

The two different modelling approaches proposed in this thesis address the abovementioned gaps. First, through the use of a hydro-economic modelling framework that captures the socio-economic effects of water shocks on smallholders in the Vergara River Basin, the third chapter sheds light on the economic impacts of changes in water availability on small-scale agricultural systems. Second, through the use of a household modelling approach applied to a semi-arid irrigated region of central Chile, the fourth chapter assesses the effects of and adaptation to climate change at the micro-level scale in consideration of heterogeneities of household level responses.

\subsection{Research framework}

This $\mathrm{PhD}$ thesis is based on studies conducted from 2012 to 2017 within the context of several projects applied in Spain and Chile. In Spain, a study was conducted from 2012 to 2014 within the framework of the EU ULYSSES (Understanding and coping with food markets volatility towards more Stable World and EU food SystEmS) project at the School of Agricultural, Food and Biosystems Engineering of the Universidad Politécnica de Madrid (UPM). In Chile, a study was conducted from 2014 to 2017 as part of the Environmental Economics and Climate Change (eec2) project and The Water

Resources Centre for Agriculture and Mining (CRHIAM) project. The former was conducted at the School of Economics and Business of the Universidad del Desarrollo 
(UDD) while the latter was conducted through the Faculty of Agricultural Engineering of the Universidad de Concepción (UdeC).

The now complete EU project ULYSSES was a project of the Seventh Framework Programme co-funded by the European Commission (EC) (http://www.fp7-ulysses.eu/). The main aim of ULYSSES was to address a strategic theme entitled "Volatility of agricultural commodity markets", for which understanding and coping with long-term volatility was a key research aim. Within this context, research tasks involving projections of long-term drivers of price variability and levels were coordinated by Professor Maria Blanco. These tasks were developed in close collaboration with the Joint Research Centre (JRC), which ran biophysical simulations of agricultural production.

This project played an important role in the development of this thesis. Through this project, the author participated in several activities that generated knowledge bases for assessing the economic effects of climate change on agriculture at different scales of application through the use of regional mathematical programming models. Among these activities, the author conducted an extensive literature review of the integration of biophysical and agro-economic models for assessing economic impacts of climate change on agriculture; participated in an analysis of different results based on crop yield changes; and acquired modelling skills needed to develop agro-economic models. The outcomes of these activities are presented in four working papers and in a scientific paper published in 2015.

In Chile, projects eec2 and CRHIAM applied acquired knowledge at the regional level. Supported by the International Development Research Centre (IDRC - Canada), project eec2 aimed to quantify relationships between the expected impacts of climate change and the quality of life of the Vergara Basin's inhabitants. Project CRHIAM aimed to assess and solve problems associated with water availability levels for the Chilean agriculture and mining sectors. Both projects supported the development of two different modelling approaches used to assess impacts of climate change at the micro level for two different regions of Chile. A hydro-economic model for the basin level was used to assess the economic impacts of climate change on small-scale farmers of the Vergara River Basin, and a household model was used to assess the economic 
impacts of climate change for farm households of four rural communes in the Maule region (a region highly vulnerable to climate change).

Research supported through the above-mentioned projects involved an extensive literature review and quantitative analyses of two different regions of Chile. The project resulted in the generation of four academic papers (three as a first author and one as a co-author) and of several working papers on the latest in terms of linking biophysical and agro-economic models to assess the impacts of climate change on agriculture. Further, during the thesis period, presentations were made at several conferences, and the author participated in various projects directly or indirectly related to the research. ¡Error! No se encuentra el origen de la referencia. summarises projects involved with this study and the various outputs generated.

Table 1. List of projects and outputs generated

\section{Ulysses project}

Publication in JCR journal

Fernández, F. J. \& Blanco, M. (2015). Modelling the Economic Impacts of Climate Change on Global and European Agriculture. Review of Economic Structural Approaches. Economics: The Open-Access, Open-Assessment E-Journal, 9 (2015-10): 1-53. http://dx.doi.org/10.5018/economics-ejournal.ja.2015-10

\section{Scientific papers}

Fernández F.J., Blanco M., Ceglar A., M'Barek R., Ciaian P., Srivastava A.K., Lecerf R., Ramos F., Niemeyer S., Van-Doorslaer B. (2013). Still a challenge - interaction of biophysical and economic models for crop production and market analysis, Working Paper $n^{\circ} 3$, ULYSSES project, EU 7th Framework Programme, Project 312182 KBBE.2012.1.4-05, http://www.fp7-ulysses.eu/ , 96 pp.

Artavia M., Blanco, M., Araujo Enciso, S., Ramos, F., Van Doorslaer, B., Fumagalli, D., Niemeyer, S., Fernández, F.J., M'Barek R.. (2014). Production and crop roots (causes?) of volatility measures including partial stochastic simulations of yields and macroeconomic variables, Scientific Paper $\mathrm{n}^{\mathbf{o}}$ 2, ULYSSES project, EU 7th Framework Programme, Project 312182 KBBE.2012.1.4-05, http://www.fp7-ulysses.eu/ , 36 pp.

Araujo Enciso, S., Blanco, M., Artavia, M., Ramos, F., Fernández, F., Van Doorslaer, B., Fumagalli, D. \& Ceglar, A. (2014). Volatility modelling: long-term challenges and policy implications, Scientific Paper $n^{\circ}$ 5, ULYSSES project, EU 7th Framework Programme, Project 312182 KBBE.2012.1.4-05, http://www.fp7-ulysses.eu/, 39 pp.

\section{EEC2 and CHRIHAM projects}

Publications in JCR journal

Fernández, F. J., Ponce, R. D., Blanco, M., Rivera, D., \& Vásquez, F. (2016). Water variability and the economic impacts on small-scale farmers. A farm risk-based integrated modelling approach. Water Resources Management, 30(4), 1357-1373. 
Fernández, F. J., Blanco, M., Ponce, R. D., Vásquez, F., Roco, L. Implications of climate change for dualistic agriculture: a case study in Central Chile. Regional Environmental Change, submitted

Ponce, R. D., Fernández, F. J., Stehr, A., Vásquez, F. Godoy-Faúndez, A. Distributional impacts of climate change on basin communities: an integrated modeling approach. Regional Environmental Change, accepted.

Conference Proceedings

Fernández, F.J. (2016) Modelling Climate change effects at micro-level scale: A Household-model approach for the Maule region. Conference Paper: Encuentro Anual 2016 de la Sociedad de Economía de Chile (SECHI). Sept 1, 2016

Fernández, F.J. (2015) Water variability and the economic impact on small-scale farmers at basin level. A risk-based integrated modelling approach Conference Paper: Encuentro Anual 2015 de la Sociedad de Economía de Chile (SECHI). Sept 25, 2015

Vásquez, F., Ponce, R. D., Letelier, E., Stehr, A., Rivera, D., Fernández, F. Economic Evaluation of Climatic Change Impacts on Water Resources at River Basin Scale: Insights from the Vergara River Basin. Paper presented in the World Water Congress XV. International Water Resources Association (IWRA). Edinburgh, Scotland. 25 to 29 May 2015.

Ponce, R. D., Fernández, F.J., Vásquez, F. Analyzing Agriculture-Water Links at River Basin Scale. Poster session presented at: World Water Congress XV; 2015 May 25; Edinburgh, Scotland

\section{Other projects and outputs}

Project

Musels - Forzantes Múltiples. Proyecto financiado por la Iniciativa Científica Milenio del

Ministerio de Economía, Fomento y Turismo Chile

Publication in JCR journal

Fernández, F.J., Ponce, R.D., Vásquez, F., Figueroa, Y., Gelcich, S., Dresdner, J. Exploring typologies of artisanal mussel seed producers in southern Chile. Ocean and Costal Management (under review)

Government Projects

Valuing Hydrological Environmental Services provided by the Nonguén National Reserve, Chile.

Tendered by Corporación Nacional Forestal - CONAF, Región del Bío Bío, Chile.

Conditions analysis for the hydro-electric development on the basins of the rivers Palena, Cisnes, Aysén, Baker, and Pascua, from the generation potential to the socio-environmental dynamics. Tendered by the Ministry of Energy, Chile.

Proposals for economic instruments for pollution control in the Villarrica lake basin. Tendered by the Subsecretaria del Medio Ambiente, Chile. 


\section{Modelling the Economic Impact of Climate Change on Agriculture: A Review of Economic Structural Approaches}

Publication: Fernández, F. J \& Blanco, M. (2015). Modelling the Economic Impacts of Climate Change on Global and European Agriculture. Review of Economic Structural Approaches. Economics: The Open-Access, Open-Assessment E-Journal, 9 (2015-10): 1-53. http://dx.doi.org/10.5018/economics-ejournal.ja.2015-10

*The present chapter is a modified version of the original article

Abstract The economic effects of climate change on agriculture have been widely assessed in the last two decades. Many of these assessments are based on the integration of biophysical and agroeconomic models, allowing to understand the physical and socio-economic responses of the agricultural sector to future climate change scenarios. The evolution of this approach has gone through different stages. This chapter analyses its evolution: firstly, framing the approach into the context of the assessments of climate change impacts, and secondly, by reviewing empirical studies at the global and regional level. Based on this chapter, common findings emerge in both global and regional assessments. Among them, the authors show that overall results tend to hide significant disparities on smaller spatial scales. Furthermore, due to the effects of crop prices over yield changes, several authors highlight the need to consider endogenous price models to assess production impacts of climate change. Moreover, there is also need to complement these studies with modelling approaches capable of accounting for farmer adaptation. Major developments are discussed: the progress made in the last two decades and the recent methods used to provide insights into modeling uncertainties. However, there are still challenges to be met. On this matter, this chapter takes these unresolved challenges as guidelines for future research. 


\subsection{Introduction}

Assessing the economic effects of climate change on agriculture implies identifying and analysing biophysical and socio-economic aspects (Blanco et al., 2014b). To address this challenge, several climate change impact assessments have based their methodology on the integration of economic models categorised as "structural approaches" with biophysical models. Amongst the different ways of modelling integration, the projected yield impacts as inputs to general or partial equilibrium models of commodity trade have been widely used for economic assessments of climate change impacts. Also, although in a lesser extent, farm models at sub-national levels have integrated biophysical inputs to assess the socio-economic responses at the farm level. These approaches have evolved over the years thanks to several improvements in the various aspects underlying this methodology, including improved computer capacities, greater data availability, and the wider scope of biophysical and economic models.

This chapter addresses three objectives; 1) To specify the structural approach when assessing the economic impacts of climate change on agriculture; 2) To review the evolution and use of structural approaches that integrates biophysical and economic models for studying the impacts of climate change on agriculture and 3) To identify common findings through the evolution of this approach and the main shortcomings that should be overcome by future research.

This chapter is organised as follows. Section 2.2 fulfils two objectives. First, it provides an overview of the main approaches used for evaluating the economic effects of climate change on agriculture and establishes the structural approaches as the focus of this chapter. Second, it describes the different methods and their variants within this specific approach. Within this context, Section 2.3 analyses both global and regional economic assessments regarding the impacts of climate change on agriculture, highlighting their main differences and similarities. Section 2.4 summarises the main findings from the literature, highlights the main lessons learned and proposes future research directions for global and regional assessments. 


\subsection{Overview of Economic Assessment methods}

A vast amount of literature is available regarding assessing the effects of climate change on agriculture. Broad categorisation divides these assessments into agriculturally oriented studies that focus on the responses of crops to climatic variations and economically oriented studies that consider the economic responses to changes in crop yield (Bosello and Zhang, 2005; Iglesias et al., 2011). Within agriculturally oriented studies, three main approaches have been distinguished, biophysical process-based models (Challinor et al., 2004; Jones et al., 2011; Van Ittersum and Donatelli, 2003), agro-ecosystem models (Fischer et al., 2002), and the statistical analysis of historical data (Lobell and Burke, 2010b). Recent reviews (Ewert et al., 2015; White et al., 2011) offer a comprehensive examination of this field, especially the field of crop modelling, to assess the impacts of climate change. Within the economically oriented category, the common taxonomy used for these approaches was proposed by Schimmelpfennig et al. (1996) and (Adams et al., 1998) which divided them into "spatial-analogue approaches" and "structural approaches". The specific aspects and features of each approach are discussed below.

\subsubsection{Spatial-analogue approach}

This approach is mainly based on econometric techniques that analyse changes in spatial production patterns. Information collected from farmers operating across a range of conditions can be used to infer and predict how future changes may affect profits. Thus, this approach can be used to estimate the impacts of climate change based on observed differences (Adams, 1999). Here, possible adaptations are embedded in the information collected regarding the farmer's behaviour, which is the main difference between this approach and the structural approach. We found two methods amongst the spatial-analogue, the Ricardian approach that estimates adaptations using crosssectional statistics and econometric techniques (e.g., Mendelsohn et al. (1996); (Mendelsohn et al., 1994)), and the duality-based model that uses geographic information systems combined with an economic model (e.g., Darwin (1999); (Darwin 
et al., 1995) $)^{1}$. Regardless of the method used, both methods assume that variations in land values reflect the welfare implication of the impacts of climate change.

The spatial-analogue approach is a powerful tool used for capturing the effects in the data used for the analysis. The main advantage of this approach over the structural approach is that the analyst does not have the responsibility for estimate possible adaptations. However, limitations are associated with the nature of these assumed responses. For example, the spatial analogue abstracts from the costs of changes in structural characteristics, which may be necessary to mimic practices in warmer climates (e.g., irrigation systems). Additionally, the assumption that agricultural prices do not respond to changes in land prices ignores the future impacts of price changes on supply and demand (Bosello and Zhang, 2005). Furthermore, this approach can only capture the effects observed in the data, questioning its plausibility for long-term projections (Nelson et al., 2014a).

Besides the seminal works mentioned above, several studies have used the spatialanalogue approach to assess the economic effects of climate change on agriculture. This approach has been applied in the USA (Mendelsohn and Dinar, 2003), Africa (Kurukulasuriya et al., 2006), Europe (Van Passel et al., 2012), South America (Seo and Mendelsohn, 2008), and several countries (Reinsborough, 2003; Wang et al., 2009), mainly by using the Ricardian method.

\subsubsection{Structural approach}

Unlike the spatial-analogue approach, this approach simulates crop and farmer responses based on the economic structural relationships suggested by theory, which are specified rather than estimated (Adams, 1999). Additionally, this approach includes changes in land values within the economic models so that the responses of all economic agents are considered explicitly and include the direct effects of specific farm-level adaptations. In addition, this approach is inherently interdisciplinary when applied to climate change because it typically uses interlinked models from several disciplines (Freeman, 1993). The most common method to assess the impact of climate change consists of using biophysical models to predict the effects of crop yields on

\footnotetext{
${ }^{1}$ Although Adams (1999) highlights that one of its component falls within the structural approach
} 
climate change scenarios that are used as input into the economic model to predict future socio-economic effects.

Amongst its strengths, this approach provides a more explicit representation of causal effects and adjustments of the agricultural sector to climate change (Shrestha et al., 2013). In addition, because of the assessment capacity of economic models to changes in market conditions under climate change, this approach is more reliable for understanding the distributional consequences of climate change (Adams, 1999). Furthermore, one of the main weaknesses of this method compared with spatialanalogue approaches is related to the construction of these models and the data and time-intensive requirements for estimating their structural relationships and parameters.

Several economic assessments of the impacts of climate change on agriculture based on the structural approach have been published since the first IPCC report in 1990. After proposing the characterisation of different methods, the following section presents an extended review of several studies performed from the mid-1990s at the global and regional levels.

\section{Categorising structural approaches}

Within the structural approach and for the studies reviewed here, this chapter proposes a taxonomy that differentiates between the six methodologies used to assess the economic effects of climate change (see Figure 2). These methods are organised based on their geographical scales and their treatment of the economic dimension. According to their geographical coverage, a common distinction is made between global and regional assessments. The latter, with different levels of disaggregation, such as country (Adams et al., 1995; Dube et al., 2013; Reilly et al., 2003; Yates and Strzepek, 1998), state (Kaiser et al., 1993), or another sub-regional level. The economic dimension is mainly distinguished by the economic models used to quantify the economic responses. Amongst these, two specific groups can be separated, supply models and market models. Within the former we can include farm economic models commonly used at regional level, while within market models we can find partial equilibrium (PE) models and computable general equilibrium (CGE) models, commonly used at global or regional level; and the Basic Linked System (BLS) trade model, mainly used at global level. 


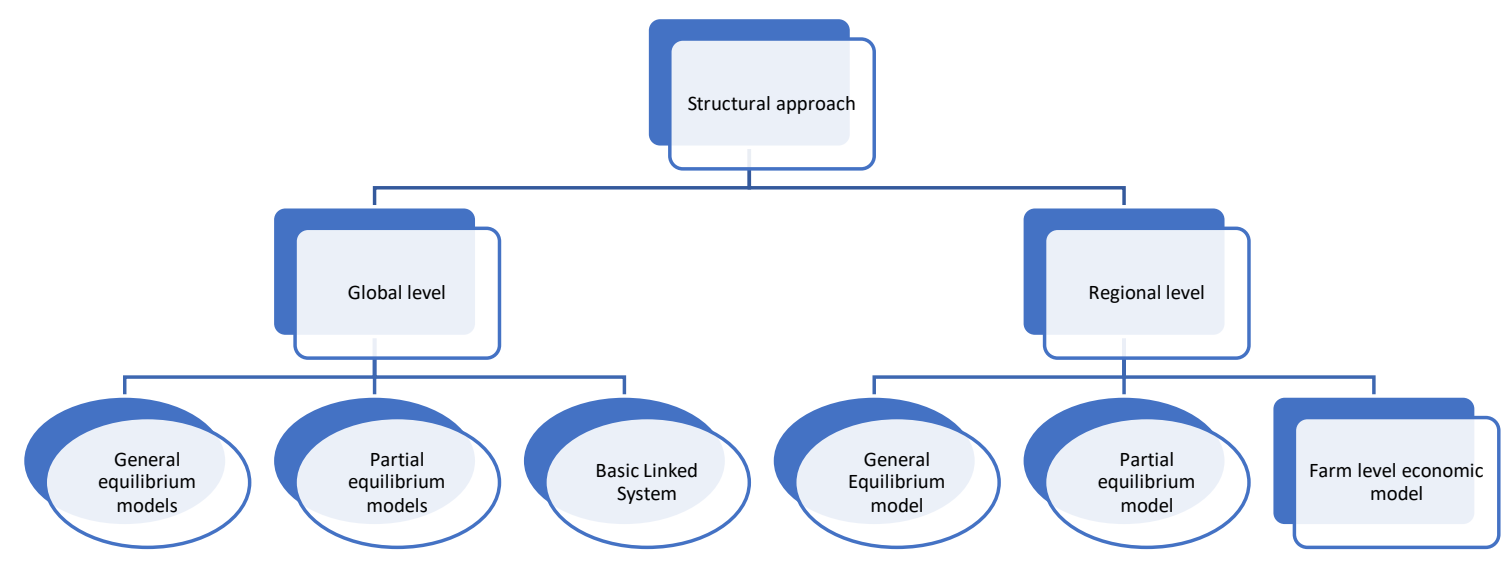

Figure 2. Scheme of the different methodologies within the structural approach.Circles represent market models, while rectangle represents supply models

Market models used at global level are mainly used to consider the impacts of crop yield changes on prices, which often depend on global supply and demand rather than local production. Market models used at regional level, are commonly used to consider the impacts of crop yield changes on prices, but in this case, they allow more detailed understanding of local yield changes with a focus on one or several regions. These approaches represent important contributions to understanding the likely economic impacts on global and regional levels. However, they fail to predict farm level responses, as management or adaptation decisions.

Farm economic models used at regional level allow to understand the effects of climate change, mainly for production levels and farm income. Furthermore, farm economic models can focus on local adaptation options that would improve production levels and farm income in the face of climate change (see Kaiser et al., 1993). However, farm economic models commonly ignore that economic estimates of damage from climate change must consider the global scale of these events. Additionally, when climate change would affect crop prices over time, these models are not suitable for capturing market feedback. Each of these six categories, have particular features with strengths and weaknesses, and choosing the approach depends on the objective of the assessment and on the problem at hand. 
Amongst the market models, it is important to highlight the main differences between each one of them. The main difference between the PE and CGE models is their scope of application. While PE models consider the agricultural system as a closed system without linkages with the rest of the economy, CGE models provide a complete representation of the national economies (Tongeren et al., 2001). On the other hand, although the literature classifies the BLS trade model as a general equilibrium approach (Fischer et al., 1988), important features make it different from the other CGE models used for assessing the impacts of climate change on agriculture. For example, the high detail in the agricultural sector and its coarse aggregation (relative to the one-simplified non-agricultural sector) make the BLS model a type of hybrid model between PE and CGE models. Annex 3 summarises their main features and differences.

The next sections focus on the development of studies within this framework that meet the following criteria: 1) structural approaches from the 1990s until present; and 2) global assessments and studies at regional level. Due to the extent of regional assessments around the world this review give special attention to those developed for the EU region.

\subsection{Global and Regional economic assessments}

\subsubsection{Global Economic Impact assessments}

In the early 1990s, only a few global assessments integrated crop responses with economic models. Amongst them, the seminal works by Tobey et al. (1992) and Kane et al. (1992) introduced crop effects suggested by previous studies into the PE model SWOPSIM. Tobey et al. (1992) presented 15 different scenarios based on three simulation experiments and divided them into five concurrent yield reductions in the U.S., Canada, and the European Community. Meanwhile, Kane et al. (1992) presented two different scenarios that reflected "moderate impacts" and "very adverse impacts". Both studies established the following common consensus regarding the role of trade and markets in economic impact assessments: "global warming would not seriously disrupt the global agricultural market, mainly because the consequences would be diffused throughout the world through trade and inter-regional adjustments". Additionally, these authors compared their results with the work of Adams et al. (1988), who only considered the impacts of climate change in the U.S. These authors observed 
smaller net welfare effects than Adams et al. (1988), which they hypothesised occurred because the impacts of climate change were offset by international price changes. Both of these studies were instrumental in establishing that climate change assessments could not be made based only on domestic yield effects.

A few years later, Rosenzweig and Parry (1994) were some of the first researchers to consider climate change with $\mathrm{CO} 2$ fertilisation effects and examine the potential impacts of adaptation measures. In this study, the two following main components were considered: 1) estimations of potential crop yield changes and 2) estimations of world food trade responses. Climate change scenarios were created by changing the observed data based on doubled CO2 simulations of three GCMs (GISS, GFDL, and UKMO). Agricultural scientists in 18 countries estimated potential changes in crop yields by using compatible crop models and GCM scenarios at 112 sites. These estimations were used to assume national level production changes for all cereals in all countries based on the similarities between the crops and countries. Next, the results were aggregated into regional yield changes based on the regions defined in the BLS model. The main results of these models show that the world cereal production decreased between 11 and $20 \%$ in the climate change scenarios without direct $\mathrm{CO} 2$ effects. The inclusion of $\mathrm{CO} 2$ effects resulted in small global production decreases of 1 to $8 \%$, which increased cereal prices by $24-145 \%$. The scenarios that included different adaptation options indicated even fewer effects on production and prices when compared with the scenarios mentioned above (Table 2). Their results exhibit several findings that will be mentioned in future global assessments, including reduced impacts on high latitude countries compared with tropical countries; greater impacts on $\mathrm{C} 4$ crops due to their lower responses to increases in $\mathrm{CO} 2$ fertilisation; a large degree of spatial variations in crop yields across the globe; and lower impacts of climate change when adaptation measures are considered.

Table 2. Percentage range of changes on global cereal production and prices.(Source: Rosenzweig and Parry, 1994).

\begin{tabular}{lcc}
\hline Scenario & $\begin{array}{c}\text { Production } \\
\text { (\% changes) }\end{array}$ & $\begin{array}{c}\text { Price } \\
\text { (\% changes) }\end{array}$ \\
\hline With CO2 fertilization & $\sim-1$ to $-8 \%$ & $\sim 24-150 \%$ \\
With CO2 and Ad. Level 1 & $\sim 0$ to $-5 \%$ & $\sim 10-100 \%$ \\
With CO2 and Ad. Level 2 & $\sim+1$ to $-2 \%$ & $\sim-5-35 \%$ \\
\hline
\end{tabular}

$\sim$ approximately equal to 
These three seminal works were the few structural studies cited in the Second Assessment Report (SAR) (Watson et al., 1996) that linked biophysical responses to climate change with economic structural models. Similar studies were also mentioned in the reports provided by Reilly and Hohmann (1993) and Reilly et al. (1994). Based on these studies, the report indicated that although the direction of change in global production resulting from climate change is still uncertain, changes in the aggregate level would be small to moderate. In addition, this report expands and updates the information contained in the First Assessment Report (FAR) and establishes a new generation of assessments that examines the impacts of climate change on agriculture. From this point forward, more accurate projections of climate change resulting from GHG forcing became available based on updated emission scenarios (Leggett et al., 1992).

Parry et al. (1999) used the same method as Rosenzweig and Parry (1994) to examine the potential impacts of climate change on crop yields, world food supply, and the risks of hunger. This study was different from previous studies, mainly because it used GCMs with better spatial resolutions and updated emission scenarios (IS92). These authors ran crop models for three future climate conditions (2020s, 2050s, and 2080s) that were predicted by the GCMs HadCM2 and HadCM3 based on an IS92 scenario. In contrast with other studies conducted during the mid-1990s (Adams et al., 1998; Darwin et al., 1995), this study predicts the actual price increases under modest climate change. Small detrimental effects on cereal production by 2080 were estimated by the HadCM2 climate change scenario and were predicted to result in a cereal price increase of $17 \%$. By contrast, the greater negative impacts on the yields projected under HadCM3 resulted in a crop price increase of $45 \%$ by 2080 , with severe effects regarding the risk of hunger, especially in developing countries. The authors indicate that these global results hide regional differences in the impacts of climate change. For instance, in the HadCEM2 scenarios, yield increases at high and high-mid latitudes resulted in production increases (e.g., in Europe and Canada). By contrast, yield decreases at lower latitudes (tropics) resulted in production decreases, an effect that could be exacerbated where the adaptive capacity is lower than the global average. Table 3 presents changes in cereal production that were estimated by Parry et al. (1999) at the global and regional levels to occur by 2080 . 
Table 3. Global and regional cereal production (\% change)for different climate models and across GCM scenarios by 2080 considering CO2 fertilization and adaptation measures (Sources: Parry et al. 1999;

IPCC, 2001)

\begin{tabular}{lll}
\hline $\begin{array}{l}\text { Climate scenario } \\
\text { GCM - forcing }\end{array}$ & Region & Cereal production change \\
\hline HadCM2- IS92a & Global & $\sim-2.1 \%$ \\
HadCM3 - IS92a & Global & $\sim-4.0 \%$ \\
Range across GCM scenarios & Range across countries: & \\
& North America & $\sim-10$ to $3 \%$ \\
& Latin America & $\sim-10$ to $10 \%$ \\
& Western Europe & $\sim 0$ to $3 \%$ \\
& Eastern Europe & $\sim-10$ to $3 \%$ \\
& Asia & $\sim-10$ to $5 \%$ \\
& Africa & $\sim-10$ to $3 \%$ \\
\hline
\end{tabular}

$\sim$ approximately equal to

For a broader use than the IS92 scenarios in 2000, the IPCC released a new set of emission scenarios called SRES scenarios (Special Report on Emission Scenarios) (Nakicenovic et al., 2000), which were used in the Third and the Fourth Assessment Reports (TAR and AR4). From this point on, the number of studies that quantified the economic impacts of climate change on agriculture at the global level increased. In the first half of the 2000s, several assessments were published that presented biophysical and economic estimates that were made by considering socio-economic futures based on SRES scenarios.

Maintaining the same methodology as previous works (Parry et al., 1999; Rosenzweig and Parry, 1994), Parry et al. (2004) based their estimations on SRES scenarios. These authors used the HadCM3 GCM to run different emission scenarios (A1, A2, B1 and B2) ${ }^{2}$ and generated seven different climate change scenarios. Each of these scenarios considered different paths for global crop yields; however, the paths did not diverge until the mid-century. Table 4 presents the impacts of climate change on global cereal production and prices under "Bs" (B1a -B2a-b) and "As" (A1FI - A2a-c) scenarios by 2080. When omitting CO2, greater reductions in cereal production and larger increases in their prices are observed relative to the scenarios in which $\mathrm{CO} 2$ fertilisation is

\footnotetext{
${ }^{2}$ Used ensemble members A1F1, A2a-c, B1a and B2a-b
} 
included. When $\mathrm{CO} 2$ effects are assumed, the differences in cereal production and prices between climate scenarios are less clear than in the scenarios without CO2. This study confirms the negative impacts of climate change in developing regions and the fewer significant changes in developed regions as well as the moderated globally aggregated effects on world food production and prices when $\mathrm{CO} 2$ fertilisation is assumed.

Table 4. Global cereal production and prices (\% change) for different averages of As (A1Fl; $\mathrm{A} 2 \mathrm{a}-\mathrm{c})$ and Bs (B1a; B2a-b) scenarios, with and without CO2 fertilization by 2080 (from Parry et al. (2004))

\begin{tabular}{lcc}
\hline $\begin{array}{r}\text { Climate scenario } \\
\text { GCM }- \text { forcing }\end{array}$ & $\begin{array}{c}\text { Production } \\
\text { (\% change })\end{array}$ & $\begin{array}{c}\text { Price } \\
(\% \text { changes })\end{array}$ \\
\hline HadCM3 - B1-B2 & $\sim-5$ & $\sim 98$ \\
- Without CO2 & $\sim-1.7$ & $\sim 14.6$ \\
With Co2 & & \\
HadCM3 - A1-A2 & $\sim-10$ & $\sim 320$ \\
- Without CO2 & $\sim-1$ & $\sim 15.2$ \\
\hline
\end{tabular}

approximately equal to

Fischer et al. (2002, 2005), assessed the global impacts of climate change on agroecosystems up to 2080. Their approach was mainly differentiated by using the agroecological zones (AEZ) model (see Fischer et al. (2002) for a detail description), and by maintaining previous modelling frameworks (SRES scenarios and the BLS model). Fischer et al. (2005), used 14 combinations of socio-economic and climate scenarios between the SRES scenarios and the 5 GCMs (see Annex 1). Overall, these authors present moderate changes in crop prices under climate change, mainly due to the small net changes in the impacts of global climate change on crop production (global cereal production changes fall by $2 \%$ ). However, as shown in previous studies, aggregated results hide regional differences. Developing countries experience a decrease in cereal production of $5-6 \%$ based on the CSIRO climate projections, while developed countries such as the U.S. increase their production by $6-9 \%$. The cereal prices present major increases under the HadCM3 (2-20\%) and the CSIRO scenarios (4-10\%) while the remaining GCMs present even fewer climate change impacts. Their conclusions are consistent with previous studies, especially regarding the heterogeneity of climate change impacts at the regional, but not global level. 
Despite the differences among the reviewed studies (especially in the magnitude of their results), a consensus is observed in several issues. First, developing regions may be more negatively affected by climate change than other regions, mainly due to their warmer baseline climates, the major presence of $\mathrm{C} 4$ crops that present little $\mathrm{CO} 2$ fertilisation, the predominance of agriculture in their economies, and the scarcity of capital for adaptation measures. Second, these studies agree that including the effects of trade in their assessments tends to offset the overall projected impacts of climate change. Third, production in the developed countries benefits from climate change and compensates for the decline projected for developing regions. These three common findings explain the small globally aggregated impacts of food production observed in previous studies. Despite this relatively broad consensus amongst researchers, new questions have arisen regarding the uncertainties of these global impact assessments and the limitations of the economic modelling tools that are currently used. For instance, crop yield projections were mainly based on a limited number of crop models (DSSAT and AEZ), and the same economic model (BLS) was used for economic assessments so that the uncertainties associated with the structure of it could not be explored.

Since the mid-2000s and the release of the IPCCs Fourth Assessment Report (AR4), several improvements in all components of the approaches that link biophysical and economic structural models were observed. Amongst them, many simulations were available from a broader range of more sophisticated climate models (Parry, 2007). In addition, better downscaling techniques for improving the climate input into biophysical models, the emergence of updated versions of crop models, and a combination of biophysical-socioeconomic modelling at a high level of detail and large extent were observed. Furthermore, the use of trade models has expanded, a greater diversity of yield projections is available for consideration, and a major disaggregation of prices by commodity has occurred. Moreover, the first attempts to identify the underlying uncertainty of these approaches appeared at this time. This issue was addressed using a range of plausible biophysical outcomes (Hertel et al., 2010), or by using a wider range of plausible climate scenarios (Nelson et al., 2009; Nelson et al., 2010).

To address the coarse aggregates at sectoral and regional levels in the earlier economic assessments and to face the underlying uncertainties of these approaches; Hertel et al. (2010), based their results on the synthesis of values from impact assessments for the Global Trade Analysis Project (GTAP) model. These authors bracket a range of 
plausible outcomes, estimate the central and tails of the potential yield impacts in 2030, and then use them as exogenous supply shocks in the GTAP model to assess the economic impacts on agriculture. In addition, these authors showed that their central case has only modest price changes, which is consistent with previous global projections (Easterling et al., 2007). However, when the tails of the distribution were used, much greater changes in food prices occurred than reported in other studies, with major average world food price increases in the low productivity scenario (32\% for cereals and $63 \%$ for coarse grains). These authors emphasise the importance of looking beyond central case climate shocks as well as the importance of considering the full range of possibilities when designing policy responses.

Using a new version of GTAP, Calzadilla et al. (2013a) assessed the potential impacts of climate change and $\mathrm{CO} 2$ fertilisation on global agriculture and food prices. This assessment was based on external predictions of changes in precipitation, temperature and river flow for the SRES A1B and A2 scenarios (Falloon and Betts, 2010; Stott et al., 2006). These authors assessed the impacts of climate change on agriculture according to 6 scenarios (see Annex 1) and applied each scenario to two time periods (2020, 2050). Crop responses were based on Rosenzweig and Parry (1994) for responses to changes in precipitation and temperature; Tubiello et al. (2007) for CO2 fertilization effects on crop yields; and 3) Darwin et al. (1995) for the runoff elasticities of water supply. As shown in previous studies, the production estimates by these authors decreased, and the price increased under both emission scenarios and time periods for most of the crops assessed (all-factors scenario). Higher prices were estimated to occur by 2050 for cereal grains, sugar cane, sugar beet, and wheat, with increases of between 39 and $43 \%$.

Nelson et al. (2009, 2010) provide two widely cited studies. Nelson et al. (2010) follows the same method described in the food policy report of 2009 and uses a wider range of plausible economic, demographic and climatic scenarios. At the time, this study was one of the first assessments to combine biophysical and economic models using such a high level of detail and large extent. These authors used the latest updated version of the DSSAT suite of crop models by combining very detailed process-based climate change productivity effects into a detail PE model of world agriculture (IMPACT model). In addition, this study utilises three combinations of income and population growth from 
2010 to 2050. For each combination, they examine a series of 4 climate scenarios ${ }^{3}$ where the baseline is perfect mitigation ${ }^{4}$. Overall, fifteen perspectives on the future are listed that encompass a wide range of plausible outcomes. The main results showed that prices would rise to $31.2 \%$ for the rice in an optimistic scenario and to $106.3 \%$ for maize in the pessimistic scenario when averaging the four climate change scenarios. Additionally, the prices still increased even with using perfect mitigation scenarios, but to a lesser extent $(18.4 \%$ for rice in the optimistic scenario to $34.1 \%$ for maize in the pessimistic scenario).

Table 5 compares the effects of climate change on the food prices obtained by different studies after the AR4 of the IPCC. As a common finding, most of the studies estimate an increase of prices for 2050 compared with the baseline. On the other hand, when focusing on the magnitude of results, the price effects of climate change are much smaller (or less pessimistic) in general equilibrium simulations than in partial equilibrium simulations. This finding is consistent with other studies, which have been explained by the use of more flexible economic functional forms by CGE models (Ciscar et al., 2009; Nelson et al., 2014a; von Lampe et al., 2014).

Table 5. Price changes comparison between different studies after AR4

\begin{tabular}{llll}
\hline Source & \multicolumn{2}{c}{$\begin{array}{c}\text { Price } \\
\text { (\% changes) }\end{array}$} \\
\hline Nelson et al. (2010) & \multicolumn{1}{c}{ Range among optimistic and pessimistic } \\
& scenarios ${ }^{\dagger}$. & \\
& $\bullet \quad$ Maize $(87.3-106.3)$ \\
& $\bullet \quad$ Rice $(31.2-78.1)$ \\
& $\bullet \quad$ Wheat $(43.5-58)$
\end{tabular}

Hertel et al. 2010

Calzadilla et al. 2013

Low productivity scenario:

- Cereals 32

- Coarse grains 63

All-factors scenario

- Wheat $(\sim 40)$

- Cereal grains ( 45$)$

- $\quad$ Rice $(\sim 20)$

- $\quad$ Oilseed ( 30)

$\dagger$ Mean across climate scenarios CSIRO and MIROC with the SRES A1B and B1; approximately equal to

\footnotetext{
${ }^{3}$ The CSIRO A1B and B1 and the MIROC A1B and B1

${ }^{4}$ Baseline defined by Nelson et al. (2010). Here the results assume that all GHG emissions ceased in 2000 and that the climate momentum in the system stopped.
} 
Since AR4 (Parry et al., 2007), new global socio-economic and environmental scenarios for climate change research have emerged. These scenarios are richer, more diverse and offer a higher level of regional detail compared with previous SRES scenarios (Field et al., 2014). The AR5 of the IPCC distinguishes between two types of scenarios. The Representative Concentration Pathways (RCPs), which were named according to their radiative forcing level in 2100, and the Shared Socioeconomic Pathways (SSPs), which represent assumptions regarding the state of the global and regional society as it evolved over the course of the 21 st century. The RCPs include one scenario that results in a very low forcing level (RCP2.6), two stabilisation scenarios (RCP4.5 and RCP6), and a high scenario (RCP8.5), which corresponds to a high greenhouse gas emission pathway (Van Vuuren et al., 2011). By contrast, the SSPs include five different pathways, each of which is assembled along the axes of the challenges to mitigation and adaptation to climate change. These SSPs contain population and gross domestic product (GDP) developments and semi-quantitative elements (Kriegler et al., 2012).

Over the last two years, most of the impact assessments that based their results on the new scenarios have focused on quantifying the uncertainty that underlies their approaches. Amongst the methodologies used to provide insights into modelling uncertainties, the comparison of results among different modelling approaches has had an important development. Several exercises within the framework of the Agricultural Model Intercomparison and Improvement Project (AgMIP) and the Inter-Sectoral Impacts Model Intercomparison Project (ISIMIP) have been performed. Focusing on agriculturally oriented studies Rosenzweig et al. (2014) used all four RCPs scenarios with 5 global climate models and 7 Global Gridded crop models (GGCMs) to quantify the global effects of climate change on major crops. This research is an important development and provides insights into crop modelling uncertainties.

Regarding economically oriented studies based on structural modelling approaches, only a few studies have quantified the economic impacts of climate change that were derived from the RCPs and SSPs scenarios. At a global level, Nelson et al. (2014a, 2014b), presented results from a global economic model inter-comparison exercise with harmonised data for future yield changes. The main aim of these exercises was to provide uncertainty estimates for the economic phase of the impact assessment process. Nelson et al. (2014b) analysed the endogenous responses of nine global economic 
models to standardised climate change scenarios produced by two GCM and five crop models under the RCP8.5 and the SSP2 ${ }^{5}$. These authors showed a global mean yield decrease of $17 \%$ by 2050 without $\mathrm{CO} 2$ fertilisation. This mean was between four crop groups and 13 regions of the globe, with a standard deviation of $\pm 13 \%$ resulting from the differences in the impacts across the crops and regions and the diversity of the GCM and crop models. The analysis of the endogenous economic responses showed that the yield loss was reduced to $11 \%$ and that the area of major crops increased by $11 \%$. Both effects resulted in a mean production decrease of $2 \%$ and a final price increase of $20 \%$. As a main finding, these results indicated that all economic models transferred the shock effects to the response of economic variables. These authors highlighted that the analyses only focused on the biophysical effects of climate change, underestimate our capacity to respond.

Using a similar approach, Nelson et al. (2014a) supplied yield projections from two global crop growth models for two implementations of the RCP8.5 emission scenario in two GCMs, all under the SSP2. These scenarios were designed to assess the upper end of climate change impacts (omitting $\mathrm{CO} 2$ fertilisation and adaptation mechanisms). Ten global agro-economic models (see Annex 2) used these productivity shocks as inputs to generate different economic responses. They analysed the effects of individual endogenous responses, such as prices, yield, and area changes. Then, they broke down the effects of climate change shock to identify the importance of the adjustment of three components in the model response (consumption, area and yield). By focusing on the individual responses, the authors presented results for five commodities/commodity groups, which were collectively called CR5 (coarse grains, rice, oilseeds, sugar and wheat). The results showed a price increase relative to the reference scenario across all the models with high variations between the economic models and crop models and small variations across the climate models. All models showed higher prices in 2050, which ranged between 3.0 to $78.9 \%$ for the CR5 aggregates and between 2.1 to $118.1 \%$ for the coarse grains (see Table 5).

Using the same scenarios used by Nelson et al. (2014a), Witzke et al. (2014) simulated long-term economic responses by using the PE model CAPRI. As shown in previous studies, these authors observed moderate impacts on the global agricultural markets at

\footnotetext{
${ }^{5}$ Population of 9.3 billion by 2050 and a global GDP triples
} 
the aggregated level and strong variations across regions. At the global level, these authors observed agricultural price increases of $6 \%$ to $13 \%$ relative to the reference scenario. As shown by Nelson et al. (2014a), these authors showed stronger price increases in the HadGEM2-ES scenario. In addition, these authors showed major variations in the price changes across regions and across commodity aggregates. For example, wheat, coarse grains and rice increase their prices by $28 \%$ to $56 \%$ by 2050 , and sugar prices did not increase by more than $4 \%$ in the four climate scenarios.

Table 6 compares some of the economic results presented by the three studies mentioned above for a selected commodity group. Focusing on price changes, we divided the results presented by Nelson et al. (2014a) into those released by PE and CGE models. The greatest variation occurred between the PE models rather than amongst the CGE models, with a higher median final price increase for coarse grains. Consistent with previous studies, the magnitude of the price changes was smaller in the CGE models than in the PE models.

Table 6. Range of price percent change between climate scenarios by 2050 for coarse grains.

\begin{tabular}{lll}
\hline Source & $\begin{array}{l}\text { Price } \\
\text { (range of \% changes) }\end{array}$ & $\begin{array}{l}\text { Endogenous yields } \\
\text { (range of \% changes) }\end{array}$ \\
\hline Nelson et al. (2014b) & Average producer price & $\begin{array}{l}\text { Average yield mean } \\
11\end{array}$ \\
Nelson et al. (2014a) & 20 & (mean in production: -2$)$ \\
& GCE models range & GCE models range \\
& 2.1 to 43.2 & -28.8 to -1.9 \\
$($ mean: 12.25$)$ & (mean: -12.3$)$ \\
\hline Witzke et al. (2014) & PE model range & PE model range \\
& 2.5 to 118.1 & -26.4 to -1.5 \\
& $($ mean: 37.9$)$ & (mean: -12.8$)$ \\
\hline
\end{tabular}

\footnotetext{
${ }^{(*)}$ Impact on global production by commodity aggregate (CGR)
} 


\subsubsection{Regional Economic Impact Assessments}

\section{Market models for regional assessments}

As one of the largest cereal producers and traders, Europe is an important region to assess in terms of the economic effects of climate change on agriculture and how these effects will affect global agricultural markets. In recent years, many studies have assessed the impacts of climate change on EU agriculture. An important portion of these assessments have focused on the biophysical consequences of climate change and evaluating these consequences through literature surveys (Lavalle et al., 2009; Olesen and Bindi, 2002; Olesen et al., 2011), yield response functions focusing on selected regions of Europe (Quiroga and Iglesias, 2009), or linking biophysical and statistical models for different agro-climatic regions (Iglesias et al., 2009). Other studies have assessed the economic impacts of climate change on EU agriculture by basing their methodologies on spatial-analogue approaches (Reidsma et al., 2007; Reidsma et al., 2009). Furthermore, economic indicators for Europe that integrate biophysical and economic models have primarily resulted from global-scale analysis (Nelson et al., 2010; Parry et al., 2004) and have delivered aggregated results. Evidence from the peerreviewed literature of the structural economic assessments at the EU regional level was sparse before the mid-2000s and became more frequent during and after 2009.

Under the PESETA project, Ciscar et al. (2009) assessed the potential economic effects of climate change on the EU agricultural sector. These authors obtained climate data that were based on two SRES emission scenarios that were used as input in two combinations of GCMs and Regional Climate models (RCMs) for 2020 and 2080. The DSSAT crop growth models were used to calculate the biophysical impacts and derive crop production functions for the nine agroclimatic regions of Europe. These yield functions were used with a spatial agro-climatic database to conduct a Europe-wide spatial analysis of crop production vulnerability to climate change. Finally, productivity shocks were introduced in GTAP as land-productivity-augmenting technical changes over the crop sector in each region, resulting in changes in the GDP. Their results showed significant regional differences between northern and southern European countries, with Mediterranean countries being the most affected.

The PESETA project not only assesses the potential effects of climate change on agriculture but also covers other market impact categories, such as river floods, coastal 
systems and tourism. In one of the latter stages of this project, the impacts of these four sectors were integrated into CGE model GEM-E3 to obtain a comparable vision of the effects across the sector. Ciscar et al. (2011) presents a detailed description of this last stage of the project and assesses the potential impacts of climate change in Europe in the four market impact categories. The results related to the agricultural sector show important regional disparities. The southern regions present high yield losses under warming scenarios. Central Europe presents moderate yield changes in all scenarios. The northern region presents positive effects of climate change in all scenarios and is the only region with net economic benefits, mainly due to agriculture.

Both of the above works mentioned mark and important step in the regional assessment of the impacts of economic climate change on agriculture in the EU. These studies are the first regionally focused, quantitative, integrated assessments of the effects of climate change on the vulnerable aspects of the European economy and its overall welfare. These studies resulted from the need for further detail and used a methodology that integrates a set of high-resolution climate change projections, detailed impact modelling tools and a regional focus integrated into an economic framework. Both works paved the way for additional studies of European regional assessments regarding the economic impacts of climate change on agriculture.

Shrestha et al. (2013) took the next step to improve economic regional impact assessments of EU agriculture. These authors analysed the economic impacts of climate change by linking climate data and biophysical and economic models at a high disaggregated regional level. The BIOMA (Biophysical models application) platform generates yield change data, which is used in the partial equilibrium CAPRI model to predict economic impacts. As a further advancement, Shrestha et al. (2013) simulated results for the EU at the sub-member (NUTS-2 ${ }^{6}$ ) level while modelling global world agricultural trade. These authors used two climate scenarios (warm and mild) that were both based on the A1B emission scenario and used as inputs for two combinations of GCMs and Regional Climate models(RCMs) for 2020. These authors showed minor effects at the EU level and stronger effects at the regional level, which were consistent with the results shown in previous studies. Shrestha et al. (2013) showed that the estimated regional effects varied by a factor of up to 10 relatives to the aggregate EU

\footnotetext{
${ }^{6}$ Nomenclature of Territorial Units for Statistics with 272 NUTS 2 regions in EU27
} 
impacts. Furthermore, the simulation results show how the price adjustments decreased the response of the agricultural sector to climate change. This study marked another landmark in European regional assessments because it showed regional disaggregated results for the EU. These results allowed us to better understand the regional disparities that climate change can cause in agriculture depending on the location or sector. However, the results of this research were subject to several limitations, including the assumption that crop yields will remain unchanged in the non-EU countries.

Blanco et al. (2014b) filled this gap and introduced several improvements in the European regional impact assessment. These authors used the same methodological approach as Shrestha et al. (2013) but considered climate-induced changes in crop yields for non-EU countries. In addition, these authors used the WOFOST (World Food Studies) crop model (through the BIOMA platform) to simulate the effects of climate change on yield at high grid resolutions across the EU and up to 2030. Simulations were performed with and without the effects of $\mathrm{CO} 2$ fertilisation. In addition, they increase the crops covered compared with previous studies. Simulations for non-EU regions were based on a study performed for the 2010 World Development Report (Müller et al., 2010). The main results of this study are consistent with those of previous works (Ciscar et al., 2009; Shrestha et al., 2013), that showed that the impacts of climate change on crop yields vary widely across EU regions and crops, while the aggregate results hide these significant disparities. According to global impact assessments (e.g., Parry et al., 2004), their simulations were strongly influenced by carbon fertilisation, which shows greater production under a full carbon fertilisation scenario. Regarding the main conclusion, the authors highlight the need for using price endogenous models to assess the impacts of climate change on production, mainly due to the counterbalanced effects of crop prices on final yield effects.

Table 7 shows economic indicators presented by two of the studies mentioned above. Although these studies employed similar methodologies, their results are very difficult to compare, mainly due to the differences in the time horizons of the studies. However, one interesting result is the observed differences between the climate scenarios and the changes in agricultural income. Although both studies used the same economic model to estimate the socio-economic responses (in contrast with Shrestha et al., 2013), Blanco et al. (2014b) presented more negative results and higher differences between the climate 
scenarios. One possible explanation for this result is the effect of the climate change simulation in non-EU countries that was considered by (Blanco et al., 2014b).

Table 7. Economic results comparison between EU-regional assessments

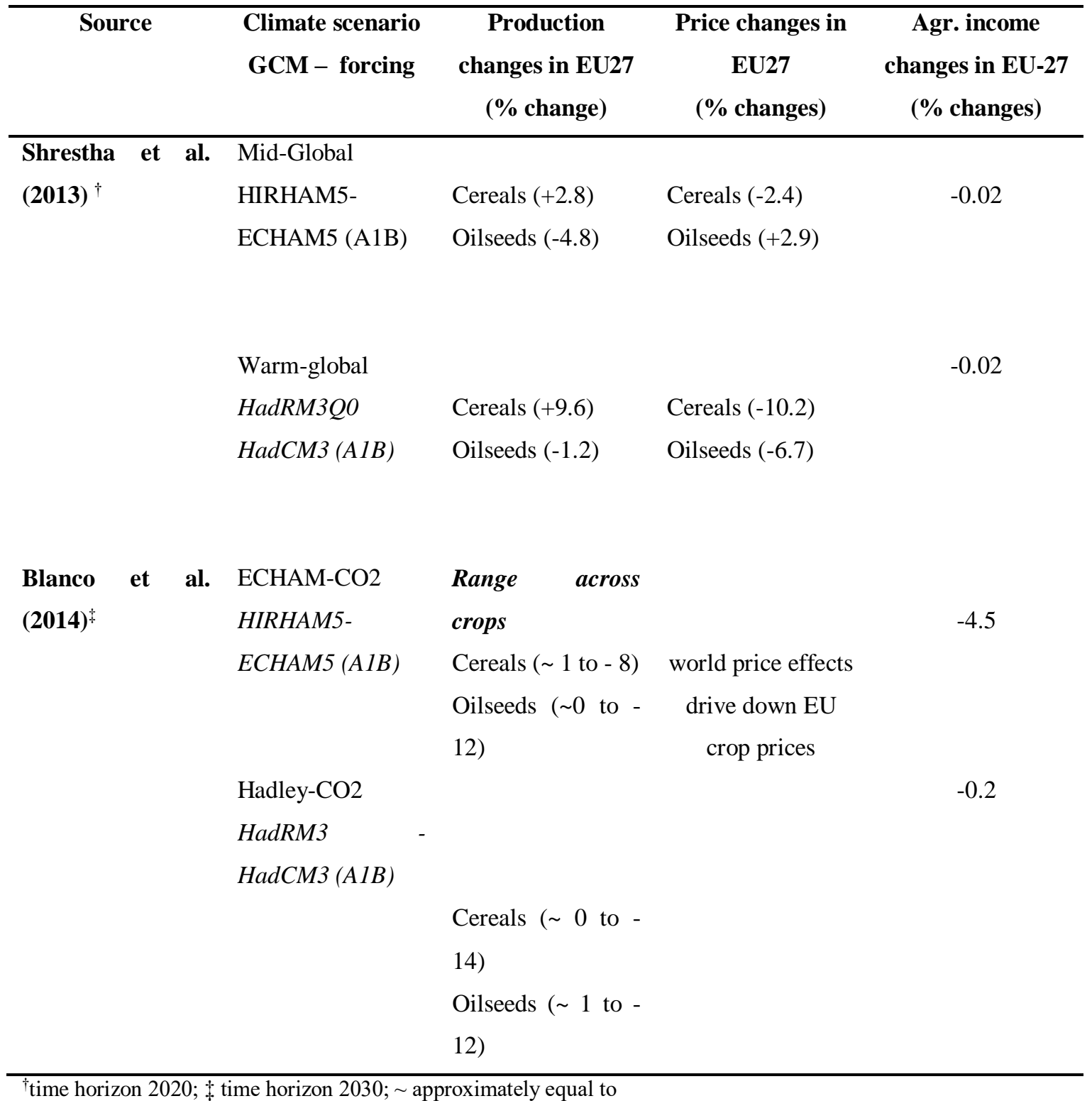

Under the new RCPs and SSPs scenarios, a recent scientific report by Blanco et al. (2014a) assessed the impacts of climate change at a regionalised level within the EU. These authors used a similar approach to that used by Blanco et al. (2014b). However, they developed important advances compared with previous works. Specifically, their simulations were based on the new RCPs and SSPs scenarios; the changes in crop yields for non-EU regions were based on a highly detailed database; there were more crops covered by the biophysical simulations; and there was a wider range of plausible climate scenarios. These authors considered six simulation scenarios that focused on the 
RCP8.5 and the "middle of the road" socio-economic scenario (SSP2). Moreover, these authors used three GCMs and considered the effects with and without $\mathrm{CO} 2$ fertilisation. Generally, their results were not different from those of previous studies, and they showed that moderate global changes in production were mainly driven by interregional adjustments in production, consumption and trade (both with and without the effects of $\mathrm{CO} 2$ ). Additionally, the direction of the effects is clearly influenced by the magnitude of carbon fertilisation. Similar production patterns and price change variations were observed and compared with global impact assessments. The variation increases as the geographical resolution of the results increases. For example, wheat production at the global level increased by 0.9 to $2.3 \%$ in the climate scenarios considering $\mathrm{CO} 2$ fertilisation. Regarding EU production, the effects varied from -0.9 to $2.2 \%$. Important variations were also observed across different commodities. Within the EU and in the same scenario (HadGEM2-CO2), the results showed a decrease in production of $0.1 \%$ for rapeseed and a decrease of $12.4 \%$ for maize.

Corresponding with current global comparison exercises, Frank et al. (2014) presented a recent analysis of the impacts of climate change on the agricultural sector from a European perspective by using two European focused global PE models. These authors quantified the economic impacts of climate change up to 2050 and applied and linked the partial equilibrium models CAPRI and GLOBIOM-EU. For comparison, these authors compare their results under the same set of scenarios based on the RCP8.5 and SSP2 scenarios. In addition, these authors considered a baseline scenario and two climate change scenarios (S3 and S6) picked from the full set of AgMIP scenarios (von Lampe et al., 2014). Overall, Frank et al. (2014) presented findings that were similar to those of the global assessments regarding the endogenous responses buffer to exogenous yield shocks due to climate change. At the global level, the exogenous yield shock varied from $-11 \%$ (S3) to $-21 \%$ (S6) when compared with global demand and production, which decreased by $4-6 \%$ in $\mathrm{S} 3$ and $7-10 \%$ in S6. At the European level, exogenous shocks of $-11 \%$ (S3) and $-16 \%$ (S6) were translated into production decreases of 3-4\% in S3 and 4-7\% in S6. When comparing the economic results and global studies, price was the most sensitive parameter that was affected by climate change. Although CAPRI predicted stronger price effects and smaller demand effects, their differences in a context of a larger model comparison exercise become negligible. 


\section{Farm mathematical programming models for regional assessments}

Amongst all the modelling approaches reviewed so far in this chapter, the economic component has relied on market equilibrium models. The weakness of these approaches is that they hardly captures climate adaptations (Reidsma et al., 2015; Wheeler and Von Braun, 2013), and although several studies have made an attempt to better account for adaptation to climate change (Nelson et al., 2010; Ringler et al., 2011) they still have failed to reflect explicitly farm level responses.

In this sense, farm economics models have emerged as a reliable tool to understand how farm level responses influence impacts of climate change. Mathematical programming models at farm level have commonly grouped within the category of farm supply models which represent the decision-making process of one individual or representative farmer considered as a pure producer (Louhichi et al., 2013). In general, these are optimization models, in which an objective function is maximised subject to agricultural, economics and institutional constraints.

Since the 1990s few studies have assessed the impacts of climate change at the farm level using farm supply models. Kaiser et al. (1993) present a seminal study in which they examined the potential economic impacts of climate change by integrating climatic, agronomic and farm supply models. As a case study, they applied their modelling approach to a grain farm in Southern Minnesota. The authors indicated that although the study's results were not intended as a basis for general conclusions across the country, it were intended to illustrate the importance of adaptive strategies in predicting outcomes. This study, in the context of climate change impact assessments, established the importance of farm level perspective and contributed to understanding farm adaptation processes under climate change scenarios. However, since the 1990s until now, these approaches have had a lesser development compared with market equilibrium models to assess the economics of climate change, which is reflected in the several IPCC WG2 reports, where the analyses give little information on adaptation and risk at farm level (Reidsma et al., 2015).

In this context, the scientific community has indicated that closer attention must be paid to the estimation of the actual range of adaptations open to farmers (Field et al., 2014). Likewise, it has stated that climate change urgently needs to be assessed at the local level to appropriately targeted policy interventions (Jones and Thornton, 2003; Pandey 
et al., 2015; Skjeflo, 2014). In this sense, farm level models have recently acquired an important role, presenting several examples for different countries and contexts.

In the context of economic structural approaches used for assessments of climate change at the farm level, farm supply models linked with models from different disciplines represent the framework for the studies considered in this chapter. Amongst this broad framework, this chapter focused on those studies used to assess the effects of both water balance changes and crop yields changes on the socio-economic responses of the agricultural sector at the farm level. That said, recently two approaches are commonly highlighted by the literature, hydro-economic models, and bioeconomic farm models.

The "hydro-economic model" concept spans a broad range of approaches and classifications. One of the most widely used classification has been established by Braat and van Lierop (1987) who distinguished between holistic and modular hydro-economic models, based on how these are integrated. The holistic hydro-economic models are tightly connected to a consistent model, while modular hydro-economic models are organized into independent modules. The former has been the approach, that in practice, most hydro-economic models have been based, whereas the latter are becoming progressively more common (Harou et al., 2009). For climate change impact assessments, this review focuses on modular hydro-economic models, in which the economic module corresponds to a structural economic model, commonly represented by supply farm models.

Although the history of the use of hydro-economic models has more than fifty years (Harou et al., 2009), its use for climate change impact assessments has a more recent history, even more, when we focus on modular hydro-economic models. Some examples of modular hydro-economic models used for climate change impact assessments are the study of Quinn et al. (2004) who assess future climate change impacts on water resources and agricultural production in the San Joaquin basin (California) linking the farm model APSIDE with the hydrological model CALSIM II. More recently, D'Agostino et al. (2014) adopt a modular hydro-economic approach to assessing the quantitative effects of climate change on water balance components and water use in the agricultural sector of Apulia region (southern Italy). Esteve et al. (2015) present a modular approach combining a farm-based economic optimisation model with 
the hydrological model WEAP, to assess the potential effects of climate change on irrigated agriculture and options for adaptation of the Middle-Guadiana basin, Spain.

The use of hydro-economic models for the assessments of climate change on the agricultural sector has proved to be a useful tool to improve the understanding of the complex relation water-climate-agriculture (Jeuland, 2010). Moreover, have allowed taking into account farm level decision with respect to crop production and water availability and allocation, representing the effects of climate change in a more realistic context.

On the other hand, several authors have assessed the impact of climate change at the farm level using a series of integrated approaches. The use of integrated assessments (IAs) in conjunction with bio-economic farm models have also emerged as a reliable tool to assess the impact of climate change at the farm level. As hydro-economic models, the concept "bio-economic model" cover a broad range of different kind of integrations, however, for this case, several authors have indicated that the term is no longer distinctive due to the diverse set of models that the concept could encompass (van Wijk et al., 2012). This chapter focuses on those bio-economic applications where the economic component is represented by a farm supply model.

Considering the above mentioned, recent examples have been applied in different regions of Europe and Central Asia. Bobojonov and Aw-Hassan (2014), used a bioeconomic farm model to assess the impact of climate change in Central Asia considering the adaptive capacity of agricultural producers. The authors used the CropSyst, and DSSAT models to assess the impacts of climate change on crop yields to then used a farm economic model under the expected value-variance framework to evaluate the economic impacts and adaptation to climate change. Kanellopoulos et al. (2014) and Reidsma et al. (2015) used the Farm System Simulator (FSSIM) bioeconomic model in an integrated assessment framework. FSSIM consists of a data module of agricultural management and a mathematical programming model which seeks to describe farmer's behaviour under a set of constraints. Both authors applied the FSSIM model to assess the impacts of climate change on arable farming systems in Flevoland. 
Both hydro-economic models and bio-economic models have proved to be particularly important due to they simultaneously consider biophysical changes and farm decision in different farms. Therefore, these approaches have allowed to researchers to fully understand how farm level responses influence the impacts of climate change. The use of these approaches provides interesting complementary insights to economic impacts assessments developed through market equilibrium models at higher scales.

\subsection{Common findings and future research directions}

Economic impact assessments of climate change in agriculture have become an important tool for understanding the physical and socio-economic responses of the agricultural sector to future climate change scenarios. Amongst the different approaches and methodologies used, approaches that integrate biophysical and economic structural models have presented an important evolution between the 1990s and today. To analyse this evolution from the range of studies reviewed here, we identified six different methodologies based on their geographical coverage and treatment of the economy. We identified three methods with global coverage that use the PE, CGE or BLS models and three modelling approaches at the regional level that use the PE, CGE or farm models.

In this chapter, we observed the evolution of the entire impact modelling chain, from early assessments onward, at the global, EU, and farm levels. Better resolution, better data availability, and the use of more biophysical and economic models are just a few of the major advances that we have mentioned in this literature survey. In addition, we have highlighted some of the major milestones within this specific approach and the methods reviewed here. These methods spanned from the first assessments considering $\mathrm{CO} 2$ fertilisation and adaptation measures to those presenting updated emissions scenarios that allowed for more accurate climate change projections and an increasing number of studies with better spatial resolution. Beyond their assessment of the effects on agricultural production and prices, these studies encompassed important issues regarding the impacts of climate change, such as food security, the distributional effects of climate change, and the evaluation of several adaptation measures. We present their main features and show how differences in the key outputs from past modelling exercises have resulted in new assessments looking for providing more insights into modelling uncertainties. Despite these differences, we have extracted common findings for several issues. 


\subsubsection{Common findings}

The review made in this chapter was based on studies with very different designs and assumptions that shared a common methodology within the framework of integrated biophysical and economic structural models. Despite their differences, we identified the following important common findings.

Aggregated results at global and regional levels hide the effects at more disaggregated scales. This is particularly evident for production changes and other endogenous responses, such as land use or income. From the global studies reviewed here, most of them present moderate globally aggregated impacts on world food production with important negative impacts in developing regions (e.g., Parry et al., 1999). The same pattern was observed in the EU studies, where most of them presented small effects at the EU aggregate level and greater effects at the regional level (Shrestha et al., 2013).

Market models, independent of their geographical coverage or economic treatment, confirm the important role of trade and inter-regional adjustments as buffers of projected climate change impacts. Most of these economic models reviewed here have transferred a portion of the climate change shock to trade responses and international price changes, resulting in lower and more reliable results than the assessments based only on domestic yield effects (Tobey et al., 1992).

In addition, economic models transfer the climate change shock to the production side of the economic model, which helps offset the primarily exogenous yield impact by resulting in a final lower endogenous yield response. Along with the issue mentioned above, this economic adjustment implies that the analyses that only focus on the biophysical effects of climate change significantly underestimate our capacity to respond (Nelson et al., 2014b).

Of the global assessments reviewed, it was commonly agreed that the impacts of climate change will be more negative in developing countries than in developed countries. Several authors have attributed this to biophysical and economic reasons. From the biophysical side, more negative impacts are expected because of 1) the warmer baseline climate of developing countries and the effects of climate change on them due to increasing temperatures and 2) the important share of developing countries that tend to rely more on $\mathrm{C} 4$ crops with less significant responses to increasing levels of 
CO2 (Lobell and Burke, 2010a). From an economic point of view, increasing world food prices due to climate change may result in 1) the reduction of real income in developing countries, where food expenditure shares are higher, and 2) important impacts on food access where consumption is more price elastic. From the farm level perspective, something similar occurs regarding who are the most affected by the impacts of climate change. Developing countries are likely the most vulnerable to climate change, mainly due to their agro-climatic and economic features. For lower scale, the poorest farmers will probably be the most affected by the impacts of climate change, which is also a circumstance of their features and the context in which they are involved.

Finally, regional disparities were observed in EU regional studies. Most of the studies reviewed agree regarding the significant regional differences within Europe. Decide what regions are winners or losers regarding climate change depend on several factors (e.g., climate scenario, crop model used, adaptation measures, and geographical features). However, most of the studies reviewed here indicated more negative impacts in southern countries than in northern countries. Similarly, at the farm level, where the heterogeneity of farm system can be captured, there are important differences regarding the impacts and responses between farm types within the same region, agreeing in the most studies that poorest farmers will probably be the most negative affected.

\subsubsection{Future research directions}

In this chapter, we have summarised the evolution of the approaches based on the integration of biophysical and economic structural models. In addition, we have summarised its evolution through the last two decades, compared their main economic outputs, and extracted common findings. However, several unresolved challenges remain that are often related to modelling shortcomings. These shortcomings must be used as clues regarding the direction of future research. Below, we provide several areas for future research based on this specific approach and the methodologies reviewed here.

\section{Lack of detail}

The global and EU assessments reviewed here have mainly focused on the impacts of climate change on a few crops (mainly wheat, maize, soybean and rice). The number of 
crops covered by these approaches has increased since the mid-2000s; however, most of these studies ignore the impacts of important commodities. For example, the responsiveness of grasslands and animal productivity to climate change are rarely considered. Several commodities within the economic impact assessment could generate more plausible results (considering the cross-sectoral relations in agricultural markets). By contrast, aspects such as those related to the responses of other crop yield drivers, such as weeds, pests and diseases have been excluded from these economic assessments. Furthermore, few studies have considered different adaptation options within this type of assessment. Most of these studies have assessed minor agronomic management changes (e.g., sowing dates), leaving several other options that could have important effects over the final results (e.g., the tolerance of the crop variety to heat or water logging from heavy rainfall). Finally, a lack of modelling approaches are available that consider the impacts of climate change on agriculture with closely related sectors. For example, the impacts of global warming on water and energy economic sectors will directly affect the final endogenous responses of economic models, which will probably understate the final negative effects.

\section{Validation of economic models}

Several authors have mentioned that model validation is one of the main challenges for future research regarding modelling the effects of climate change on agriculture (e.g., Schmitz et al., 2014). Among the issues discussed in the literature, several difficulties imply model validation in the context of long-term projections (Schwanitz, 2013); the methods used for model validation and their limitation; and the lack of guidelines and standards for testing these models (Bonsch et al., 2013).

When focusing on the studies reviewed here, we observed several issues related to the problems mentioned above. First, information was lacking regarding the validation of the economic model used in these studies. Only three of the reviewed studies explicitly mentioned that their economic components were subjected to a validation process. Amongst these studies, all of them based the validity of their economic models in previous studies to validate their internal structure (Kane et al., 1992) or their output behaviour (Fischer et al., 2005; Hertel et al., 2010). In this context, several authors indicated that the validation process should aim to confirm that the models generate the "right output behaviour for the right reasons" (Barlas, 1996). Thus, the validation tests 
must assure both "structural validity" and "behavioural validity". However, no validation process was mentioned in these studies that encompass both objectives. Furthermore, within the validation of the output behaviour underlies the problem of the future behaviour of empirical data. Thus, comparisons with observed data are only possible in retrospect (through backcasting or hindcasting methods). Although this is considered a reliable approach, there is a risk of over calibrating models to past processes that might not necessarily be the processes driving future developments (Uthes et al., 2010).

Second, after the new scenarios, we observed a concentration of validation processes by comparing different model outputs. Although this process has been used to provide insights regarding modelling uncertainties, it has also been used to support claims of a model's validity. The model intercomparison exercises mentioned in this review (Frank et al., 2014; Nelson et al., 2014a) are examples for model output comparisons. Although it is important to test a model's validity, caution must be used if calibration is involved in the process (Bonsch et al., 2013).

\section{Data and input parameters}

More work is needed regarding estimations of the key parameters in economic models. The values of these estimations must be determined consistently with the availability and quality of data. However, the absence of data availability and quality is one of the major constraints faced by the modelling community. Among the studies reviewed here, several authors have highlighted this problem and pointed out challenges that they must overcome due to extremely poor data sources in critical areas, such as data for supply and demand parameters (Nelson et al., 2010). Additionally, a low diversity of available data and significant proportions of data are synthetically constructed rather than based on direct empirical observations. Nelson et al. (2014a) confirmed that these problems are major challenges and have underlined that many of the parameters used in the economic models "have limited econometric and validation studies to back them up with significant confidence". Future research must aim to strengthen elementary economic estimations, and data should be shared within the community.

\section{Model structure and market failures}

The structure of the economic models reviewed here all follow the same basic neoclassical theory. Thus, these models use several simplifying assumptions, including 
the rationality of consumers and producers and the absence of market imperfections. Consequently, several findings, such as the role of trade as a buffer of climate impacts, must be treated with caution. For instance, welfare estimates through simulation models are characterised as an aggregate of consumer and producer rent. These aggregate estimates mask significant differences in impacts across regions and the population (Arent et al., 2014). On the other hand, with the absence of market imperfections, externalities are not considered when, for instance, trade barriers are abolished. This may result in an incorrect vision of reality. Future research must aim to assess the real possibilities that exist to incorporate market imperfections in these types of methodologies.

The latter also occurs at the farm level, where the different modelling approaches presented assumed that all farms are commercial farms. This is not according to the reality of several developing countries, where peasant agriculture co-exists with small, medium and large commercial farms. Therefore, these approaches fail to consider both additional constraints associated with household consumption and many constraints related to market imperfections which in turn are related to the adaptations at the farmhousehold level.

\section{Food security}

Food security is probably one of the most important issues regarding the impacts of climate change on agriculture. Nevertheless, food security has been characterised by its complexity and multiple dimensions, including food availability, food access, food utilisation, and stability. These features and the interaction between these dimensions have resulted in enormous challenges for researchers and modelling teams that aim to evaluate the impacts of climate change on food security. The structural approach and the methods reviewed here have contributed to understanding some of the effects of climate change. However, several challenges remain.

First, the studies reviewed here have been unevenly distributed over two of the four dimensions that food security encompasses (Schmidhuber and Tubiello, 2007; Wheeler and Von Braun, 2013). Until the mid-2000s the global assessments reviewed here were able to focus mainly on the impacts on food availability. By contrast, in the late 2000s, Nelson et al. (2010) assessed the impacts of climate change on agricultural markets and connected the economic consequences of food availability drivers to food access and 
food utilisation. Second, these studies rely on a few economic models to assess the effects of climate change on food security, including the BLS model within the modelling framework of the IIASA system and through the PE model IMPACT. Thus, it is important to add to this type of assessment new economic models to explore the uncertainties associated with modelling the impacts of climate change on food security. Some efforts in this direction have been reported under the FACCSU-MACSUR project, with the PE model CAPRI ${ }^{7}$. Finally, food prices at the producer level provide little information about the burden for consumers. Future modelling efforts should consider more indicators at the consumer levels, such as consumer prices, food expenditure shares, the nutrition values of food baskets, food access or food utilisation.

\section{Adaptation policies}

Another important issue encompassed by the structural approach and their methods is the assessment of climate change adaptations. One particular dimension of the adaptation question is related to adaptation policies. Several studies have assessed the effects of trade liberalisation as a tool for adapting to climate change (e.g., Hertel and Randhir, 1999). However, it is still necessary to assess a wider range of adaptation policies in modelling frameworks (Easterling et al., 2007). An interesting aim of future research could be to determine the effects of adaptation policies that increase public spending on research and technology. On-going efforts in this direction have been reported in Ignaciuk and Mason-D'Croz (2014). By contrast, several potential adaptation options extend beyond in food production adaptations. For instance, storage policies have not been analysed although they largely influence food prices.

Finally, although farm level impact assessments have allowed reflecting farm-level responses explicitly, still there is a need for further developing integrated assessments and farming system analysis in developing countries. These approaches will allow to better understanding the impacts of the climate change in a context closer to the reality of future scenarios, therefore shedding lights to more reliable adaptation measures and strategies.

\footnotetext{
${ }^{7}$ See http://macsur.eu/index.php/products
} 


\section{Water Variability and the Economic Impacts on Small- Scale Farmers. A Farm Risk-Based Integrated Modelling Approach}

Publication: Fernández, F. J., Ponce, R. D., Blanco, M., Rivera, D., \& Vásquez, F. (2016). Water variability and the economic impacts on small-scale farmers. A farm riskbased integrated modelling approach. Water Resources Management, 30(4), 1357-1373.

Abstract Strengthening the planning of hydrological resources to optimize the use of water in agriculture is a key adaptation measure of the Chilean agricultural sector to cope with future climate change. To address this challenge, decision-makers call for tools capable of representing farmers' behaviours under the likely stresses generated by future climate conditions. In this context, of special concern are the effects of water variability on small-scale farmers, who commonly operate with narrow profit margins and who lack access to financial resources and technological knowledge. This chapter sheds light on the economic impacts of changes in water availability on small-scale agriculture. We provide a hydro-economic modelling framework that captures the socio-economic effects of water shocks on smallholders in the Vergara River Basin, Chile. This approach links a farm risk-based economic optimization model to a hydrologic simulation model adjusted for the basin. The results indicate that at the aggregated level, there will be minor economic impacts of climate change on the basin's small-scale agriculture, with small decreases in both expected utility and wealth. However, large differences in the economic impacts of wealthy and poor small-scale farmers are found. Changes in water availability, reduce the options of land reallocation to increase farmer's expected utility, being the poor small-scale farmers the most negatively affected. 


\subsection{Introduction}

The Fifth Assessment Report (AR5) of the Intergovernmental Panel on Climate Change (IPCC), suggests that climate change impacts on water resources will be uneven across sectors and regions (Field et al., 2014). Changes in precipitation and temperature and increases in extreme weather events (e.g., floods and droughts) could seriously threaten water supplies for different users, including the agricultural sector (Stocker et al., 2013). These new climatic conditions may impact agricultural yields, the suitability of agricultural lands, and the distributions of pests, among other key agricultural factors. Consequently, these changes could modify farmers' incomes, with consequences on both social and economic dimensions (Bates et al., 2008; Field et al., 2014).

Considering the uneven distribution of climate change impacts on the agricultural sector (Tol et al., 2004), local conditions play a key role in reshaping productive systems to cope with the expected impacts and to exploit, when possible, beneficial opportunities. Thus, the assessment of climate change impacts on the agricultural sector should be conducted at the local level by linking agronomic, hydrologic, and socioeconomic information (Harou et al., 2009; Hurd and Coonrod, 2012). In this regard, there is a consensus in the literature about the use of the river basin as the proper spatial unit to analyse water resources management (Brouwer and Hofkes, 2008; Harou et al., 2009; Heinz et al., 2007).

Within this context, special attention should be paid to the most vulnerable groups, among which are small-scale farmers (Bellon et al., 2011; Easterling et al., 2007; Kurukulasuriya and Rosenthal, 2013). Small-scale farmers are characterized as rural producers whose household incomes come mainly from agricultural activities, and they develop their agricultural practices within a "complex, diverse, and prone-risk" environment (Morton, 2007). Small-scale farms play important roles in the economies and rural lives of developing and developed countries (Hazell, 2005) and constitute a significant portion of the world's farms (FAO, 2014b; Nagayets, 2005). Smallholders are also estimated to represent a major share of poor people in rural areas (World Bank, 2008). Thus, greater exposure to climate risks will exacerbate their intrinsic vulnerability (Morton, 2007), leading to long-term negative outcomes regarding wellbeing and food security (Porter et al., 2014). Moreover, the negative climate change 
impacts on small-scale agriculture can undermine key socio-economic priorities, such as rural poverty alleviation, food security or the balance of rural-urban migration (Ravallion and Datt, 2002; Rosegrant and Hazell, 2000).

This chapter presents a farm risk-based hydro-economic model, which analyses the economic impacts of changes in water availability due to climate change with a focus on the small-scale farmers ${ }^{8}$ of the Vergara River Basin (VRB). The model links the physical impacts of climate change with farmers' economic responses. The former is conducted through a hydrologic model for the basin, developed since 2008, and updated for this research, while the latter is estimated through a risk-based farm model that accounts for the water demand of each farm type.

Within Chile, the socio-economic features of the VRB and the regions it encompasses make this sector one of the most vulnerable to the impacts of climate change on agriculture. These regions present the larger share, at national level, of small-scale farmers (Apey and Barril, 2006; Donoso et al., 2010), among which an important share is characterized by high poverty rates (Agostini et al., 2008). On the other hand, scientific research that involved these regions suggest that the study area and farmers within, will likely face a major exposure to climate risk (Christie et al., 2011; Falvey and Garreaud, 2009). This greater exposure to climate risk will likely reduce smallfarmer's profits. It can: 1) decrease food security within the already poor rural population; 2) limit the success of regional governments in reducing poverty; and 3) increase excessive rural-urban migration related to available jobs.

The integration of hydrological and economic models has become an important tool to support policy-makers in the assessment of the potential consequences of climaterelated issues (Esteve et al., 2015; Medellín-Azuara et al., 2009). As reported in Harou et al. (2009), the hydro-economic approach has been widely used in a variety of settings such as water conservation (Blanco-Gutierrez et al., 2013; Foster et al., 2014; VarelaOrtega et al., 2011; Ward and Pulido-Velazquez, 2012), economic impacts of water variability (Graveline et al., 2014; Maneta et al., 2009a; Maneta et al., 2009b; Torres et al., 2012), water quality (Heinz et al., 2007; Peña-Haro et al., 2010; Peña-Haro et al., 2011; Qureshi et al., 2008), and economic impacts of climate change (D'Agostino et

\footnotetext{
${ }^{8}$ Classification of small-scale farmers in Chile accounts for agro-ecological characteristics, access to capital and technology, market orientation, cultivated land area and agricultural potential (OECD 2008).
} 
al., 2014; Hurd and Coonrod, 2012; Jiang and Grafton, 2012; Qureshi et al., 2013; Yang et al., 2013). Most of the hydro economic models rely on risk neutral expressions, undervaluing the decision makers' responses to avoid risky events. Despite the numerous studies indicating that farmers behave as risk-averse agents (Chavas, 2004; Rosenzweig and Binswanger, 1992; Von Neumann and Morgenstern, 1944), only a few studies explicitly include risk in the objective function (Blanco-Gutierrez et al., 2013; Foster and Valdés, 2013; Varela-Ortega et al., 2011).

Three features of this chapter are the most salient. Regarding the methodological contribution, two aspects are highlighted. First it is presented an extended version of the approach proposed by Petsakos and Rozakis (2015) by explicitly including a new constraint to the optimization problem, allowing the linkage with the hydrological module. Second, the few studies that explicitly include risk in the objective function rely on a linear mean-variance framework that assumed zero wealth effects. In this case, this chapter presents a hydro-economic model where risk is included in a nonlinear mean-variance approach where the economic module captures the wealth effects that are typically ignored. Finally, considering that no studies have so far addressed the economic impacts of climate change on small-scale agriculture in Chile, this chapter aims at filling this gap.

\subsection{Methodology}

\subsubsection{Hydrological model}

The SWAT model (Arnold et al., 1998) is a conceptual physically based, semi-spatially distributed hydrological and water quality model designed to route water, sediments and contaminants from individual watersheds through a whole river basin system. It can be used to predict the impact of land management practices on water, sediment and agricultural chemical yields in large complex watersheds with varying soils and land use and management conditions over long periods. The basin is divided into sub-basins, and the input information organized for each sub-basin includes climate, hydrologic response units (HRUs), ponds/wetlands, groundwater, and the main reach draining each sub-basin. The hydrology of the watershed is conceptually divided into the land phase of the hydrologic cycle and the routing phase. The land phase controls the water, sediment, and nutrient and pesticide loads to the main channel of any given sub-basin, 
while routing determines the movement of water, sediment and pollutants from the channel network to the basin outlet.

Since 2008, hydrological data was collected and analysed to simulate through SWAT, the hydrology of the Vergara River Basin of Chile (Figure 3). Several results of the hydrological analysis have been already published in peer-reviewed journals (Stehr et al., 2010a; Stehr et al., 2010b; Stehr et al., 2008), which has validated a highly reliable model that was designed specifically for the Vergara Basin. Under the context of the Environmental Economics and Climate Change (eec2) project, it is used and updated this hydrological data using historical dataset for calibration that overlaps the economic time series. A detail description of hydrological data and the main features of the VRB are described below.

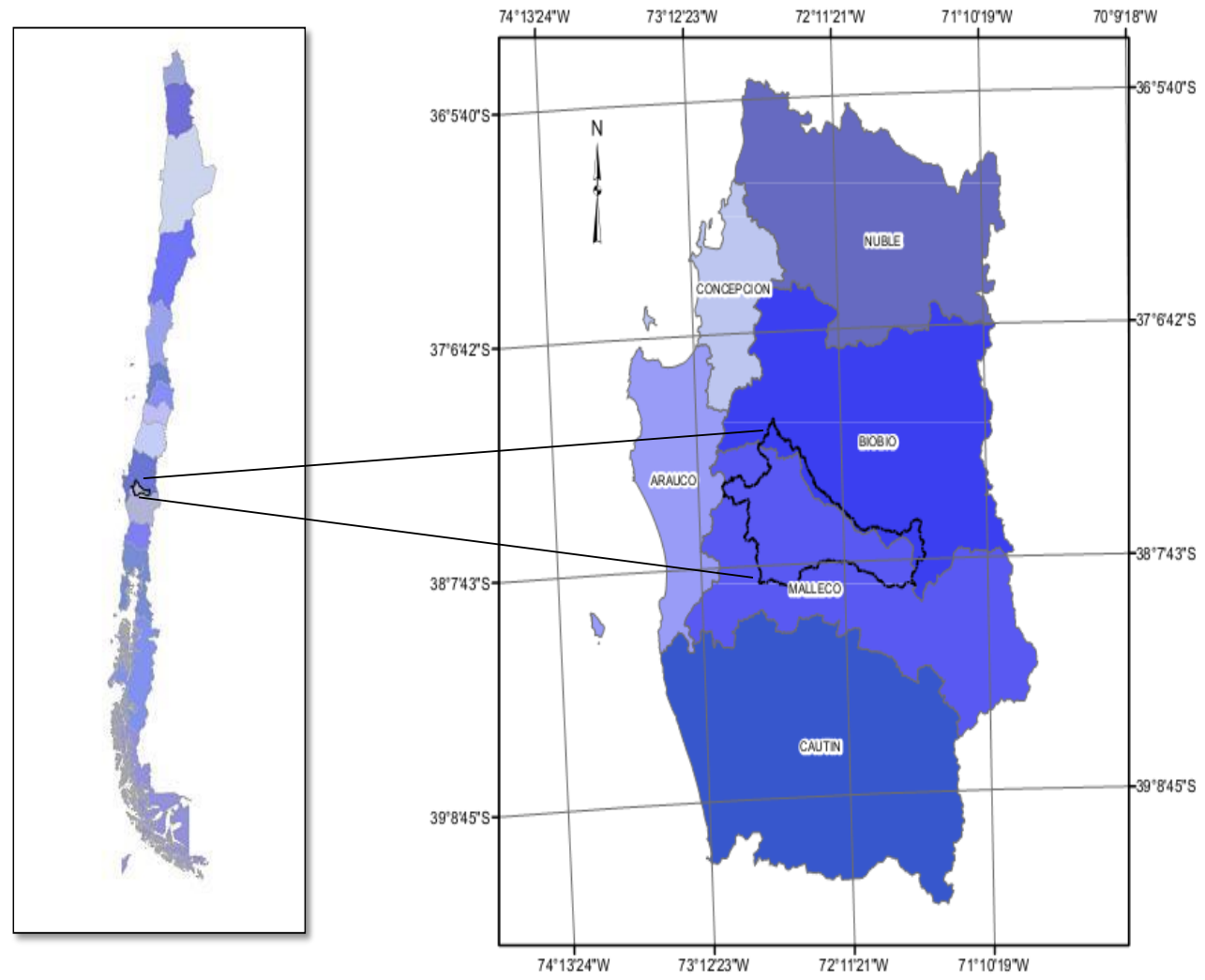

Figure 3. Vergara River Basin

The Vergara basin exhibits a rainfall-dominated hydrological regime -high flow during austral winter and minimum flows during summer- with an important orographic effects and soil variability. Land use is limited to forest plantations and agriculture, and surface 
water is the main source of water for irrigation. Therefore, rainfall-runoff generation is the main hydrological process for irrigation. Previous research has shown a good match between observed and SWAT-simulated streamflow for similar watersheds using the Curve Number Method (Cano et al., 2014; Espinosa et al., 2011; Stehr et al., 2008), supporting the choice of SWAT. For evapotranspiration, a temperature-based model (Hargreaves method) was used, considering the lack of evaporation tanks or more complete and reliable meteorological records. The Hargreaves method has shown good performance for similar watersheds (Rivano and Jara, 2005). The model setup is described in detail in Stehr et al. (2008, 2010a, 2010b).

The HRUs in SWAT are spatial homogeneous units in terms of hydrological response considering soil type, land use and slope. The procedure to define HRUs consists in overlapping spatial data to define non-interacting land parcels. SWAT's routine defined 272 HRUs for 22 soil types, seven land uses (deciduous forest, evergreen forest, range grasses, spring wheat, winter pasture, water, and low- density residential areas), and slopes ranging from 0.03 to 0.42 . Sub-basins (51) were defined considering gauging stations and main streams. Predominant soils are silt-loam soils derived from volcanic ashes at the piedmont and the Andes (33\% of the watershed's area) and silty soils in the Central Valley (30 \%) from old volcanic ashes. Clay soils are present in the granitic Coastal Range and deposition areas in the Central Valley, attaining $13 \%$ of total area.

Meteorological data from 22 stations and five streamflow gauging stations were used to calibrate the model using time series for years 2000-2002. Records span the period 1977-2002. Mean streamflow range $57 \mathrm{~m}^{3} \mathrm{~s}^{-1}$ at Tijeral station located in the Central Valley (maximum flow of $162 \mathrm{~m}^{3} \mathrm{~s}^{-1}$ in July) and $6 \mathrm{~m}^{3} \mathrm{~s}^{-1}$ at Rehue station at the Andes (maximum flow of $17 \mathrm{~m}^{3} \mathrm{~s}^{-1}$ in July). Most sensitive parameters were those related to groundwater dynamics (aquifer's depth and deep percolation fraction), available water capacity and Soil Conservation Service Curve Number for rainfall-runoff modelling. The calibration procedure included in SWAT follows the Latin Hypercube sampling /One-at-time and validation was performed considering two different land use scenarios. This procedure leads to high confidence on simulating the hydrological processes within the watershed. Model simulations were able to reproduce the magnitude, timing and trends in streamflow data, with correlation coefficients $>0.7$ for calibration and $>0.75$ for validation. The Tijeral gauging station is the proxy for the whole-watershed, showing correlation values of $r^{2}=0.96$ for calibration and $r^{2}=0.93$ for validation. Values 
of goodness-of-fit indices are consistent for all five gauging stations. Details of calibration and results can be found in Stehr et al. (2010a, 2010b)

Water Yield is the total amount of water leaving sub-basins and entering to the main channel. As the main mechanism for water abstraction is diverting water from rivers, we used water yield for each sub-basin as equivalent to water availability. The water balance considers surface water, lateral flow, groundwater flow, transport losses and surface storage. Water availability for each commune (county) was calculated as the area-weighted average of water availability for each sub-basin within the county's boundary.

\subsubsection{Risk-Based Economic Model}

The economic module of this chapter is based on Petsakos and Rozakis (2015), integrating risk into a positive mathematical programming (PMP) model (Howitt, 1995). The model is formulated as a non-linear mean-variance (E-V) specification, assuming a logarithmic function and, thus, a decreasing absolute risk aversion (DARA) coefficient that is a concave function of wealth. Within the model, the farmer maximizes the expected utility (EU) of their stochastic income, subject to resource and non-negativity constraints. The farmer's behaviour is characterized by a selection of 18 representative farms - farm types - regarding crop pattern, farm size, irrigated area, and geographical location. The model estimates the optimal crop area distribution that satisfies all the constraints and yields the highest possible EU by farm type.

Based on the E-V method, the objective function of the model is formulated as follows:

$$
\operatorname{Max} E U=W-\frac{1}{2} \frac{x^{T} S x}{W}
$$

In Eq. 1, EU is the farmer's expected utility; $\boldsymbol{w}$ is the total wealth given by $\boldsymbol{W}=\boldsymbol{w}_{\mathbf{0}}+$ $\hat{g}^{T} x$, where $w_{0}$ is the non-stochastic component of wealth, which is commonly called “initial” wealth (Bar-Shira et al., 1997; Chavas, 2004; Petsakos and Rozakis, 2015). Correspondingly, $\widehat{\boldsymbol{g}}^{T} \boldsymbol{x}$ is the stochastic component of the farmer's wealth, where $\widehat{g}^{T}$ denotes the transpose $I \times 1$ vector of the final implicit profits by activity level (e.g., CLP\$ per hectare), and $\boldsymbol{x}$ is the $I x I$ vector of unknown activity levels. Finally, $\boldsymbol{S}$ is the 
I $x$ I covariance matrix of activity profits. Here, the maximization of $\boldsymbol{E} \boldsymbol{U}$ is approximately equivalent to the maximization of the certainty equivalent, which means that the farmer would maximize the guaranteed return rather than taking a chance on a higher but uncertain return.

According to Petsakos and Rozakis (2015), through the calibration process, the farm's "true" wealth distribution is recovered, resulting in a profit covariance matrix $S$ for each farm type. Furthermore, the farmer's implicit expected profits are estimated as $\widehat{g}=\hat{\boldsymbol{r}}-$ $\boldsymbol{c}-\boldsymbol{q}$, where $\hat{\boldsymbol{r}}$ is considered the "true" vector of expected revenues, $\boldsymbol{c}$ is the $I x l$ vector of average variable costs, and $\boldsymbol{q}$ is the vector of the implicit marginal costs ${ }^{9}$.

Along with the resource and non-negativity constraints (Eqs. 2 and 4), the model includes two calibration constraints (Eq. 3).

$$
\begin{gathered}
A x \leq b \quad[z] \\
x^{+} \leq x_{0}^{+}+\varepsilon \quad\left[h^{+}\right] \quad ; \quad x^{-} \geq x_{0}^{-}-\varepsilon \quad\left[h^{-}\right] \\
x \geq 0
\end{gathered}
$$

Eq. 2 represents the resource constraints (land and water), $A$ is the $M x I$ matrix of technical coefficients, and $\boldsymbol{b}$ is the $M x 1$ vector of available resources. The dual values associated with the resource constraints are given by the vector $z$. Eq. 3 represents the calibration constraints that bounds the model to the observed activity levels in the base year, where $x_{0}$ denotes the land allocation in the base year, and $\varepsilon$ represents a small deviation from the base year land allocation. In order to force the model to reproduce base year observations, the calibration constraints for activities with negative profits $\left(x^{-}\right)$were defined as $x^{-} \geq x_{0}^{-}-\varepsilon$, thus setting a lower bound for the optimal activity levels (see Kanellopoulos et al. (2010) and Petsakos and Rozakis (2015) for similar approaches). Conversely, activities with positive expected profits $\left(x^{+}\right)$retain the form $x^{+} \leq x_{0}^{+}+\varepsilon$ (Howitt, 1995, 2005). The dual vectors for the calibration constraints are represented by $\boldsymbol{h}^{+}$and $\boldsymbol{h}^{-}$. Finally, Eq. 4 represents the non-negativity constraint on land allocation.

\footnotetext{
${ }^{9}$ The complete mathematical details of the calibration process used here are provided in Petsakos, A., Rozakis, S. (2015) Calibration of agricultural risk programming models. European Journal of Operational Research 242, 536-545. , ibid. .
} 
The resource constraints (Eq. 2) can be disaggregated into the following constraints for land and water. The land constraints, which limit the total area of land availability fland (ha) by farm type (Eq. 5), and the potential area under irrigation iland (ha), where irr $_{f}$ refers to the irrigated crops of each farm type (Eq. 6) are represented as follows:

$$
\begin{aligned}
& \sum_{c} X_{c, f} \leq \text { fland }_{f} \\
& \sum_{c \in i r r_{f}} X_{c, f} \leq \text { iland }_{f}
\end{aligned}
$$

The water constraints indicate that the total amount of water used for irrigation at the farm level cannot exceed the farm water availability fwater (thousand $\mathrm{m}^{3}$ ) (Eq. 7), where $\boldsymbol{C} \boldsymbol{I R}_{\boldsymbol{c}}$ refers to the crop irrigation requirements of irrigated crops (thousand $\mathrm{m}^{3} / \mathrm{ha}$ ).

$$
\sum_{c} \text { CIR }_{c} X_{c} \leq \text { fwater }_{f}
$$

Eq. 7 takes into account the conveyance and distribution efficiency of the water network $\boldsymbol{h d}$ and the gross water delivered $\boldsymbol{g} \boldsymbol{w \boldsymbol { d }}\left(\mathrm{m}^{3}\right)$ at farm level $\boldsymbol{f}$ (Eq. 8).

$$
\text { fwater }_{f}=g w d_{f} * h d
$$

For calibration it is used the Percentage Absolute Deviation (PAD) statistical parameter to measure the accuracy of the economic model in replicating the initial crop area distribution for the base year 2011. According to this parameter, the error scores were calculated as the sum of absolute percentage differences between observed and simulated crop areas among farms overall and by farm type, reaching the best calibration when the PAD is close to 0 (Hazell et al., 1986). The PAD values generated by the model correspond fairly well to the actual values for the basin as a whole, although this is not necessarily true for the 18 farm types. A PAD of $0.25 \%$ across all crops for the entire basin is obtained, which is fairly good for this type of model. At the farm level, the PAD values varied from $1.2 \times 10^{-9} \%$ (Farm 11) to $24.6 \%$ (Farm 12). Although the model predicts a major deviation for the latter, in absolute terms this is a small and insignificant change, mainly due to the small areas dedicated to crops. 


\subsubsection{Modelling Integration and Water Scenarios}

The integration of economic and hydrologic models is performed using a farm-tocommune mapping simulating water availability scenarios in both models. Within this integrated approach, we organize the economic and hydrologic models into independent modules, transferring input/output data between them.

Using the calibrated hydrological model, two periods were simulated: 1981-2010 (current conditions) and 2011-2040 for future conditions. For climate change modelling, SWAT applies a "perturbation" approach, i.e. a base scenario is perturbed to simulate changes in total precipitation (rainfall-runoff processes) and mean temperatures (snowmelt and evapotranspiration). The SWAT model simulates water variability by considering the Regional Climate Model (RCM) PRECIS outputs for A2 climate change scenario (Nakicenovic et al., 2000). PRECIS operates at a $25 \mathrm{~km}$ resolution, which is appropriate for resolving small-scale features of topography and land use and also capturing the variability of precipitation (Gutowski et al., 2003). Outputs from PRECIS are the best estimates to date of climate change for Chile, showing a consistent change of $-30 \%$ in annual precipitation for the first half of the XXI century and an increment of $4-5^{\circ} \mathrm{C}$ for Central-South region of Chile.

The scenario development follows Stehr et al. (2010b) under the assumptions that the changes in land use are related to changes in the area under irrigation, and that main hydrological processes remain unchanged. Therefore, streamflow simulations maintained land use patterns from the model calibrated with historical data, only changing meteorological drivers. According to the hydrologic model, the average expected change in water availability for the $50^{\text {th }}$ percentile at basin level is $-21.4 \%$. The details for each commune are presented in Table 8.

To include hydrological uncertainty, it is constructed a cumulative probability function for water availability using the outputs from the hydrologic model. To develop streamflow simulations, we fitted a Generalized Extreme Value (GEV) distribution to each time series. GEV-type distributions are often used to model the smallest or largest values in a large set of independent, identically distributed random values (Katz et al., 2002). It was used maximum likelihood estimation for the shape, scale, and location 
parameters. The cumulative distribution functions allow the assessment of water availability within each sub-basin, comparing current and future climate drivers.

The base simulation is conducted using the $50^{\text {th }}$ percentile of the range generated by the hydrologic model; then, it was used the resulting water availability as a hydrologic shock in the economic model for each farm type. Finally, in the economic model, the expected utility impacts of water variability and the optimized crop distribution for each farm are computed, considering the difference between the current (baseline) and water variability scenarios.

Table 8 Expected change in water availability for the $50^{\text {th }}$ percentile by commune (\%)

\begin{tabular}{lc}
\hline Commune & Expected change in water availability (\%) \\
\hline Angol & -25.9 \\
Collipulli & -21.6 \\
Curacautín & -20.1 \\
Ercilla & -17.0 \\
Los Sauces & -22.6 \\
Lumaco & -21.4 \\
Nacimiento & -22.4 \\
Negrete & -22.7 \\
Quilaco & -21.6 \\
Renaico & -23.1 \\
Traiguén & -21.4 \\
Victoria & -17.0 \\
\hline
\end{tabular}

\subsection{Data and Study Area}

\subsubsection{Study Area}

The study area is the Vergara River Basin, located $600 \mathrm{~km}$ south from the country's capital Santiago, whit coordinates $37^{\circ} 30^{\prime}$ and $38^{\circ} 14^{\prime} \mathrm{S}$ and $71^{\circ} 36^{\prime}$ and $73^{\circ} 03^{\prime} \mathrm{W}$. The area of the basin is $4,265 \mathrm{~km}^{2}$, representing the third largest basin in the Bio Bio region (Stehr et al., 2008). The basin has its boundaries in two regions, Bio Bio and Araucanía, including 12 municipalities with a total population of 200,000 inhabitants. The area is part of the country's most important centre for forestry activities and 
contains an important share of Chilean agricultural land (Stehr et al. 2008), representing $17.8 \%$ of land devoted to cereal production and $18.3 \%$ for industrial crops (INE, 2007).

Agricultural smallholders, international forestry companies, and fruits exporters are major players in the basin's economy while an important share of the population includes indigenous inhabitants. Currently, land use is dominated by forestry (64\%), with a small share of agricultural activities. Despite the dominance of forestry in terms of land use, agriculture is one of the most relevant activities in socioeconomic terms within the basin. According to Traub (2014), in seasons with intensive agricultural activity, the sector may provide more than $20 \%$ of regional employment in the regions where the basin is located. Moreover, Foster and Valdés (2013) considering an expanded agricultural GDP, indicate that the Bio Bio region contributes $6.3 \%$ of silvoagricultural GDP (twice the national average), while the share of national silvoagricultural GDP in the Araucanía region can reach 11.9\%.

Here, as in other sectors in Chile (see Berger et al. 2006), it can be observed the contrast between competitive export-oriented and local agriculture as represented by small-scale farmers and indigenous peoples oriented towards an internal market (OECD, 2008; Torres et al., 2015). Small-scale farmers predominate in the regions in which the basin is located (Apey and Barril, 2006), which are also the regions with the largest use of policies aimed at promoting local economic development and small-scale farmers (Donoso et al., 2010). The predominance of small-scale farmers is partially explained by the production of import-substituting crops, of which cereals, beans, and potatoes are among the most relevant (OECD, 2008).

\subsubsection{Data Collection and Analysis}

Farm data was obtained from targeted surveys addressed to smallholders in both the Araucanía and Bio Bio regions in 2011 by the National Institute for Agricultural Development (INDAP) (see Annex 4). All surveyed farmers participate in the Local Development Programme (PRODESAL) and the Indigenous Territorial Development Programme (PDTI). These programmes are the main instruments for promoting the local economic development of small-scale farmers in Chile (FAO, 2014a). As a result of this process, it was obtained data from more than 7,000 farmers. 
Based on the cropping patterns observed, data availability, and the main activities of small-scale farmers, it was considered the impact of water availability on four main crops that are crucial for the smallholder economy in the basin: oats, wheat, potatoes, and common beans (Apey and Barril, 2006). Together, these regions account for $85.5 \%$ of oat production, $67.6 \%$ of wheat, $52 \%$ of potato, and $35.8 \%$ of common bean at the national level (INE, 2010). By focusing on these crops, we cover 1,488 farms (approximately 1,400 hectares) comprising 12 communes and accounting for 52\% of the registered farmers dedicated to the main cereals, legumes and potatoes.

For the final database, farms were grouped according to 1) communes; 2) size class; and 3) used technologies (Hazell et al., 1986). Thus, farmer behaviour is characterized by a selection of 18 representative farms regarding crop pattern and distribution, farm size, and geographical location (see Table 9). The selected farm types represent the variety of production systems for cereals, legumes, and potatoes that small-scale farmers used within both the PRODESAL and the PDTI programmes. 
Table 9 Summary of representative farm types in the Vergara River Basin

\begin{tabular}{|c|c|c|c|c|c|}
\hline $\begin{array}{c}\text { Farm } \\
\text { type }\end{array}$ & $\begin{array}{c}\text { Commune } \\
\text { Code }^{\mathrm{a}}\end{array}$ & $\begin{array}{l}\text { Farm } \\
\text { size } \\
\text { (ha) }\end{array}$ & $\begin{array}{c}\text { Area } \\
\text { irrigated (ha) }\end{array}$ & $\begin{array}{l}\text { Total Wealth }^{\mathrm{b}} \\
\text { (millions of } \\
\text { CLP\$) }\end{array}$ & Cropping pattern ${ }^{\mathrm{c}}$ \\
\hline F1 & ANG & 14.5 & 3.47 & 9.87 & $\begin{array}{l}\text { Potdry (50.7\%); Whtdry (21.0\%); Potirr } \\
(20.3 \%) \text {; Oatdry }(5.5 \%) \text {; Whtirr }(2.5 \%)\end{array}$ \\
\hline F2 & $\mathrm{COL}$ & 188.44 & 59.32 & 51.99 & $\begin{array}{ll}\text { Whtdry }(36.2 \%) ; & \text { Whtirr(30.8\%); } \\
\text { Oatdry }(30.8 \%) ; & \text { Potdry(1.5\%); } \\
\text { Potirr(0.7\%) } & \end{array}$ \\
\hline F3 & $\mathrm{COL}$ & 35.46 & 17.53 & 15.89 & $\begin{array}{l}\text { Whtirr }(42.6 \%) \text {; Oatdry }(24.5 \%) \text {; Whtdry } \\
(16.2 \%) \text {; Potdry }(9.9 \%) \text {; Potirr }(6.8 \%)\end{array}$ \\
\hline $\mathbf{F 4}$ & CUR & 11.5 & 1 & 2.09 & $\begin{array}{l}\text { Oatdry }(78.3 \%) \text {; Whtdry }(13.0 \%) \text {; Whtirr } \\
(8.7 \%)\end{array}$ \\
\hline F5 & ERC & 175.1 & 84.6 & 66.85 & $\begin{array}{l}\text { Whtirr (46.5\%); Whtdry (32.3\%); Oatdry } \\
\text { (19.4\%); Potirr (1.8\%) }\end{array}$ \\
\hline F6 & ERC & 11.59 & 4.61 & 5.16 & $\begin{array}{l}\text { Potdry }(38.6 \%) ; \text { Potirr }(35.5 \%) ; \text { Oatdry } \\
(21.6 \%) ; \text { Whtirr }(4.3 \%)\end{array}$ \\
\hline F7 & LSA & 144.83 & 39.58 & 53.21 & $\begin{array}{l}\text { Whtdry }(44.0 \%) \text {; Oatdry }(28.0 \%) \text {; Whtirr } \\
(26.9 \%) \text {; Potdry }(0.7 \%) \text {; Potirr }(0.4 \%)\end{array}$ \\
\hline F8 & LSA & 8.65 & 1.865 & 3.33 & $\begin{array}{l}\text { Potdry }(52.4 \%) \text {; Oatdry }(25.0 \%) \text {; Whtirr } \\
(13.5 \%) \text {; Potirr }(9.1 \%)\end{array}$ \\
\hline F9 & LUM & 46.4 & 6.3 & 13.59 & $\begin{array}{l}\text { Whtdry (40.5\%); Oatdry (37.7\%); Whtirr } \\
(12.6 \%) \text {; Potdry }(8.6 \%) \text {; Potirr }(0.6 \%)\end{array}$ \\
\hline F10 & LUM & 83.41 & 19.6 & 41.69 & 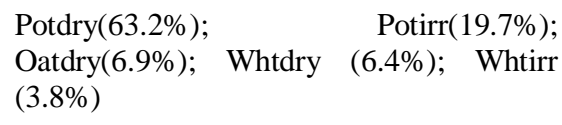 \\
\hline F11 & NAC & 13.01 & 1.46 & 7.69 & $\begin{array}{l}\text { Potdry }(86.5 \%) ; \quad \text { Potirr(11.2\%); } \\
\text { Whtdry }(2.3 \%)\end{array}$ \\
\hline F12 & NEG & 5.65 & 3.16 & 5.25 & $\begin{array}{l}\text { Potirr (33.6\%); Potdry }(24.0 \%) \text {; Whtirr } \\
(22.9 \%) \text {; Whtdry }(19.5 \%)\end{array}$ \\
\hline F13 & QUI & 22.12 & 6.82 & 3.87 & $\begin{array}{l}\text { Oatdry }(31.7 \%) \text {; Whtirr }(27.1 \%) \text {; Whtdry } \\
(22.6 \%) \text {; Potdry (14.9\%); Potirr }(3.7 \%)\end{array}$ \\
\hline F14 & REN & 14.41 & 10.71 & 2.62 & $\begin{array}{l}\text { Cmbirr }(51.4 \%) \text {; Whtirr }(13.8 \%) \text {; Oatdry } \\
(13.9 \%) \text {; Potdry }(11.8 \%) \text {; Potirr }(9.1 \%)\end{array}$ \\
\hline F15 & TRA & 70 & 20 & 22.04 & $\begin{array}{l}\text { Whtdry }(53.3 \%) \text {; Whtirr }(28.6 \%) \text {; Oatdry } \\
(16.0 \%) \text {; Potdry }(2.1 \%)\end{array}$ \\
\hline F16 & TRA & 13.38 & 3.2 & 3.05 & $\begin{array}{l}\text { Potdry }(44.7 \%) \text {; Oatdry }(21.7 \%) \text {; Whtirr } \\
(15.3 \%) \text {; Whtdry }(9.7 \%) \text {; Potirr }(8.6 \%)\end{array}$ \\
\hline F17 & VIC & 514.6 & 168.05 & 17.93 & $\begin{array}{l}\text { Oatdry }(36.2 \%) \text {; Whtirr }(32.6 \%) \text {; Whtdry } \\
(30.8 \%) \text {; Potdry }(0.4 \%)\end{array}$ \\
\hline F18 & VIC & 18.93 & 5.63 & 6.57 & $\begin{array}{l}\text { Whtdry (34.3\%); Whtirr (25.1\%); Oatdry } \\
(19.8 \%) \text {; Potdry (16.1\%); Potirr }(4.7 \%)\end{array}$ \\
\hline
\end{tabular}


To include both market and agroclimatic uncertainty, both price and yield variance were calculated using national averages for prices and regional averages for yields for the 2000-2010 period. Series of prices were obtained from FAO Statistics (FAOSTAT, 2015), while regional time series of yields data were collected from the Annual Report of Agricultural Statistics from the National Institute of Statistics (INE, 2009, 2010). Crop irrigation requirements (CIR) for wheat, potatoes, and common beans were extracted from Santibáñez et al. (2008).

The economic model uses a non-linear E-V model with a DARA coefficient to bypass the theoretical limitations of linear E-V models regarding "zero wealth effects" (Petsakos and Rozakis, 2015). In this context, we specify a $\boldsymbol{w}_{\mathbf{0}}$-the non-stochastic component of wealth- using income share data from the 2013 National Socioeconomic survey (CASEN), considering $\boldsymbol{w}_{\mathbf{0}}$ as the rural monetary subsidy for the base year. After the calibration process, the "true" wealth distribution and implicit marginal costs are recovered using maximum entropy.

To simplify the interpretation of the results, farmers were categorized into two groups depending on their level of final wealth after the calibration process. This final wealth is the sum of $w_{\mathbf{0}}$, which is considered a subsidy that is decoupled from production, and the farmer's implicit expected profits, which is the fixed stochastic component of wealth. Thus, for the base year, were classified as "poorer farmers" those with less than CLP\$10 million in total wealth after the calibration, and as "wealthier farmers" those with total wealth equal to or greater than CLP \$10 million (see Table 9).

\subsection{Socio-economic effects of water shocks on smallholders in the Vergara River Basin}

The expected changes in water availability (Table 1) will have minor impacts at the overall basin level, with small reductions in total agricultural land (less than $0.1 \mathrm{ha}$ ), total EU $(-3.3 \%)$, and final wealth $(-2.8 \%)$. However, the estimated impacts across farm types are uneven, with the largest impact affecting the poor farmers. For instance, on average, the EU of poor farms decreases by $5.3 \%$, while the average decrease is $2.9 \%$ for the wealthier farms. A similar pattern is observed for changes in final wealth due to the impact of water variability. Final wealth of poorest farms decreases by $5.6 \%$ (on average) while the final wealth of wealthier farms decreases by $2.7 \%$ (Figure 4 ) 


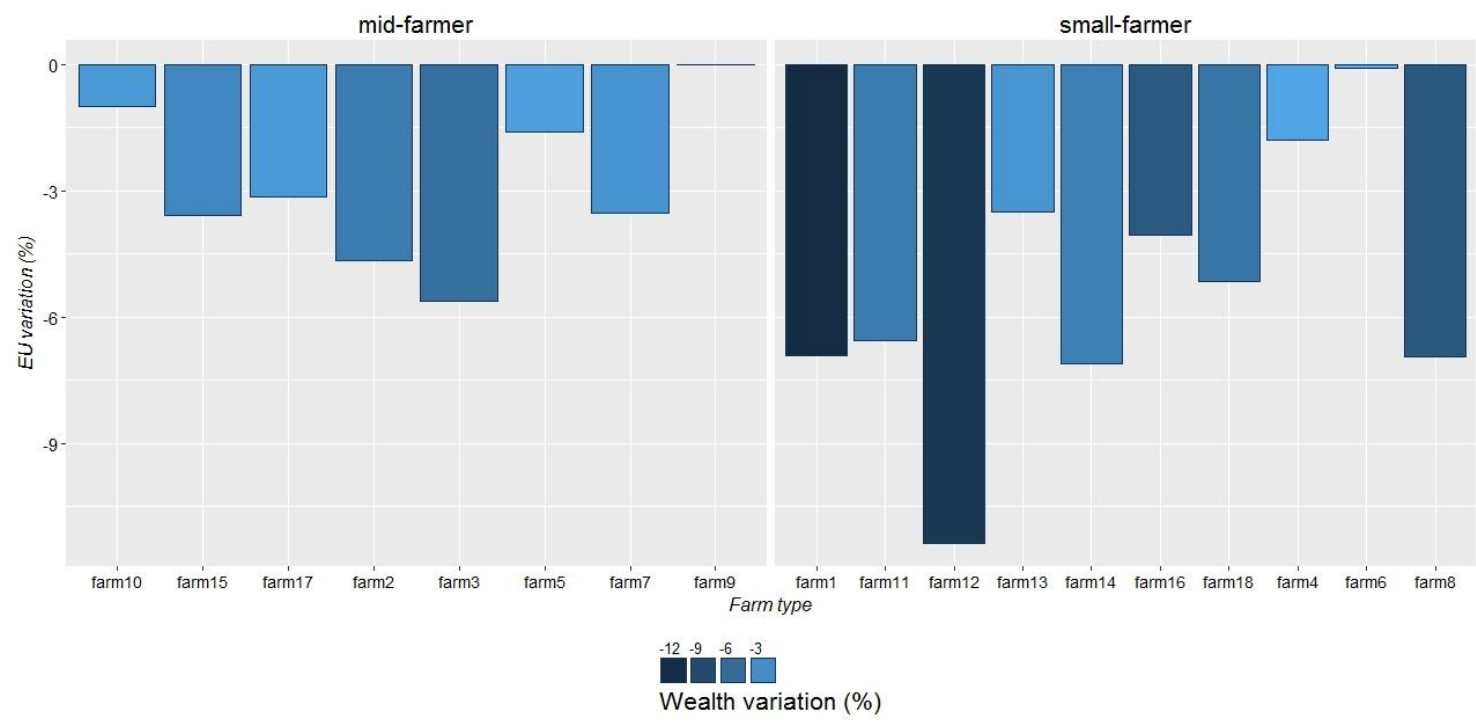

Figure 4. Wealth and EU change (\%) after water shock scenario

Uneven changes in wealth and EU are not observed only among the more and less affluent farmers. Figure 4 presents the differences within each group. These differences may be explained by several factors: the crop pattern used by each farm type; the share of irrigated land, and the trade-off between income variability and profitability (see Table 9 for the specific features of each farm type). Among the wealthier farms, farm type 9 stands out because of its low relative wealth and EU changes. This pattern is explained by the low share of irrigated land (13.6\%) compared with other wealthy farms, and a cropping pattern focused on rain-fed crops (86.4\% of total land). A similar pattern is observed among the poorest farms. For instance, farm type 12, which experiences important negative changes in both wealth and EU, irrigates a $55.9 \%$ of their total land. From this area, the cultivation of irrigated potatoes represents an important share (33.6\%), with the highest estimated revenue and the greatest variance in crop profits.

Regarding irrigated land at the basin level, the decrease in water availability drives a 2.0\% (9.09 ha) decrease on irrigated land allocation. Results by activity show a relevant reallocation of land from irrigated to rain-fed crops. Table 10 shows that the decrease in water availability will drive a major decrease of land devoted to irrigated wheat ($22.4 \%$; $91 \mathrm{ha})$. On the contrary, land allocation for most rain-fed crops will increase, with rain-fed wheat showing the largest increase $(11.2 \%$; 48 ha), followed by oats (9.0\%; 35 ha). 
Table 10 Land allocation changes by activity

\begin{tabular}{lcccc}
\hline Activity/System & $\begin{array}{c}\text { Baseline } \\
\text { (ha) }\end{array}$ & $\begin{array}{c}\text { CC } \\
\text { (ha) }\end{array}$ & \% Var & $\begin{array}{l}\text { Diff } \\
\text { (ha) }\end{array}$ \\
\hline Rain-fed oat & 391.91 & 427.26 & 9.0 & 35.38 \\
Irrigated wheat & 409.54 & 318.11 & -22.4 & -91.76 \\
Rain-fed wheat & 432.46 & 480.96 & 11.2 & 48.29 \\
Irrigated potato & 39.43 & 43.72 & 10.9 & 4.30 \\
Rain-fed potato & 110.72 & 108.31 & -2.2 & -2.39 \\
Irrigated common bean & 7.90 & 13.58 & 83.5 & 6.18 \\
\hline
\end{tabular}

The land allocated to rain-fed potatoes, irrigated potatoes, and common beans at the basin level does not show a direct relationship with changes in water availability; that is, the irrigated land allocated to those crops does not decrease after the water shock. Within the optimization model, two factors may explain this behaviour: the profit variance of each activity and the level of wealth of each farm. For instance, farm type 2 has one of the highest levels of wealth in the basin (CLP\$52 million). After the shock, the land allocation for irrigated wheat, which represents $30.8 \%$ of its total surface, is reduced by $-32.2 \%$ (nearly 19 ha). This change in irrigated land drives a decrease in the farm's wealth level, which triggers changes in the farm crop patterns to maximize the EU under the climate change scenario. In this case, the land allocated to rain-fed potatoes (a crop with the highest variance) decreases to reduce the associated risk. However, the allocations for crops with the lowest profit variance, such as rain-fed wheat and irrigated potatoes, increase by $11.7 \%$ ( $8 \mathrm{ha}$ ) and $625.2 \%$ (7 ha), respectively.

At disaggregated level, were observed different changes in the land allocation between wealthy and poor farmers. Wealthier farmers present major average decreases in land allocations for irrigated wheat (-11 ha), while major average increases are observed for rain-fed crops, such as wheat (5.8 ha) and oats (3.8 ha). Poor farmers, in contrast, have a different crop pattern, commonly including a major share of land allocated to potatoes and, in some cases, common beans. After the water shock, the average decrease in irrigated land is explained mostly by average decreases in potatoes $(-0.4$ ha), wheat $(-0.3$ 
ha), and common beans (-1 ha), while, the major increase in the rain-fed land is explained mainly by oat production (0.6 ha).

To account for the uncertainty associated with the change in water availability, a series of simulations were developed. The objective was to determine the probability of occurrence of a certain EU and wealth level, depending on the water availability scenario analysed. Through a GEV distribution, it was simulated a series of 1,000 water scenarios. Figure 5 shows the different levels of both aggregate wealth and EU, at the basin scale, for each water scenario.

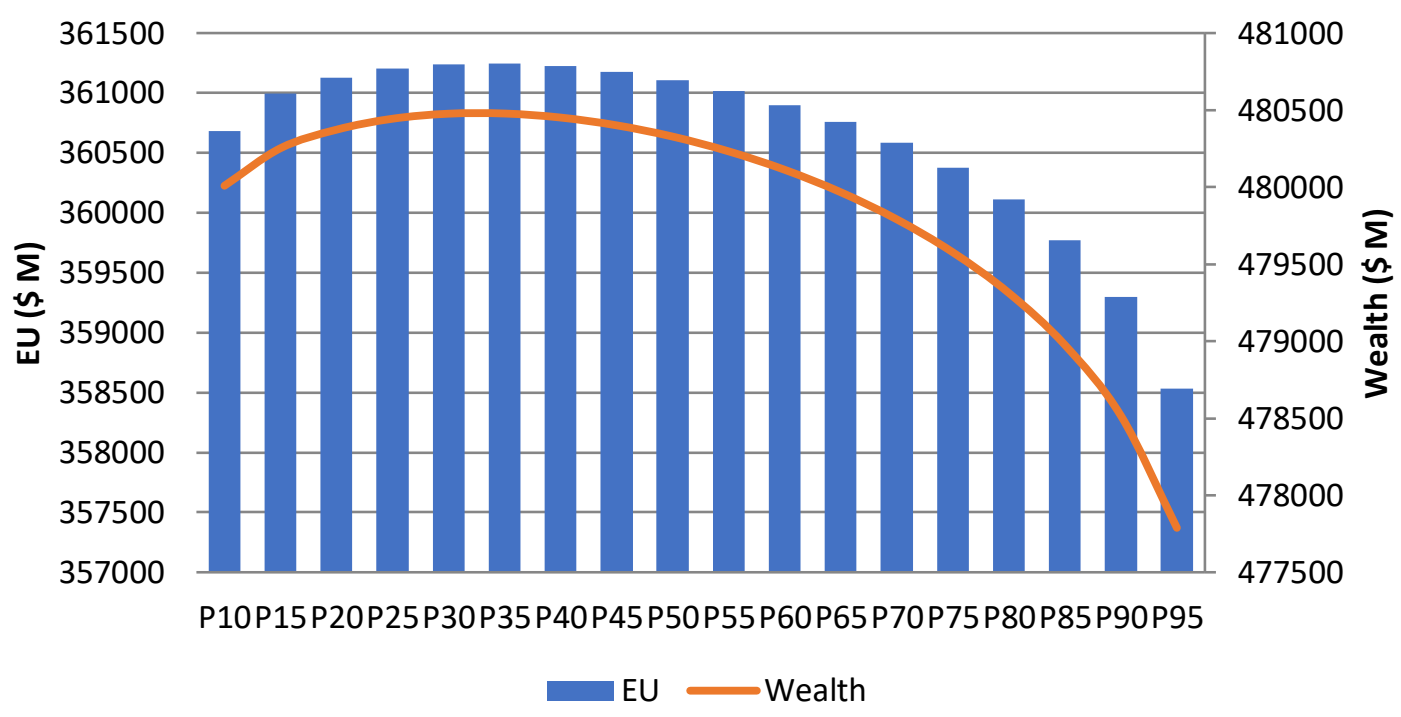

Figure 5. Wealth and EU level by Percentile of climate change

At the aggregate level, for the $50^{\text {th }}$ percentile (median), the estimated values of EU and wealth are CLP\$ 360.900 million and CLP\$ 480.150 million, respectively. Within the $15^{\text {th }}$ and $85^{\text {th }}$ percentiles, which corresponds to one standard deviation from the median, the impacts on EU and wealth remain small. Within this range, the difference between streamflows at the $85^{\text {th }}$ percentile would impose the worst-case scenario $(-3.6 \%$ for EU and $-3.1 \%$ for final wealth, respectively). Finally, Figure 5 shows that the major decreases in wealth and EU are observed for the $95^{\text {th }}$ percentile onwards, which is consistent with the major differences observed between the current and future streamflow distributions. However, their probability of occurrence is rather low.

The results reported in this chapter are consistent with those reported in previous studies where overall results, tend to hide significant disparities on smaller scales (ODEPA, 2010; Ponce et al., 2014; Samaniego et al., 2009). For instance, the overall EU at the 
Basin level hides what happens in each farm type (EU of farm type 12 decreased for $11 \%$ ), or, the overall effects on land distribution hides the particular effects for each activity. These disparities may translate into distributional consequences, due to the major economic impacts on poorest, rather than on wealthier farmers. Furthermore, this is a common phenomenon observed in national, regional or global assessments as a consequence of changes in yield or water availability (Fernández and Blanco, 2015; Parry et al., 1999; Ponce et al., 2015).

The results are also consistent with other studies regarding the major economic impacts on the smallest farmers. Using a different approach, Rosenzweig and Binswanger (1992) showed that the effect of climate variability on profitability is likely to depend on the total level of wealth. Wealthier farmers absorb climate-related risks without giving up profits while smaller farmers invest their limited wealth in reducing their vulnerability at the cost of lower profit rates. Similar results have been recently found by other authors (Deressa et al., 2009; Hassan and Nhemachena, 2008; Wood et al., 2014). Finally, our results are consistent with recent climate change impact assessments showing that smallholders are particularly vulnerable to extreme weather events (Harvey et al., 2014; Lindoso et al., 2014; Morton, 2007).

\subsection{Policy implications and future paths for research}

This chapter describes the application of a hydro-economic model whose power lies in reflecting small-scale farmers' economic behaviours by explicitly considering risk. The model was employed to estimate the economic changes in wealth and EU as well as the changes in crop allocation after a water availability shock. The results show that the small-scale agriculture of the VRB is vulnerable to changes in water availability as a consequence of climate change, with small economic impacts at the basin level. For the farm levels considered here, our hydro-economic model shows differentiated economic impacts for wealthier and poor farmers. Although both categories present negative economic impacts, the poorest farmers show the largest changes in both EU and wealth. Therefore, even if a reduction in water availability for irrigation does not have large overall consequences, it may produce distributional consequences, with the less affluent farmers being worse-off than wealthier farmers. 
The hydro-economic modelling approach presented in this chapter could be useful to inform policy-makers about the likely economic impacts of water availability changes at the basin level. However, two limitations need to be considered, which must also point to future improvements. First, the SWAT model used in this chapter did not include groundwater for irrigation. Thus, future research could consider the use of a coupled watershed-groundwater model to improve the current physical representation of the hydrologic process. Second, the representative farms considered in this chapter are assumed to be commercial farms, and no constraint associated with household consumption is considered. An interesting approach recommended for the future research could couple a hydrological model with a farm household model. 


\title{
4. Adaptation assessment to climate change for dualistic agricultural sectors: a case study in Central Chile
}

\author{
Publication: Fernández, F. J., Blanco, M., Ponce, R. D., Vásquez, F., \& Roco, L \\ (submitted). Implications of climate change for dualistic agriculture: a case study in \\ Central Chile (under review).
}

Abstract The nexus between climate change, agriculture and poverty has recently become a major topic of concern. However, few studies have examined the impacts of and adaptation to climate change by more vulnerable farmers from emerging countries characterised by dualistic agricultural sectors, in which peasants co-exist with commercial farms. Modelling approaches at the global or regional level have estimated average impacts at the expense of household heterogeneity and have failed to account for farmer adaptation. On the other hand, integrated assessments at the farm level have commonly assumed that all farms are commercial farms. Therefore, current methods need to be complemented with micro-level assessments, considering differences of all constituencies, especially in heterogeneous agricultural regions. The objective of this chapter is to propose a framework to assess the impact of and adaptation to climate change at the micro-level scale, considering the heterogeneity of household-level responses. Here, a typology of farm households was constructed by using multivariate statistics. Then, a farm household model was developed to assess farm-households' responses to both climate change effects and adaptation policy scenarios. The proposed framework is applied to a case study for a semi-arid irrigated agricultural region in Central Chile. Aggregated results indicate that climate change has a substantial economic impact on regional agricultural income. At the micro-level scale, the results show a high degree of vulnerability among small-scale farmers. Further, the improvement of irrigation efficiency, show a great potential at the regional level but yield uneven results at the household level. Findings show that households' features can increase its resilience, playing an important role for adaptation strategies to climate change. As such, this approach is well-suited for ex-ante micro-level adaptation analysis and can thereby provide useful insights to improve decision-making in adaptation planning at local level. Therefore, it could support national and global efforts engaged in raising and improving resilience among rural households. 


\subsection{Introduction}

Despite undeniable advances in modelling the economic impacts of climate change on agriculture (Fernández and Blanco, 2015), little attention has been paid to better understanding the links among climate change, agriculture and poverty. This concept thus remains a major topic of concern (Hertel and Rosch, 2010). Although this topic has been studied, the chapter on livelihoods and poverty in the latest Intergovernmental Panel on Climate Change Working Group II (IPCC WG2) report states that most research on the poverty-climate nexus has focused on the poorest countries (Olsson et al., 2014). Therefore, more research is needed to understand how climate change may affect poor people living in countries with agricultural dualism, in which peasant agriculture co-exists alongside a large-scale food sector and significant pockets of poverty remain. In the same context, there is also need to further distinguish the different adaptive capacities and responses to adaptation measures from heterogeneous groups of households involved, particularly the poorest.

To address these concerns, it is essential to assess household-level responses to both climate change effects and adaptation measures which require an understanding of both household characteristics and the contexts in which rural households interact (Skjeflo, 2014). Many authors have noted that climate change urgently needs to be assessed at the household level (Jones and Thornton, 2003; Pandey et al., 2015; Skjeflo, 2013; Skjeflo, 2014) so that poor people who are dependent on agriculture can be appropriately targeted in policy interventions. Hence, the advance of household level analysis could be crucial for a more efficient allocation of global strategies on agriculture adaptation to global change. This chapter intends to tackle such gap by developing an explicit analysis based on household level data. This work will be centred on a particular case study. Nevertheless, its analytical basis is of interest for any agricultural region affected by global change, particularly those characterised by a high farm-household heterogeneity.

In this context, the aim of this chapter is to present a modelling framework to assess the impacts of and adaptation to climate change by considering farm household heterogeneity within countries characterised by agricultural dualism (Cervantes-Godoy, 2015). As a case study, we focus on four rural communes in Central Chile, a representative semi-arid, irrigated, agricultural zone, with a large proportion of small- 
scale farms (INE, 2007) and relatively high poverty levels compared to other regions (CASEN, 2015). We build a typology using multivariate statistics to capture household variability, and then develop a farm household model calibrated to these household types to simulate farm-households' responses to potential effects of climate change and how these are affected by adaptation policies. Our results suggest that the impacts of climate change may vary greatly between households within the same region, with the poorest households experiencing the greatest effects. Moreover, the modelling framework allows identifying how adaptation actions counterbalance the negative climate change effects on heterogeneous households. In this sense, there are many inexpensive adaptation strategies, deeply rooted in household features, such as high diversification of crops and the growth of high value-crops. Therefore, this system allows policy makers to have a good understanding of different local capacities and thus aid them in promoting type- or location-specific adaptation strategies.

Since the 1990s, most economic assessments of the impacts of and adaptation to climate change on agriculture have been based on market equilibrium models (Calzadilla et al., 2013b; Fischer et al., 2005; Kane et al., 1992; Nelson et al., 2014a; Reilly and Hohmann, 1993). The scientific community has since used these models to assess the future impacts of climate change on production, consumption, trade and prices. In the same way, they have been used to analyse the economy-wide impact of different adaptation scenarios to cope with climate change. Commonly, the results are obtained at the global level or rely on coarse national- or regional- level aggregations for economic analyses on smaller scales. These global models are mainly used to consider the impacts of crop yield changes on prices, which often depend on global supply and demand rather than local production (Lobell and Burke, 2010a). Although these assessments represent important contributions to understanding the likely economic impacts of climate change on global or regional levels, they are inadequate for predicting probable effects on a micro-level scale. Thus, in these models, farm-level responses are not explicitly reflected, although that many decisions, including management and adaptation, are made at this level (Reidsma et al., 2015).

Several authors have assessed the impacts of climate change at the farm level using a series of integrated approaches. Kaiser et al. (1993) present a seminal study in which they examined the potential economic impacts of climate change by integrating climatic, agronomic and farm supply models. Other authors have used integrated 
assessments (IAs), in conjunction with bio-economic farm models (BEFMs) to assess the impacts of and adaptations to climate change at the farm level. Bobojonov and AwHassan (2014) used a BEFM to assess the impact of climate change in Central Asia by considering the adaptive capacity of agricultural producers. Kanellopoulos et al. (2014) and Reidsma et al. (2015) used the Farm System Simulator (FSSIM) bio-economic model in an IA framework to assess the impacts of climate change on arable farming systems in Flevoland. These approaches are particularly important because they simultaneously consider biophysical changes and farm decisions in different farms, thus allowing researchers to fully understand how farm-level responses, including adaptation, influence the impacts of climate change. However, the development of an IA through a BEFM requires the considerable integration of disciplines and an extensive data collection, which is often difficult to obtain in emerging or developing countries, especially when considering micro-level scales (e.g., household level). Moreover, the economic component of BEFMs is commonly based on farm supply models, which assume that the decision-making process of representative farmers is the same as that of commercial farms, with no additional constraints associated with household consumption.

Therefore, an economic farm-household-level modelling approach is a useful tool for reflecting farm-household-level responses to climate change, considering the nonseparability of farm-household behaviour, particularly among the poorest farmers. Some studies have quantified the livelihood impacts of climate change by using Computable General Equilibrium (CGE) models. Hertel et al. (2010) used the poverty-extended version of the Global Trade Analysis Project (GTAP) model to analyse the link between climate change and poverty at the national level and refine the modelling approach compared to previous studies (Fischer et al., 2005). Furthermore, Skjeflo (2013) used a static CGE model for Malawi that measured household vulnerability to climate change and distinguished between households' statuses as net sellers or net buyers. These CGE studies allow the inclusion of autonomous adaptation to climate change and consider the impact of climate change effects on prices. However, CGE studies allow for limited heterogeneity and assume perfect markets and thus fail to consider that many constraints to adaptation at the household level are related to both household characteristics and market imperfections for this type of assessment (Deressa et al., 2009; Skjeflo, 2014). 
Farm programming models, through farm-household models, have become useful tools for addressing the shortcomings mentioned above in analysing both the impact and the adaptation to climate change. Farm household models have been widely used to assess the policies of rural economies in less developed countries (Brooks et al., 2011; Holden et al., 2004; Louhichi and Gomez y Paloma, 2014). However, they have only rarely been used to assess the impact of and adaptation to climate change on rural households, especially in emerging countries with dual agricultural regions. In this sense, our first aim is to propose an economic farm household modelling framework to assess impacts of and adaptation to climate change at the household level, considering consumption and production behaviour. Along the same line, our second aim is to understand and compare the impacts of and autonomous adaptation to climate change for a heterogeneous set of farm-households. Finally, our third aim is to complement global, regional and farm-level economic impact and adaptation assessments with household modelling to improve our understanding of household-level responses to the effects of climate change.

The chapter is structured as follows. Section 4.2 describes how irrigated agriculture in dryland regions have currently being affected by climate change, linking this issue, with the current agricultural situation in Chile and its central area. The study area is described, and the importance of applying the methodology is presented in this context. Section 4.3 describes the methodology and steps applied for the typology construction and the use of the farm household model to assess the economic impact of climate change at the micro-level scale. Section 4.4 presents the resultant effects of the scenarios of climate change effects. Finally, Section 4.5 discusses the main results, and Section 4.6 draws conclusions and describes policy implications.

\subsection{Background}

\subsubsection{Climate change and irrigated agriculture in dryland regions}

Arid and semi-arid areas belong to the category of drylands (Feng and Fu, 2013; Koohafkan and Stewart, 2008), occupying together about $30 \%$ of the earth's terrestrial surface (Newton and Tejedor, 2011). Drylands are home to more than a third of the world's population (Mortimore et al., 2009); and grasslands and agricultural lands are important components of it, providing much of the world's grain and supporting many 
vegetable species and fruits (Koohafkan and Stewart, 2008). Several authors have warned about the fragility and sensitivity to climate change of ecosystems over drylands (Reed et al., 2012; Reynolds et al., 2007). Climate change associated with changes in precipitation and evapotranspiration will likely increase aridity and thus will extend its area. Moreover, climate changes in drylands are likely to lead to scenarios of both water scarcity and declining crop yields. These effects, predicted for many dryland regions, along with extensive land uses means that communities need to adapt to these challenges (IPCC, 2014).

The drylands of South-Central Chile have already been affected by an upward trend of temperature (Falvey and Garreaud, 2009) and a high strain on water resources (Hannah et al., 2013). Agriculture in South-Central Chile is highly sensitive to climate change and is likely to experience one of the greatest freshwater impacts in Mediterraneanclimate growing regions (Berger et al., 2006; Hannah et al., 2013). Additionally, it is expected that these impacts will drive uneven economic consequences within the region (Fernández et al., 2016; Ponce et al., 2014).

This framework is applied to the case study of the Maule region in South Central Chile. This region is an important component of the Chilean agricultural sector and is a proper example of 1) an irrigated agricultural system in a semi-arid region already threatened by global change; 2) an impact assessment and an adaptation analyses in a dual agricultural region with a high heterogeneity between their farm households (Berger and Troost, 2013) and 3) a region with a large proportion of small-scale farmers and high poverty levels.

\subsubsection{Regional context for farm household modelling framework applications}

The Maule region (Figure 6), located in the South-Central Chile, is a major contributor to the agricultural output of the country. The region devotes approximately $25 \%$ of its territory to agricultural activities (Salinas and Mendieta, 2013b). It contains an important share of Chilean agricultural land, representing $16.5 \%$ of all land devoted to cereal production and $14.9 \%$ for legumes and tubers, as noted by the National Institute of Statistics (INE, 2013). Moreover, it is an important producer of some spring vegetables, including $43 \%$ of national land devoted to watermelon cultivation and $17.8 \%$ for melon cultivation (INE, 2013). The Agrarian Policies and Studies Bureau 
(ODEPA) indicates that agriculture generated approximately $12 \%$ of Maule's regional gross domestic product (GDP) in 2013 and that agricultural activities generated 29\% of local employment during the three-month period between December 2014 and February 2015 (ODEPA, 2015). Furthermore, family farm agriculture in the Maule region accounts for $16 \%$ of the national total (Jara-Rojas et al., 2012).

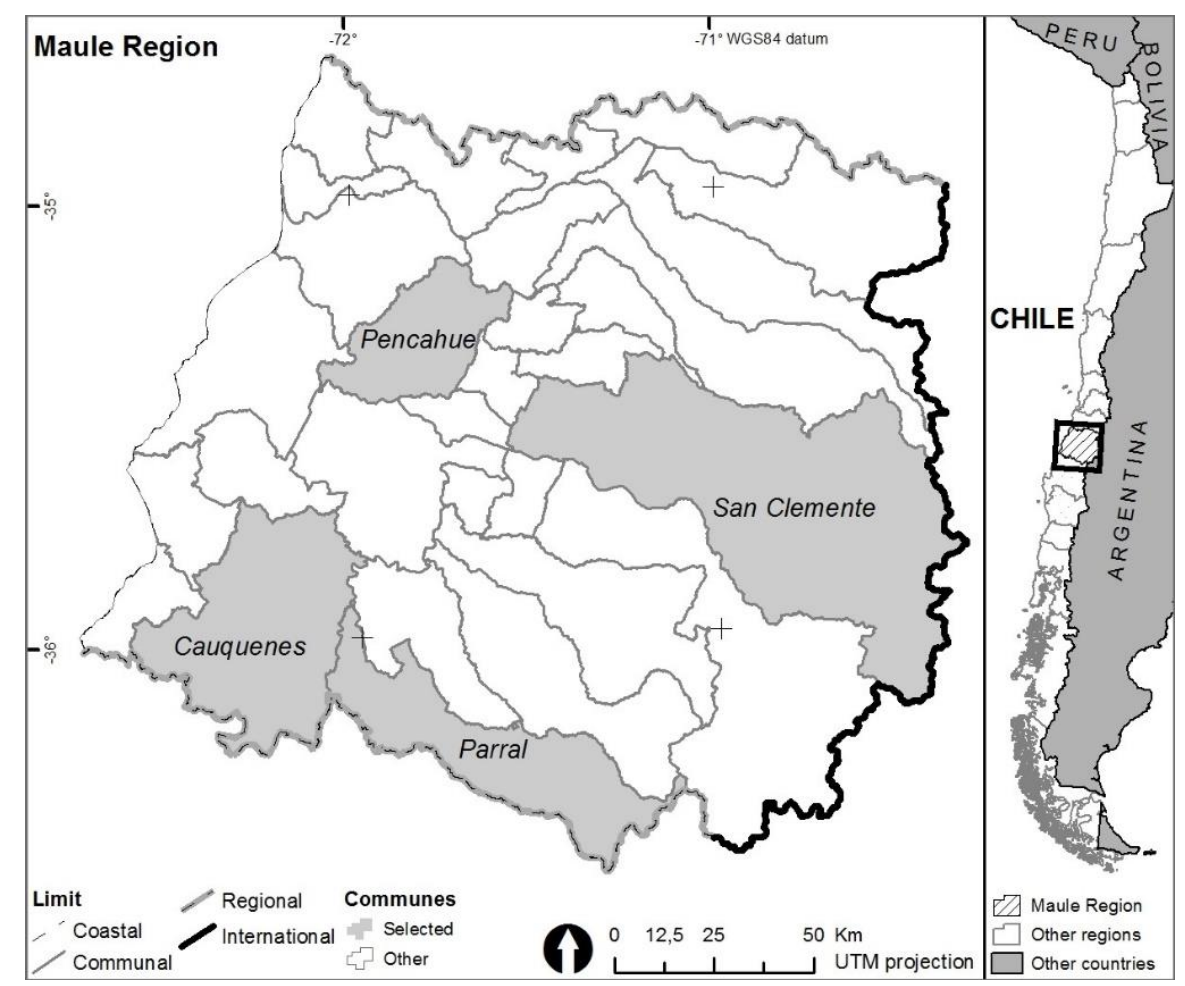

Figure 6. Maule region and selected communes

Several studies have determined that the Maule Region is especially vulnerable to climate change due to four reasons: 1) its high rural population (35.5\%), as indicated by the United Nations Development Programme (UNDP, 2008); 2) its large proportion of small-scale farms (16\%) (INE, 2007); 3) the important share of agricultural production depending on annual crops, as indicated by the Foundation of Agrarian Innovation (FIA, 2010); and 4) its relatively high poverty levels compared with other regions, according to the National Socio-Economic Characterization Survey (CASEN) 2015.

Finally, the farm structure within the region is highly heterogeneous, ranging from large-scale, export-oriented enterprises to peasant farm households (Berger et al., 2006). In this context, before policymakers can promote adaptation strategies to help farmers, they need to have a good understanding of the local capacities (Roco et al., 2014; Wang et al., 2013). 


\subsection{Methodology}

\subsubsection{Farm Household Modelling Framework}

It is presented a framework capable of both providing detailed results on the farm household scale and capturing heterogeneity across households, thus allowing us to better understand farm household dynamics within the context of climate change.

We calibrate a farm household model using four representative farm household types from four central valley communes in the Maule region (San Clemente, Pencahue, Parral and Cauquenes) (Figure 6), each of which has different agrological and socioeconomic characteristics. The primary mathematical structure of the model is based on the farm-household model presented by Louhichi et al. (2013). It was adapted to (1) the agricultural and socioeconomic features of the Chilean agricultural sector and (2) the availability of data for this region. This is a static, non-linear optimisation model that relies on both the household's general utility framework and the farm's technical production constraints. The objective function is represented by the weighted sum of the farm households' expected income, which is subject to resource (water, land and labour), consumption and cash constraints.

The overall mathematical design of the model is

$$
\max U=\sum_{h=1}^{H} w_{h} R_{h}
$$

s.t.

- Resource constraints (land, water and labour)

- Consumption constraint using a linear expenditure system

- Price bands and complementary slackness conditions

- Commodity balances at the farm level

- Cash constraint

where $\boldsymbol{U}$ is the value of the objective function, $\boldsymbol{h}$ denotes a farm household and $\boldsymbol{w}$ is its weight within the Maule region. $\boldsymbol{R}$ is the farm household's expected revenue. A detailed description of the overall structure of this model can be found in Louhichi et al. (2013). 
In Annex 7, it is presented a detailed description of the main constraints, in which major adaptations from the original model were made in the context of this chapter.

We consider the impact of climate change on 14 crops that are of central importance to the rural economies of this region. We group these crops into three categories: grains (wheat, oat and rice), spring crops (maize, common beans, green beans, chickpeas and potatoes) and spring vegetables (peas, onions, tomatoes, melons, watermelons and squash) and simulate different productivity shocks in each. The following subsections describe each stage of the model, from the typology construction to the application of both the scenarios of climate change effects and the adaptation scenario.

\subsubsection{Typology construction}

From a survey of farmers in Central Chile (Annex 5) that was obtained in 2011 and whose information was used by Roco et al. (2014) and Roco et al. (2015), the main information was extracted to build the household typology through a multivariate analysis. Selection of variables, correlation coefficient analysis, data control, principal component analysis and cluster analysis were performed. After a first run of the PCA, the variables that were not well represented in the framework and those that did not appear to offer additional information were deleted. In this context, the following variables presented in Table 11 were chosen.

Table 11. Variables chosen for typology construction after data control ${ }^{\mathrm{a}}$

\begin{tabular}{ll}
\hline Code & Variable (units) \\
\hline Farm_size & Land area (ha) \\
Hrd_ratio & Hired labour ratio (Hired/total lab) \\
Ttl_Lab & Total labour (workday/years/ha) \\
Ttl_Rev & Total Revenue (\$CLP/ha) \\
Grn_shr & Share of grain crops on total land (\%) \\
SV_shr & Share of spring vegetables on total land (\%) \\
SC_shr & Share of spring crops on total land (\%) \\
Cons & Consumption (ton/year) \\
\hline Variables selected after passing through data control and two runs of the PCA (see details in appendix A)
\end{tabular}

Considering these variables, Table 12 presents the principal component loading vectors for the survey data after applying PCA. Table 12 shows that the first loading vector places approximately equal weight on Total Revenue and the Share of grain crops, while Consumption presents an important contrast with these two variables. Hence, this 
component roughly expresses the relative importance of revenue and the size of the share of grain growth at negative PC1 scores and increasing consumption at positive PC1 scores. The second vector places most of its weight on Farm size. Thus, the second component roughly corresponds to the size of the surface used for agricultural activities, and the third vector places most of its weight on the share of spring crops growth. Therefore, the last component roughly expresses the relative importance of the size of the share of spring crop growth.

Table 12. Principal components loading vectors for the survey data

\begin{tabular}{lccc}
\hline & Comp 1 & Comp 2 & Comp 3 \\
\hline Farm_size & -0.2901 & 0.5761 & -0.0430 \\
Hrd_ratio & -0.3065 & 0.1306 & -0.0841 \\
Ttl_lab & -0.3615 & -0.4278 & -0.1046 \\
Ttl_Rev & -0.4034 & 0.3974 & -0.1551 \\
Grn_shr & -0.4185 & 0.3283 & -0.3033 \\
SV_shr & -0.3028 & -0.4233 & -0.4779 \\
SC_shr & -0.2895 & -0.0329 & 0.7800 \\
Consumption & 0.4214 & 0.1477 & 0.1645 \\
\hline
\end{tabular}

Through the Hierarchical Cluster analysis to the PCA results, four farm household types were identified. Table 13 presents the main characteristics of the clusters and their frequencies in the database. In the following, a detailed description of each of the farm household types is given.

Table 13. Household Typology

\begin{tabular}{lcccc}
\hline Household-cluster name & $\begin{array}{c}\text { Mean } \\
\text { size } \\
\text { (ha) }\end{array}$ & $\begin{array}{c}\text { Irrigated } \\
\text { land } \\
(\boldsymbol{\%})\end{array}$ & $\begin{array}{c}\text { Mean Revenue } \\
\text { (CLP\$ million/ha) }\end{array}$ & $\begin{array}{c}\text { Frequency } \\
\text { (\%) }\end{array}$ \\
\hline Medium-mixed-farm & 8.4 & 91.6 & 11.2 & 19.2 \\
Large-SpringCrop-farm & 24.9 & 94.9 & 37.8 & 13.4 \\
Medium-Grain-farm & 19.8 & 86.6 & 16.3 & 28.4 \\
Smallholder Farm & 2.56 & 17.5 & 0.8 & 38.8 \\
\hline
\end{tabular}

The Medium-mixed-farm is a medium-sized farm (with an average size of 8.4 ha) that mainly produces spring vegetables $(65 \%)$; tomato crops represent $20 \%$ of the total area, followed by melons (13.9\%), watermelons (9.6\%), and onions (6.8\%). Spring crops also represent an important proportion (27\%) of the total area. Most crops (91.6\%) are irrigated. Hired labour represents $69.5 \%$ of the total labour, which is mainly distributed among spring vegetables. This farm-household type accounts for $19.2 \%$ of all farm 
households surveyed and controls $13.7 \%$ of the agricultural land represented in this survey. Most of these farms are located in the communes of Pencahue (60\%) and San Clemente $(36 \%)$.

The Large-SpringCrop-farm is a large farm that mainly cultivates spring crops, which represent $95 \%$ of the total area and are mostly maize $(87.8 \%)$, common beans $(2.8 \%)$ and potatoes $(0.9 \%)$. Grains and spring vegetables represent only $7.1 \%$ and $1.1 \%$ of the total area, respectively. Nearly $95 \%$ of this farm's land is irrigated. Hired labour represents $68.5 \%$ of its total labour, and its average farm size is approximately 25 ha. This farm type accounts for $13.4 \%$ of all farm households surveyed and controls $28.9 \%$ of all agricultural land represented in this chapter. These farms are mainly located in San Clemente (57\%), Pencahue (17\%) and Parral (17\%).

Medium-Grain is a medium farm type (approximately 20 ha in size) that produces mainly grains, which represent $87 \%$ of the total area. These grains mostly consist of rice (46.9\%) and wheat (39.4\%). Spring crops, which are predominantly maize, represent $8.3 \%$ of the total area. Within this farm type, $86.6 \%$ of all land is irrigated, but there also exists an important share of rain-fed crops (mainly wheat). Hired labour represents $45.8 \%$ of the total labour, which is distributed mostly among maize and grains. This farm type accounts for $28.4 \%$ of all farm households surveyed, which accounts for $48.8 \%$ of all agricultural land represented in this study. This type is mainly located in San Clemente (41.9\%) and Parral (41.9\%).

Smallholder Farm is a small-scale farm type (less than 3 ha in size) that cultivates mainly wheat $(85 \%$ of the total area) and oats $(10.7 \%$ of the total area), with the remaining $4.3 \%$ of land allocated for legumes, maize and rice. Unlike the other farm types, only $17.5 \%$ of all land within this farm type is irrigated. This farm type tends to primarily use family labour, which represents $84.4 \%$ of total labour. This farm type accounts for nearly $40 \%$ of all farm households surveyed but controls only $8.5 \%$ of the agricultural land represented in this survey. Most of these farms are located in Cauquenes (73\%) and Parral (17.8\%).

A complete report of data control for the PCA, the selection of the key variables, the PCA and cluster analyses and their results are presented in Annex 6. 


\subsubsection{Application of assessments of climate impacts}

The model presented in this chapter simulates the potential effects of climate change, which is represented as a series of productivity shocks on irrigated and rain-fed crops, as well as shocks to water availability due to climate change. To represent yield changes, we adjusted the yield parameters in the function of produced goods (Equation 2) at the farm household level:

$$
Q_{h, j}=\sum_{a} \sum_{s} y_{h, a, s, j} \times X_{h, a, s}=S_{h, j}+C_{h, j}^{s}
$$

where $\boldsymbol{Q}$ is the (n x 1) vector of the produced quantities of goods $\boldsymbol{j}$ by a household $\boldsymbol{h}, \boldsymbol{y}$ is the ( $\mathrm{n} \times 1$ ) vector of yields of activity $\boldsymbol{a}$, and $\boldsymbol{X}$ is the (n $\mathrm{x} 1)$ vector of the simulated levels of the agricultural activities $\boldsymbol{a}$ per system $\boldsymbol{s}$ in household $\boldsymbol{h}$. This function also determines the self-consumed and sold quantities of goods, where $S$ represents the (n X 1) vector of sold quantities of goods, and $C^{s}$ is the $(n \times 1)$ vector of self-consumed quantities of goods. Therefore, any change in yields directly affects the agricultural income $\left(Z_{h}\right)$, which is calculated using Equation 3:

$$
\begin{gathered}
Z_{h}=\sum_{j}\left(S_{h, j}+C_{h, j}^{s}\right) P_{h, j}+s b_{h}-\sum_{a} \sum_{s}\left(\left(\alpha_{h, a, s} \times\left(X_{h, a, s}\right)^{\beta_{h, a, s} \times X_{h, a, s}}\right)\right. \\
-\sum_{l s} \text { labwage } \times \operatorname{HLABOUR}_{h, l s}
\end{gathered}
$$

where $\boldsymbol{P}$ is the (n $\times 1$ ) vector of prices of $\operatorname{good} \boldsymbol{j}, \boldsymbol{s} \boldsymbol{b}$ is the vector (n $\times 1$ ) of the subsidies, $\boldsymbol{\alpha}$ and $\boldsymbol{\beta}$ are cost function parameters estimated using a variant of the Positive Mathematical Programming Approach (Howitt, 1995), labwage is the average hired labour wage (in millions of \$CLP per work day), and HLABOUR is the (n x 1) vector of hired labour by household $\boldsymbol{h}$ and in labour season $\boldsymbol{l} \boldsymbol{s}$.

To determine water availability, an adjustment by changing the gross water delivered parameter $(\mathbf{g} \boldsymbol{w d})$ was implementd, which is part of the functions used to determine water constraints. These water constraints indicate that the total amount of water used 
for irrigation at the household level cannot exceed the farm water availability $\boldsymbol{F} \boldsymbol{W}$ (in thousand $\mathrm{m}^{3}$ ) (Equation 4), where fir $_{\boldsymbol{h}, \boldsymbol{a}}$ refers to the farm gate irrigation requirements of the irrigated crops (thousand $\mathrm{m}^{3} / \mathrm{ha}$ ) and $\boldsymbol{i r r}_{\boldsymbol{h}}$ refers to the irrigated crops of each household type.

$$
\sum_{a} \operatorname{fir}_{h, a} X_{h, a, s} \leq F W_{h} \quad \forall s=i r r_{h}
$$

Equation 4 considers the conveyance and distribution efficiency of the water network $\boldsymbol{h d}$ and the gross water delivered $\boldsymbol{g} \boldsymbol{w \boldsymbol { d }}\left(\mathrm{m}^{3}\right)$ at household level $\boldsymbol{h}$ (Equation 5). A change in the gross water delivered parameter $\boldsymbol{g} \boldsymbol{w d}$, directly affects farm water availability, thus affecting the level of irrigated agricultural activities $\left(\boldsymbol{X}_{\boldsymbol{h}, \boldsymbol{a}, \mathrm{s}}\right)$, and changing the agricultural income.

$$
F W_{h}=g w d_{h} \times h d
$$

The base year information for which the model was calibrated is from the year 2011, which is when the survey was carried out. The model also uses a Business as Usual (BAU) scenario as its baseline, which implies a simple projection of the current situation and assumes that there are no changes.

Three scenarios are simulated, and their results are compared to those of the baseline. These include two scenarios depicting climate change effects and one assuming an improvement in irrigation efficiency. We base these scenarios on data from the recent National Climate Change Action Plan 2017 - 2022 (PANCC), which was developed by the Chilean Ministry of the Environment (MMA, 2016). This report compiles the results of several assessments of climate change impacts in Chile, in which several studies assess the impacts of climate change on agricultural productivity, precipitation, and the availability of water for irrigation.

The PANCC's report, based on Santibáñez et al. (2008), indicates that rain-fed agriculture will be the most affected by climate change due to changes in temperature and precipitation. Santibáñez et al. (2008) compared the potential yield changes between the baseline (average over the period from 1960 to 1990) and future scenarios (average over the period from 2071 to 2100) based on climatic scenarios A2 and B2. Their results indicated different ranges of yield changes for different crops. In their 
main results, they estimated yield decreases between $5 \%$ and $10 \%$ for irrigated wheat and between $10 \%$ and $30 \%$ for rain-fed wheat. Further, they estimated a decrease between $10 \%$ and $20 \%$ for irrigated maize. Because maize and wheat represent nearly two-thirds of the total land considered in the case study presented in this chapter, these yield changes were the main information extracted.

These data from Santibáñez et al. (2008) have been widely used by both academic and governmental impact studies (MMA, 2016; ODEPA, 2010; Ponce et al., 2014). Although these data do not cover the set of crops modelled here or the specific communes of the study area, they do represent the most reliable information on climate change effects on crop yields in Chile. These data thus allow to approximate the likely crop yield changes under climate change conditions and reflect the different impacts between rain-fed and irrigated crops within the central valley of Chile. In this context, the first scenario (YdChg) assumed a yield decrease of 30\% for rain-fed crops and 10\% for irrigated crops, based on climatic scenario A2.

A second scenario ( $\boldsymbol{Y} \boldsymbol{d} \_$less $\boldsymbol{W}$ ) assumes that yields will decrease as in the first scenario but also plus a $30 \%$ reduction in water availability from the baseline, keeping irrigation efficiency fixed. This scenario is based on recent projections obtained using data from the ensemble mean of different Global Circulation Models (GCM) using the Representative Concentration Pathway (RCP) 8.5 (Rojas, 2012). This study projects a $15 \%$ decrease in precipitation by the year 2030 compared to historically simulated values for the period 1961-1990. Rojas (2012) also indicates that this process will be intensified by the period 2031 - 2050, thus significantly reducing the monthly mean flow rates of rivers in the central valley of Chile.

Although there could be an inconsistency between the climate scenarios underlying the biophysical effects on yields and water availability, both the main objective of our chapter and the literature that has compared climate scenarios support our decision. This chapter aims to assess the farm-household's economic behaviour based on the climate change effects and mechanisms of adapting to these effects. Thus, based on data availability, the biophysical effects selected are reliable data to use in this chapter. Further, for the $\mathrm{CO} 2$ concentration, which is an important factor for both climate and crop productivity changes, the literature indicates that RCP8.5 is somewhat comparable to the A2 scenario until mid-century (van Vuuren and Carter, 2014). 
Finally, recent studies within the region have suggested that the proposed incentives for adaptation strategies should focus on promoting irrigation efficiency (Roco et al., 2014). A third scenario (Yd_irrEff) assumes a 20\% improvement in irrigation efficiency, which is reflected in the parameter of conveyance and the distribution efficiency $\boldsymbol{h} \boldsymbol{d}$ in Equation 5. The Organization for Economic Co-operation and Development (OECD) and the Economic Commission for Latin America and the Caribbean (ECLAC) support this scenario, based on previous investments in irrigation infrastructure and subsidies in on-farm irrigation made by Chile (OECD/ECLAC, 2016). A comparison between the 1997 and 2007 agricultural censuses reveals that the average irrigation efficiencies increased from $41 \%$ to $51 \%$ at the national level (Donoso, 2015). Further, the National Irrigation Commission (CNR) indicated that the Maule region has the highest share of incentives for the adoption of water-saving technologies by farmers (CNR, 2015). Indeed, currently, the region is one of the areas with the most surface interventions by CNR, which aims to improve the irrigation efficiency in the country (Salinas and Mendieta, 2013a). In this scenario, it is difficult to determine the real cost of irrigated production by farm-households; thus, we assumed no adjustment costs. A summary of the scenarios and their key assumptions is given in Table 14.

Table 14. Summary of scenarios, effects of climate change and key assumptions

\begin{tabular}{|c|c|c|}
\hline Name of scenario & Effects & Key assumption $^{\mathrm{c}}$ \\
\hline YdChg $^{\mathrm{a}}$ & Crop yield decrease & $\begin{array}{l}30 \% \text { decrease of rain-fed crops / } 10 \% \\
\text { decrease of irrigated crops }\end{array}$ \\
\hline Yd_less W ${ }^{b}$ & $\begin{array}{l}\text { Crop yield decrease }+ \text { water } \\
\text { availability shock }\end{array}$ & $\begin{array}{l}\text { - Previous assumptions } \\
\text { - } 30 \% \text { decrease of water availability for } \\
\text { irrigation }\end{array}$ \\
\hline Yd_IrrEff & $\begin{array}{l}\text { Crop yield decrease }+ \text { water } \\
\text { availability shock }+ \\
\text { improvement of irrigation } \\
\text { efficiency }\end{array}$ & $\begin{array}{l}\text { - Previous assumptions } \\
\text { - } 20 \% \text { improvement of irrigation } \\
\text { efficiency }\end{array}$ \\
\hline
\end{tabular}

${ }^{a}$ Scenario based on literature on national crop yield responses to climatic scenario A2. ${ }^{\text {b }}$ Scenario based on precipitation changes under RCP8.5 in the Central Chile. ${ }^{\mathrm{c}}$ All prices are the same and are fixed in all scenarios

\subsubsection{Limitation of the study}

The biophysical impacts used in this chapter are based on recent reports whose impacts have been determined at the aggregated communal, regional or national level. Further, the crops covered by these studies are limited to a few cereal and industrial crops, which force to assume similar yield changes for different crops. Additional research is needed 
to link the framework with crop-based models or hydrological models calibrated at the local level. These linkages would add value to the study and may produce robust evaluations of climate change effects.

The lack of price changes in response to climate change implies that all prices are the same and are fixed in all scenarios. Incorporating price changes into climate change scenarios requires overcoming several challenges. For example, the considerable coordination of different disciplines and modelling approaches is not always available in emerging and developing countries. Further, using produced and reported commodity prices in climate change scenarios (Hertel et al., 2010; Nelson et al., 2014a; Nelson et al., 2010), does not always report input prices, which can produce problematic results. Although this issue may represent a major shortcoming of this chapter, the framework presented here is sufficiently flexible to both incorporate outputs from other modelling approaches and serve as a starting point for future integrated assessments.

Finally, due to the static condition of the framework, this model does not consider the accumulated effects of climate change or provide information about future technological changes. To incorporate possible technological improvements, such as those affecting crop varieties, further research is needed to adjust model parameters.

\subsection{Results}

Figure 7 shows that at the regional level, the distribution of the crop categories, on land cultivated, is subject to minor changes across all three scenarios (see Table 14 for a summary of the scenarios); however, the results show decreases in the total cultivated land, particularly for the scenario Yd_less W (nearly 923 ha). The YdChg scenario leads to a substitution of spring vegetable activities, largely in the group of spring crops, while also inducing an increase in irrigated land $(0.1 \% ; 2.65$ ha) due to the higher impact on rain-fed crops. In the same scenario, the total land will decrease by $2.4 \%$ (73.9 ha). In this case, within the group of grains, the impact of climate change on rainfed crops is offset by the increase in irrigated oat and irrigated maize on some farm households. The decrease in spring vegetable crops is not counterbalanced by other crops of the same group, which explains their loss of share over the total land (although this is not significant $(-0.4 \%))$. 


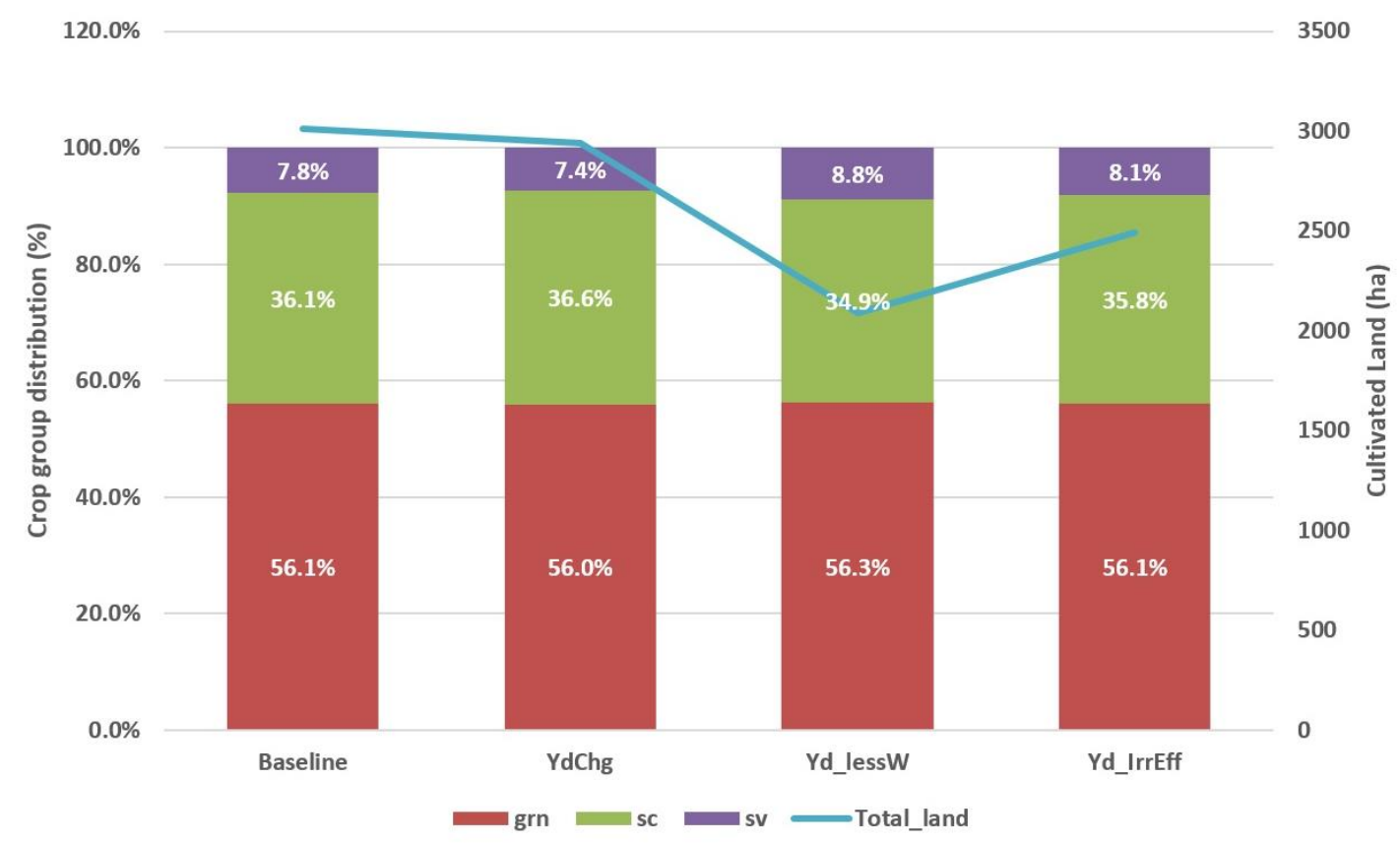

Figure 7. Regional crop distribution and cultivated land change. grn: grains; sc: spring crops; sp: spring vegetables. Data within bars indicates the regional distribution of crop groups for baseline and all scenarios, based on land cultivated. Secondary Y-axis indicate changes (in ha) on cultivated land

For the $Y \boldsymbol{d}$ _less $\boldsymbol{W}$ scenario, Figure 7 shows a sharp decrease in the total cultivated land (31\%), with the total irrigated land decreasing at a similar magnitude (34\%). A $20 \%$ increase in irrigation efficiency (Yd_IrrEff) partially offsets the impact of the second scenario, with a $17.3 \%$ decrease in the total land and a $17.9 \%$ decrease in the irrigated land compared with the baseline.

Regarding the economic impacts of climate change, Figure 8 shows that the overall effect on the weighted regional expected income is negative, varying from $-24.0 \%$ in the Yd_less W scenario to $-17 \%$ in the $Y \boldsymbol{d C h}$ scenario. As expected, the improvement in irrigation efficiency counterbalances the impact of the water scarcity scenario, diminishing the impact from $-24 \%$ to $-20 \%$ compared with the baseline. Figure 8 also presents the regional variation of labour use between the baseline and scenarios of climate change effects. The labour use is also more negatively affected by scenario YD_Less W than it is by scenario YdChg, which is explained by the decrease in crop activities with higher labour requirements under a water scarcity scenario. The latter also explains the higher counterbalanced impact of the improvement of water efficiency on the regional labour, diminishing the impact from $-27 \%$ to $-16 \%$ compared to the baseline. 


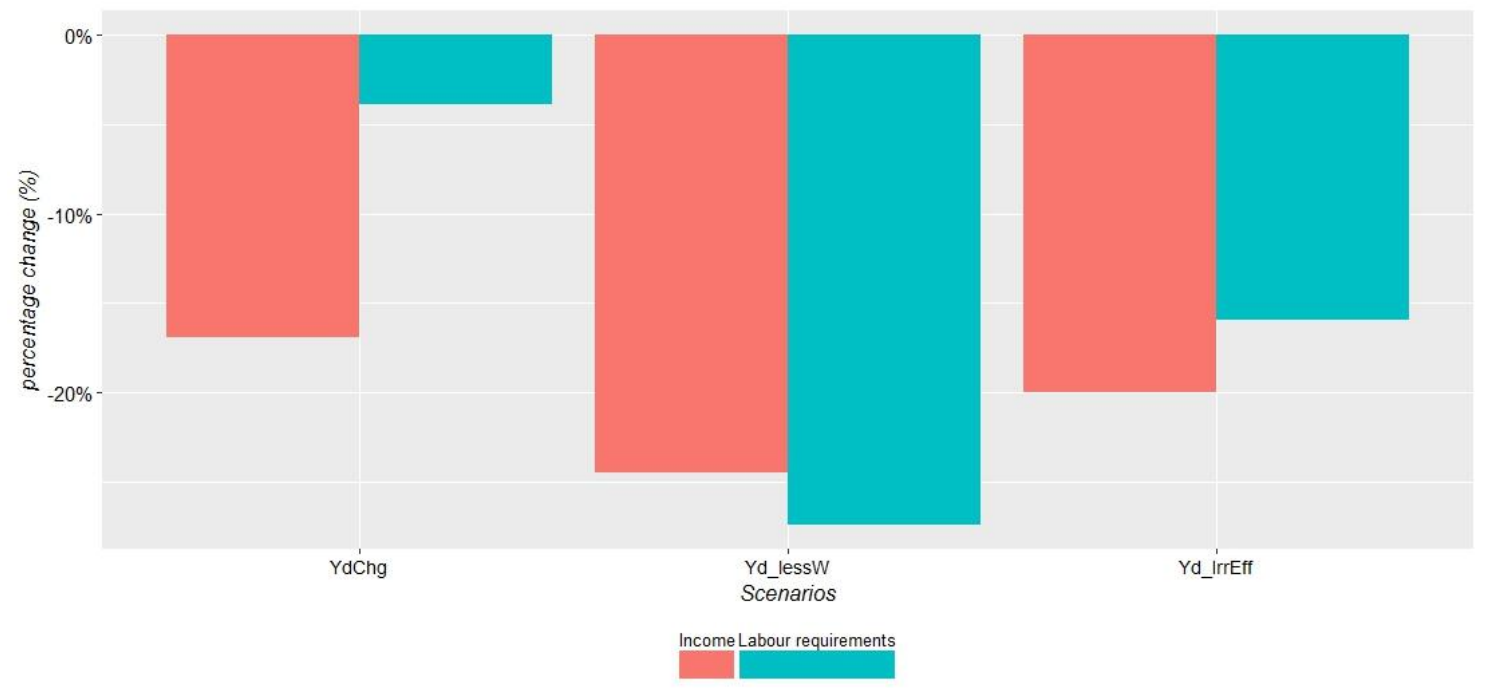

Figure 8. Regional income and labour change compared to the baseline

Despite these regional effects, it is important to highlight that there are high levels of heterogeneity across households. The impacts of the three scenarios on the farm households' income and labour use are reported in the next figures. The left panel of Figure 9 shows the percentage change of the agricultural income compared to the baseline for each household type under the three scenarios. This panel shows that under the YdChg scenario, the major changes in agricultural income would occur in the poorest farm households ('smallholder farm'). Due to the more important share of rainfed crops compared to irrigated crops for these households, the effects of less water availability or increased efficiency in irrigation techniques does not have major impacts, other than that observed in the scenario of yield changes.

Within the other three farm households, the impacts of each scenario vary depending on the features of each household. The same panel shows that in the yield scenario, all households undergo similar changes in agricultural income, varying from $-19.4 \%$ in 'Medium-mixed-farm' households to $-13.7 \%$ in 'Large-SpringCrop-farm' households. On the other hand, within the water-limiting scenario (Yd_less $\boldsymbol{W})$, differences in the impact of climate change on agricultural income are more evident. These impacts vary between $-37.9 \%$ for the farm household type 'Medium-Grain' to $-20.9 \%$ for the farm household type 'Medium-mixed-farm'. The combination of yield impacts and reduced water availability for irrigated crops significantly affects the agricultural income of 'Medium-Grain' and 'Large-SpringCrop-farm' households, mainly due to their high dependence on water-intensive crops. In the $\boldsymbol{Y d C h}$ scenario, major decreases in rain- 
fed crops are offset by irrigated crops such as oat and maize; however, after a shock on water availability, the impact on income could not be stopped.

Figure 9 also shows that an increase in irrigation efficiency (Yd_IrrEff) has major impacts on some households (particularly 'Medium grain' and 'Large-SpringCropfarm') and must be considered an important adaptation measure for likely climate impacts. However, this modelling framework suggests that adaptation measures that improve irrigation efficiency are not equally beneficial for all. This can be observed in 'smallholder farm', which largely depends on rain-fed agriculture, and in 'Mediummixed-farm', where the high diversification of crops and the growth of high value-crops are one of their main features.

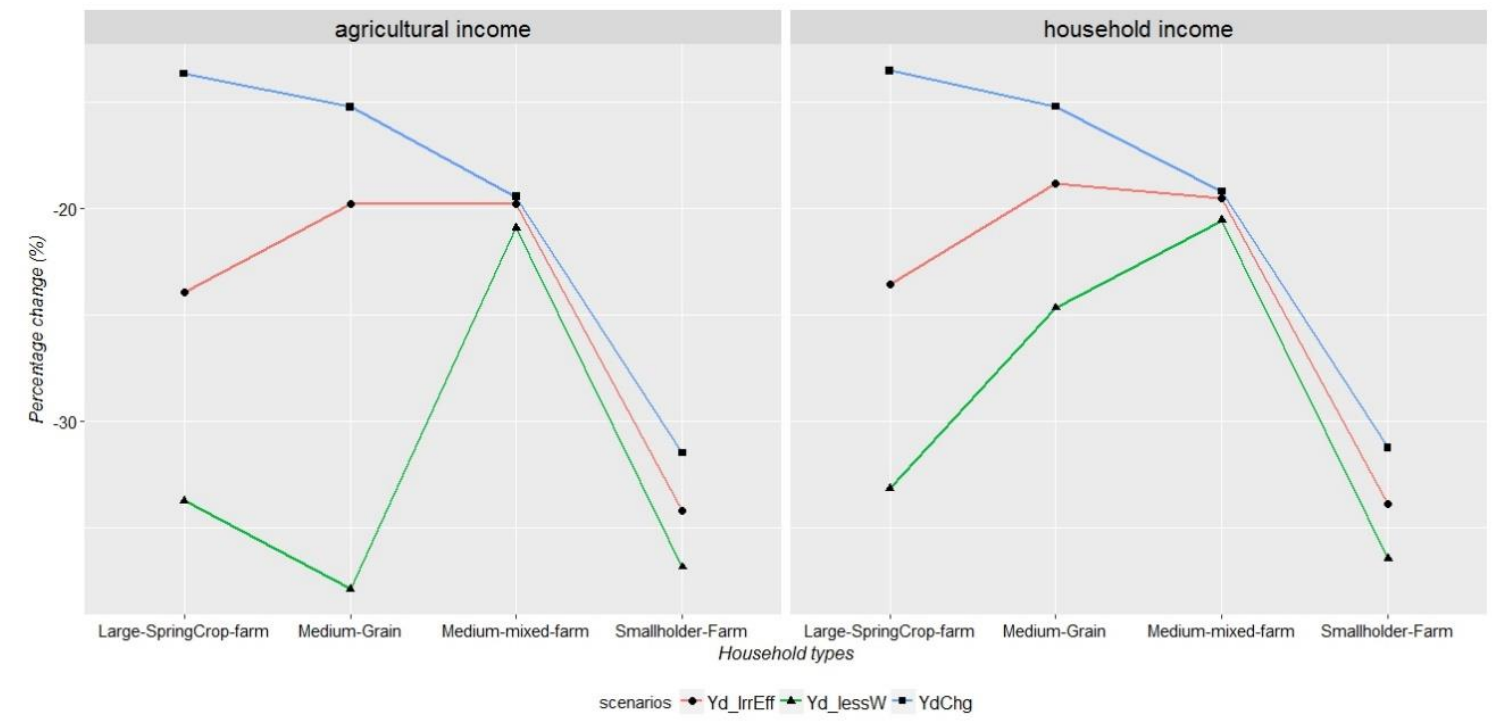

Figure 9. Agricultural Income and Farm household expected income change.Percentage changes compaed to the baseline by farm household type

The right panel of Figure 9 shows the percentage change of expected household incomes compared to those of the baseline for each household type within the three different scenarios. Unlike agricultural income, household expected income is specified as the income received from all activities, including agricultural income, non-farm wages, and off-agricultural farm incomes (see Appendix B). Although in most households, there are not significant changes compared with their agricultural incomes, the 'Medium grain' households under the water scarcity scenario counterbalance the impact from $-37.8 \%$ of agricultural income to $-24.6 \%$ of household income. This is explained by the increase in the participation in off-farm activities such as hiring out labour, which is a consequence of the decline in crop productivity. 
Labour requirement changes are quite different between households. Contrary to the large effects of climate change on the income of 'smallholder farm', in this case, the labour requirement changes are insignificant mainly because they tend to use mostly family labour. The other three farm-households present heterogeneous responses regarding their labour requirement changes. Figure 10 shows that although 'Medium grain' undergoes minimal changes in its labour requirements in a YdChg scenario, a shock on both, yields and water availability will have major impacts on it. As we observed in the typology construction, unlike the other households, family labour represents an important share of the total labour of 'Medium-Grains' households, which is mainly distributed among grains. When these crops are hit hard by climate change, the labour requirements decrease, but (as shown in the right panel of Figure 9), this household can counterbalance the impacts on income by participating in off-farm activities.

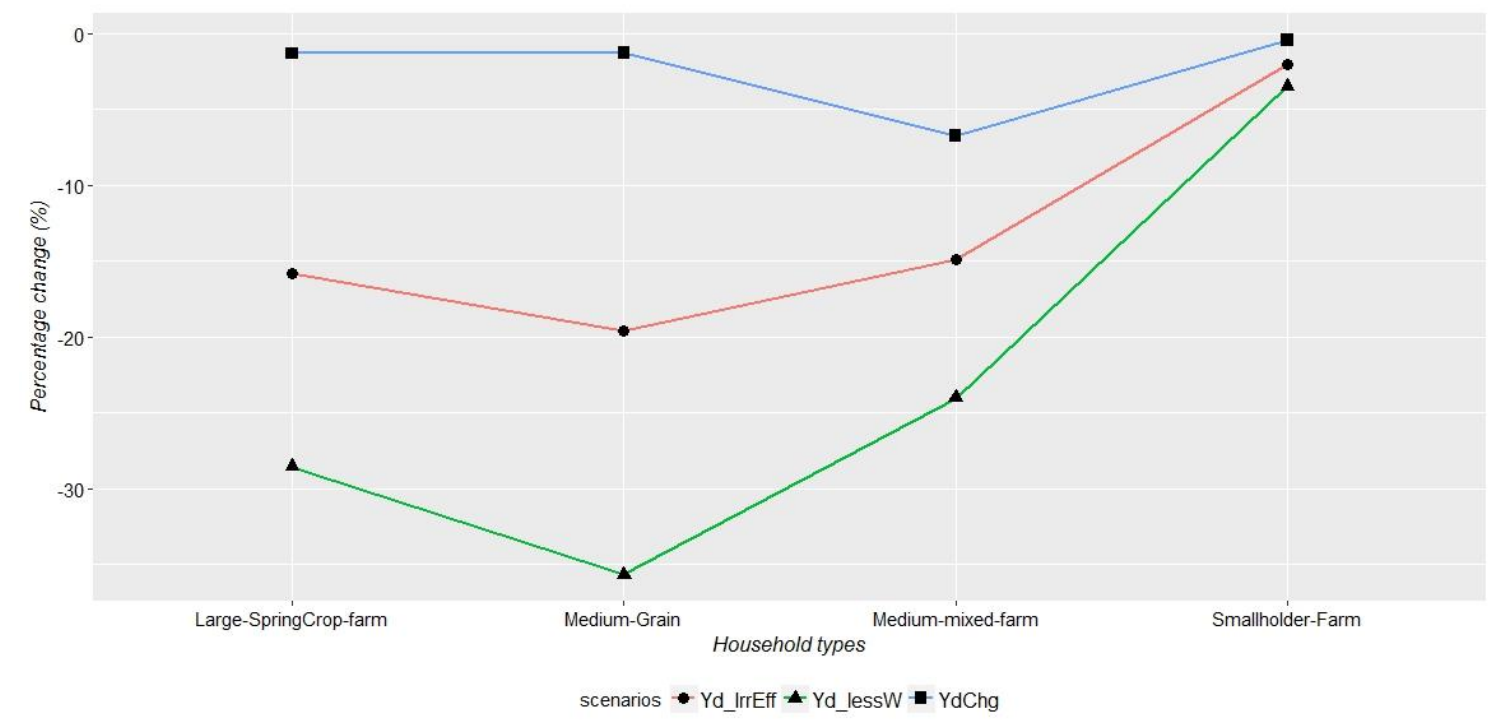

Figure 10. Labour requirements change by household compared with the baseline

\subsection{Discussion and Findings}

The modelling framework presented in this chapter allows to represent different responses to likely effects of climate change on agriculture. First, the results under the scenario of yield changes occurring at the local level show that the poorest farmers will suffer the largest diminishing in expected income. In line with other authors (Antle et al., 2004), the results show that in assessments that consider the importance of producer 
heterogeneity, the poorest farm households are the hardest hit by climate change. This highlights the special attention that must be paid to the most vulnerable groups, including the small-scale farmers, as noted in other studies (Bellon et al., 2011; Kurukulasuriya and Rosenthal, 2013; Morton, 2007). Moreover, this chapter underlines that this intrinsic vulnerability is represented by the farm-households' socioeconomic and agricultural features, such as crop diversification, farm size, resource endowment, and available family labour. The autonomous adjustments of these factors reflect the response of each household modelled, which represent the trade-offs that farmers will face to optimise their resource allocation.

Second, the results of a water scarcity scenario show that most of the farm-households in this region are very vulnerable to risks related to water availability for irrigation. In particular, those that are highly dependent on specific irrigated crops. As shown in other studies, this is a common result in irrigated, arid (Bobojonov and Aw-Hassan, 2014) and semi-arid regions (Esteve et al., 2015), where a further demand increase of water is expected, thus making the profitability of household production more vulnerable to changes in water availability. In this sense, improving water management for irrigation is an important adaptation strategy, particularly in countries that are characterised by agricultural sectors within semi-arid regions, as suggested in other studies (Bobojonov and Aw-Hassan, 2014; Kurukulasuriya and Rosenthal, 2013).

In this context, this chapter also assesses the use of an irrigation efficiency improvement scenario as an adaptation measure to climate change. At the aggregated level, our findings under this scenario are consistent with those of Roco et al. (2014), who reported, based on expert opinion, that it has some of the greatest potentials. These results highlight that the incentives prioritised in the PANCC report regarding the improvement of irrigation systems are in the right direction in a regional context. At the farm level, improving the conveyance and distribution efficiency of the water network allows counterbalancing the effects of a water scarcity scenario, particularly for those households that grow water-intensive crops. Although this policy will improve households' situation, the expected changes will not be equally beneficial for all. Farmhouseholds with a high diversification of crops, which also assign a share of their surface to high-value crops, show a lower income decrease under a water scarcity scenario compared with other households. Thus, improving irrigation efficiency, as adaptation measure, does not act as a significant buffer for the impact of water scarcity 
on income for this type of household. This finding shows that certain household features enhance their resilience, which can lead to inexpensive adaptation alternatives and obtain higher incomes under likely events of water scarcity, as indicated in other studies (Esteve et al., 2015; Tanaka et al., 2006). These results highlight the need to understand stakeholders and their management resources when implementing adaptation strategies, as several authors have argued in previous studies (Downing et al., 1997).

This approach allows us to identify and assess levels of household resilience, which are represented by the household features identified within the cluster analysis and the autonomous adjustments of the household model. Regarding household features, the framework identifies different combinations of crops within each farm household. The heterogeneity level of cultivated crops is a proxy for crop diversification. Mediummixed farms are the household type featuring more alternative methods for changing their cropping patterns and are thus more resilient to climate change. These observations are in line with those of other studies, which have highlighted the diversification of crops as a key factor for coping with climate change (Aerts et al., 2008; Fraser et al., 2005; Tonhasca and Byrne, 1994). Moreover, this result provides a concrete example of a complementary adaptation measure to the improvement of irrigation efficiency, with the potential to be implemented in different irrigated dry regions. This finding is in line with Aleksandrova et al. (2016), who suggest that increased diversification is a key strategy for supporting global efforts to cope with water scarcity in semi-arid regions.

Regarding the autonomous adaptation, the efficient use of resources, as the model's endogenous responses, are adaptive measures adopted by the farmer to maximise his benefits in a new context. These autonomous adjustments depend on the features of each household and are reflected in a variety of ways, ranging from adjustments in cropping patterns to increasing participation in off-farm activities. The latter underscores the importance of labour mobility as an adaptive response to climate change for particular households, which is in line with several studies (Barnett and O'Neill, 2012; Karfakis et al., 2012). These adjustments represent farmer's behaviour activated by the changes observed on yields and water availability. These different answers presented by each farm-household are in line with the finding of Reidsma et al. (2010) regarding their relevance to understanding the particular farm features for adapting to climate change. 
The proposed framework can be applied in other regions as an analytical tool to evaluate the adaptive capacity of different rural households sharing both a common area and a common national adaptation plan. Several authors have indicated that adaptation plans have tended to overemphasize technological and infrastructural measures while often overlooking poor people's needs, and livelihood and adaptation strategies (Agrawal and Perrin, 2009; Olsson et al., 2014; Perch, 2011). Further, particularly in less developed countries, micro-level analysis for adaptation planning are scarce, constraining the identification of specific groups and contexts where vulnerability is intensified (Perch, 2011). Therefore, considering that many funding mechanisms linked to climate adaptation in agriculture prioritize most vulnerable communities, this framework could support to national and international donors to gain an ex-ante comprehensive understanding of the micro-level responses to adaptation strategies. In this sense, our framework allows fund managers to allocate resources more efficiently, disentangling the effects of adaptation strategies from other factors that impact on the degree to which adaptation policy objectives are realized. Moreover, it could shed lights about how adaptation strategies can be formulated to address the needs of all constituencies in heterogeneous agricultural regions.

\subsection{Policy implications}

This chapter describes the application of a farm household model whose power lies in reflecting the farm heterogeneity of a dualistic agricultural region and the household's economic behaviours under different shocks induced by climate change. The model was employed to estimate the economic impacts in both agricultural and household's income, assessing the changes in crop and resource allocation. The results show that the different household groups, independent of their socio-economic features, are vulnerable to the impact of climate change. At an aggregated level, there will be substantial economic impacts of climate change on both regional agricultural income and agricultural employment. However, when the irrigation efficiency is improved, the negative impacts of climate change are partially offset.

At the household level, this model highlights relevant aspects that merit consideration in the implementation of policies to promote adaptive mechanisms to climate change in dualistic agricultural sectors. Our results show that although all the households categories present negative economic impacts, these are different for each group, with 
the smallest farmers showing the largest negative changes in expected income in all scenarios. Consequently, regional plans aimed at promoting adaptation to climate change in dualistic agricultural regions need to address specific adaptive policies to support these small holders.

In scenarios in which the effects of climate change on both crop yield and water availability are considered, the results show that internal features may enhance households' resilience to climate change by minimising its negative effects and providing effective methods of adaptation. Our findings indicate that farm-household characteristics such as crop diversification, land shares of high-value crops, and nonfarm incomes, which can be strengthened by policy interventions, increase resilience and play an important role in adapting to climate change. Therefore, providing incentives to increase crop diversification, training farmers to grow high-value crops, and implementing policies to facilitate labour mobility from the agricultural sector to other economic sectors, represent adaptation options to counterbalance the negative impacts of climate change.

Our findings further emphasise the relevance of understanding local conditions and household features before implementing a specific adaptation measure. The results show that although irrigation efficiency is a key adaptation mechanism, this strategy is only beneficial at the household level for a specific group of households - namely, those growing water-intensive crops. In contrast, smaller farmers, who are more dependent on rain-fed crops, and households characterised by high levels of crop diversification do not benefit substantially from this policy. These findings highlight the need for differentiated policies to address the impacts of climate change, especially within dualistic agricultural sectors that are characterised by heterogeneous farm households.

The framework proposed in this chapter can be used to inform policy makers and fund managers for adaptation in agriculture about the likely economic effects of climate change at the household level and the likely households' responses to specific adaptation mechanisms. However, these results should be interpreted with caution because of data limitations and the shortcomings of the analysis discussed above in sub-section 4.4.4. 
Chapter 4. Implications of climate change for dualistic agricultural sectors 


\section{Conclusions}

Agriculture as a primary economic activity is particularly sensitive to climate change. Changes in weather factors directly affect physiological crop processes, having direct effects on agricultural productivity levels. These changes in productivity yield different socio-economic responses at the global, regional, and local levels as a way to coping with a new climate context.

The complexities of these socio-economic responses have led to the development of quantitative tools capable of disentangling some of these reactions at different scales. Of these quantitative tools, structural approaches, through mathematical programming models, have been proven to serve as powerful tools for the analysis of the impacts of climate change on agriculture at any scale. In such a context, market equilibrium models have played an important role at global and regional levels in assessing the economic impacts of climate change on the production, consumption, prices, and trade of agricultural commodities. However, more disaggregated analyses must be conducted to consider farm level socio-economic responses and heterogeneities among these farms.

In this sense, the importance of sub-national economic impact assessments of climate change has been underscored in this thesis. Although several sub-national modelling approaches for developed regions have been formulated, there is still a lack of microlevel assessments on developing countries that could complement macro-level assessments. Such studies could facilitate understanding of micro-level socioeconomic responses, which are especially important for smallholders in developing countries in which agricultural sectors are highly heterogeneous. Macro-level assessments of heterogeneous agricultural regions could bias the results. Average impacts at the expense of household heterogeneity may hide varying responses of different farms, thus overestimating the adaptive capacities of more vulnerable farm types. To understand smallholder behaviours in a context of climate change and to disentangle the particular responses of heterogeneous farms of the same region, a more detailed representation of farm resources and activities is required in consideration of heterogeneities between farm types.

The aim of this thesis is to analyse the economic effects of climate change on agriculture at different sub-national scales through the use of mathematical 
programming models. Through a thorough review of the evolution of mathematical programming models used to assess the economic impacts of climate change on the agricultural sector, common findings are identified from global to regional assessments on how aggregated results hide distributional impacts of climate change and on how regional and local features influence the vulnerability of countries and farmers at the local level. Further, several research gaps are identified. Some of these gaps (e.g., underlying assumptions regarding distinctions between farm household supplies and consumption decisions and the current lack of micro-level assessments on heterogeneous agricultural regions within developing countries) are addressed through the application of two sub-national modelling frameworks to two specific study case studies of Chile. The first modelling approach detailed in Chapter 3 of this thesis represents a hydro-economic modelling framework that captures the socio-economic effects of water shocks on smallholders of the Vergara River Basin. Chapter 4 presents a household modelling approach applied to a semi-arid irrigated region of central Chile. This study has yielded relevant results that can guide decision-making, shedding light on appropriately targeted interventions and especially for more vulnerable farmers. The study's most relevant findings and contributions are summarised in the following section.

\section{Major findings}

The literature review and modelling frameworks presented in this research reveal several findings that may help decision makers respond to several needs expressed by the IPCC and by the scientific community. These needs concern two particular issues. First, little attention has been paid to better understanding links between climate change, agriculture, and poverty and especially for developing countries, wherein agricultural regions include heterogeneous entities from subsistence farms to large commercial farms. Second, there is a need to carry out assessments of impacts of climate change and adaptation at the local level and especially to highlight the relevance of farm features and the contexts in which they interact for the design of appropriate adaptation interventions.

A common finding found regardless of assessment scale is that the poor are those most vulnerable to climate change. Global and regional assessments based on market models show that climate change will more negatively affect developing countries than 
developed countries, mainly due to their agro-climatic features (i.e., warmer baseline climates and dependence on more vulnerable crops) and socio-economic characteristics (i.e., high expenditures on food, consumption price elasticity, or limited capital available for adaptation measures). Similar findings have been revealed from assessments conducted at sub-national scales. Such results show that for both study cases, the poorest farmers will likely be the most affected in economic terms by the effects of climate change. Reflecting results found through global and regional assessments, the vulnerability of the poorest farmers is highly determined by their agricultural and economic characteristics. These results show that climate change will have major distributional consequences with the poorest being worse off, which could exacerbate inequities already present in Chile.

In relation to the same context, our results highlight the importance of considering distributional rather than merely the aggregate effects of climate change and especially when modelling outputs are used as inputs for policy-making decisions. Aggregated results often hide effects at more disaggregated scales, underestimating (overestimating) impacts of or capacities to adapt to climate change for different farms. From both modelling approaches, results show that overall outputs tend to hide significant disparities at smaller scales. For the Vergara River Basin, expected changes in water availability will have minor effects at the overall basin level. However, estimated impacts across farm types are uneven, with the most significant impacts affecting poor farmers. For the Maule region, overall results show its vulnerability to risks related to water availability levels and how water management improvements for irrigation could counterbalance water scarcity effects. However, results for lower scales show that improvements of irrigation efficiency will not be equally beneficial for all.

For the Maule region, results highlight the vulnerability of irrigated semi-arid regions. It is expected that in such regions, water demand will increase further, rendering farm household profitability more vulnerable to changes in water availability levels. Moreover, our results show that depending on their productive or economic characteristics, farm households respond to different effects of climate change or to different adaptation strategies in varying ways.

The economic modelling frameworks developed through this study allow for a more thorough understanding of the various socio-economic responses of smallholders at the 
local level within a heterogeneous agricultural sector. They thus serve as useful tools for distinguishing between different adaptive capacities and responses to adaptation strategies from all constituencies from subsistence farms to large commercial farms and assist policy-makers in the development of effective and targeted adaptation methods in a context of climate change.

\section{Research contributions}

This thesis addresses several shortcomings of climate change impact assessments of the agricultural sector highlighted by the scientific community. Both modelling frameworks applied to specific areas of Chile (the Vergara River Basin and the Maule region) offer key contributions to the understanding of local responses to climate change, complementing impact and adaptation assessments conducted at aggregated scales.

The literature shows that structural methods used to assess the economics of the impacts of climate change and adaptation for agriculture have strongly relied on the use of global or regional market equilibrium models. However, the importance of understanding local impacts and local adaptation capacities has recently been highlighted by the scientific community, and particularly in reference to developing countries where smallholders still represent an important share of agricultural communities. This study addresses this challenge, serving as an important complement to global and regional economic assessments through the use of structural methods in terms of levels of assessment detail and capacities to consider the heterogeneity of the agricultural sector and different local capacities to cope with climate change.

From a methodological perspective, two contributions of this research are most salient. First, while few economic models explicitly consider risks in objective functions, those that do commonly assume the presence of zero wealth effects. In the present study, for the case study of the Vergara River Basin, the hydro-economic model, which considers risks of non-linear mean-variance approaches whereby economic modules capture wealth effects, is proposed. This approach allows one to assess farmers' socio-economic responses to climate change effects by considering two important issues: the farmer as a risk-averse agent and how wealth levels influence the effects of climate variability on profitability. 
Second, the modelling framework used for the case study of central Chile accounts for farmer adaptation measures in consideration of heterogeneous household-level responses. Modelling approaches at the global and regional levels have commonly estimated average impacts at the expense of household heterogeneity on one hand and have failed to account for farm level adaptation measures on the other. Further, this modelling framework can make significant contributions in terms of understanding factors that exacerbate the vulnerability of regions and of specific farm households. Both the typology constructed and the household model developed shed light on how dependence on water-intensive crops increases vulnerability to climate change. It follows from this that farm household features enhance or decrease resilience to climate change.

From the perspective of the applied models, this thesis measures economic impacts of climate change on small-scale agriculture in Chile that no studies have modelled thus far. Moreover, in considering the Maule region, the study reveals socio-economic responses at the household level, thus presenting a novel modelling approach for such levels of disaggregation in reference to Chilean agriculture. Finally, modelling frameworks developed through this research, although based on particular case studies, can be transferred to other regions. In this case, it is important to highlight how the presented micro-level assessment of the Maule region may shape different regions characterised by high levels of farm household heterogeneity and especially for irrigated semi-arid regions.

\section{Limitations and recommendations for further research}

This section briefly discusses the limitations of this study and from these shortcomings presents avenues for further research.

In this study, biophysical effects on crop yields are based on studies or reports focused on crop models of different spatial resolutions than those of the economic modelling frameworks used here. Moreover, these reports have mainly focused on a few crops (mainly wheat, maize, rice, and oats) without considering commodities that at the subnational level may represent an important share of farmers' incomes. These shortcomings imply that biophysical data are subjected to several assumptions before their use as inputs of economic modules. For the Maule region, for instance, it was 
assumed the same crop yield changes for all communes within the study area without considering local agro-ecological features. Moreover, for crops with no direct representation in reports from which biophysical data were extracted, similar climate change responses to crops considered in these reports were assumed. The development of local studies based on crop-based and/or hydrological models and subsequent links to farm-household economic models would improve evaluations of climate change at the local level.

As another limitation of this study, in both modelling frameworks presented here, no price changes in response to climate change are presented. The assumption that commodity prices are the same and fixed under all scenarios is unlikely to manifest under a global climate change scenario. Few studies have assessed the economic impacts of climate change at sub-national levels while considering commodity price changes from global market equilibrium models. Of these studies, most have focused on developed countries where knowledge and interdisciplinary coordination required to develop integrated approaches is available. Improving relationships between subnational economic models and global or regional market equilibrium models and especially for developing countries would allow for a more realistic evaluation of the effects on farmers' incomes.

In addition to the above concerns, several key datasets remain uncertain. For instance, the use of hydrologic model SWAT to the Vergara River Basin in Chapter 3 presents limitations in not considering groundwater for irrigation. This limitation could have been addressed through the use of a coupled watershed-groundwater model to improve the physical representation of hydrologic processes, but this would also have increased levels of detail involved and the complexities of modelling frameworks presented in this research. On the other hand, due to a lack of data available for determining transaction costs, simulations of real household trading status cannot be carried out and especially for subsistence households. Thus, the framework applied in Chapter 4 does not recognise the likelihood that some households cannot participate in markets due to the presence of high transaction costs. Empirical studies on transaction cost estimations and on heterogeneous rural areas of developing countries in particular that makes such considerations in applying modelling approaches would further understanding of poorest farmers' responses to climate change scenarios. 
Finally, validating typology construction results in consultation with local experts would render results more useful from a policy perspective. When local experts agree with farm types or groups of households detected through statistical analyses, results acquire a higher degree of relevance and are more valuable for adaptation policy makers. 


\section{References}

Adams, R. (1999) On the search for the correct economic assessment method. Climatic Change 41, 363-370.

Adams, R.M., Fleming, R.A., Chang, C.-C., McCarl, B.A., Rosenzweig, C. (1995) A reassessment of the economic effects of global climate change on US agriculture. Climatic Change 30, 147-167.

Adams, R.M., Hurd, B.H., Lenhart, S., Leary, N. (1998) Effects of global climate change on agriculture: an interpretative review. Climate Research 11, 19-30.

Adams, R.M., McCarl, B.A., Dudek, D.J., Glyer, J.D. (1988) Implications of global climate change for western agriculture. Western Journal of Agricultural Economics, 348-356.

Aerts, J.C., Botzen, W., Veen, A., Krywkow, J., Werners, S. (2008) Dealing with uncertainty in flood management through diversification. Ecology and Society 13, 1-17.

Agostini, C.A., Brown, P.H., Góngora, D.P. (2008) Distribución espacial de la pobreza en Chile. Estudios de economía 35, 79-110.

Agrawal, A., Perrin, N. (2009) Climate adaptation, local institutions and rural livelihoods. Adapting to climate change: thresholds, values, governance, 350-367.

Aleksandrova, M., Gain, A.K., Giupponi, C. (2016) Assessing agricultural systems vulnerability to climate change to inform adaptation planning: an application in Khorezm, Uzbekistan. Mitigation and Adaptation Strategies for Global Change 21, 1263-1287.

Andersen, L., Breisinger, C., Jemio, L.C., Mason-D’Croz, D., Ringler, C., Robertson, R., Verner, D., Wiebelt, M., (2016) Climate Change Impacts and Household Resilience. Prospects for 2050 in Brazil, Mexico and Peru. International Food Policy Research Institute, Washington, D.C. : International Food Policy Research Institute (IFPRI). doi:http://dx.doi.org/10.2499/9780896295810

Antle, J.M., Capalbo, S.M., Elliott, E.T., Paustian, K.H. (2004) Adaptation, spatial heterogeneity, and the vulnerability of agricultural systems to climate change and $\mathrm{CO} 2$ fertilization: an integrated assessment approach. Climatic Change 64, 289-315.

Apey, A., Barril, A., (2006) Pequeña agricultura en Chile. Rasgos socioproductivos, institucionalidad y clasificación territorial para la innovación, Santiago de Chile: INDAPODEPA-MUCECH-IICA.

Arent, D.J., Tol, R., Faust, E., Hella, J.P., Kumar, S., (2014) Key economic sectors and services, Climate Change 2014: Impacts, Adaptation, and Vulnerability. Part A: Global and Sectoral Aspects. Contribution of Working Group II to the Fifth Assessment Report of the Intergovernmental Panel on Climate Change. Cambridge University Press, Cambridge:, pp. 659-708.

Arnold, J.G., Srinivasan, R., Muttiah, R.S., Williams, J.R. (1998) Large area hydrologic modeling and assessment part I: Model development. JAWRA Journal of the American Water Resources Association. doi:10.1111/j.1752-1688.1998.tb05961.x

Bar-Shira, Z., Just, R.E., Zilberman, D. (1997) Estimation of farmers' risk attitude: an econometric approach. Agricultural Economics 17, 211-222. 
Barlas, Y. (1996) Formal aspects of model validity and validation in system dynamics. System dynamics review 12, 183-210.

Barnett, J., O'Neill, S.J. (2012) Islands, resettlement and adaptation. Nature Climate Change 2, 8-10.

Bates, B., Kundzewicz, Z.W., Wu, S., Palutikof, J. (2008) Climate change and water. IPCC Secretariat, Geneva, 210 pp.

Bellon, M.R., Hodson, D., Hellin, J. (2011) Assessing the vulnerability of traditional maize seed systems in Mexico to climate change. Proceedings of the National Academy of Sciences 108, $13432-13437$.

Berger, T., Birner, R., McCarthy, N., DíAz, J., Wittmer, H. (2006) Capturing the complexity of water uses and water users within a multi-agent framework. Water resources management 21 , 129-148. doi:10.1007/s11269-006-9045-z

Berger, T., Troost, C. (2013) Agent-based Modelling of Climate Adaptation and Mitigation Options in Agriculture. Journal of Agricultural Economics 65, 323-348.

Blanco-Gutierrez, I., Varela-Ortega, C., Purkey, D.R. (2013) Integrated assessment of policy interventions for promoting sustainable irrigation in semi-arid environments: a hydro-economic modeling approach. J Environ Manage 128, 144-160. doi:10.1016/j.jenvman.2013.04.037

Blanco, M., Ramos, F., Van Doorslaer, B., (2014a) Climate change as a key long-term driver for agricultural markets developments: A global assessment with a closer look at the EU, PreCongress Workshop" New developments in understanding price dynamics", EAAE 2014 Congress, Ljubbljana, Slovenia.

Blanco, M., Ramos, F., Van Doorslaer, B., (2014b) Economic impacts of climate change on agrifood markets: A bio-economic approach with a focus on the EU, In XIVth EAAE Congress" Agri-Food and Rural Innovations for Healthier Societies". Ljubbljana, Slovenia.

Bobojonov, I., Aw-Hassan, A. (2014) Impacts of climate change on farm income security in Central Asia: An integrated modeling approach. Agriculture, ecosystems \& environment 188, 245-255.

Bonsch, M., Dietrich, J., Popp, A., Lotze-Campen, H., Stevanovic, M., (2013) Validation of land-use models, 16th Annual Conference on Global Economic Analysis (GTAP).

Bosello, F., Zhang, J. (2005) Assessing climate change impacts: agriculture. Nota di Lavoro, Fondazione Eni Enrico Mattei.

Braat, L.C., van Lierop, W.F., (1987) Economic-ecological modeling, in: Braat, L.C., Van Lierop, W.F. (Eds.), Integrated economic ecological modelling North Holland Publishing Co., Amsterdam, pp. 49-67.

Brooks, J., Filipski, M., Jonasson, E., Taylor, J.E. (2011) "The Development Policy Evaluation Model (DEVPEM): Technical Documentation", OECD Food, Agriculture and Fisheries Papers, No. 51, OECD Publishing. doi:http://dx.doi.org/10.1787/5kg26152k135-en

Brouwer, R., Hofkes, M. (2008) Integrated hydro-economic modelling: Approaches, key issues and future research directions. Ecological Economics 66, 16-22.

Calzadilla, A., Rehdanz, K., Betts, R., Falloon, P., Wiltshire, A., Tol, R.S. (2013a) Climate change impacts on global agriculture. Climatic Change 120, 357-374. 
Calzadilla, A., Zhu, T., Rehdanz, K., Tol, R.S., Ringler, C. (2013b) Economy wide impacts of climate change on agriculture in Sub-Saharan Africa. Ecological Economics 93, 150-165.

Cano, C., Andreoli, A., Arumi, J.L., Rivera, D. (2014) Uso de imágenes de satélite para evaluar los efectos de cambio de cobertura de suelo en la escorrentía directa de una cuenca andina. Tecnologia y Ciencias del Agua 5, 145-151.

CASEN, (2015) Encuesta "Caracterización Socieconómica Nacional". Ministerio del Desarrollo Social, Santiago Chile. Available from: <http://www.encuestacasen.cl/>

Cervantes-Godoy, D. (2015) "Strategies for Addressing Smallholder Agriculture and Facilitating Structural Transformation" OECD Food, Agriculture and Fisheries Papers, No. 90, OECD Publishing, Paris. doi:DOI: http://dx.doi.org/10.1787/5jrs8sv4jt6k-en

Ciscar, J.-C., Iglesias, A., Feyen, L., Szabó, L., Van Regemorter, D., Amelung, B., Nicholls, R., Watkiss, P., Christensen, O.B., Dankers, R. (2011) Physical and economic consequences of climate change in Europe. Proceedings of the National Academy of Sciences 108, 2678-2683.

Ciscar, J.-C., Soria, A., Goodess, C.M., Christensen, O.B., Iglesias, A., Garrote, L., Moneo, M., Quiroga, S., Feyen, L., Dankers, R., (2009) Climate change impacts in Europe. Final report of the PESETA research project. Directorate Growth \& Innovation and JRC-Seville, Joint Research Centre.

CNR, (2015) Resultados Ley $\mathrm{N}^{\circ}$ 18.450. Comisión Nacional de Riego. Ministerio de Agricultura, Chile. doi:http://www.cnr.gob.cl/FomentoAlRiego/Resultado\%20y\%20Aplicacin\%20Ley\%2018450\% 20por\%20ao/Resultados\%202014.pdf

Challinor, A., Wheeler, T., Craufurd, P., Slingo, J., Grimes, D. (2004) Design and optimisation of a large-area process-based model for annual crops. Agricultural and forest meteorology 124, $99-120$.

Chavas, J.-P. (2004) Risk analysis in theory and practice. Elsevier Academic Press, San Diego, California.

Christie, D.A., Boninsegna, J.A., Cleaveland, M.K., Lara, A., Le Quesne, C., Morales, M.S., Mudelsee, M., Stahle, D.W., Villalba, R. (2011) Aridity changes in the TemperateMediterranean transition of the Andes since AD 1346 reconstructed from tree-rings. Climate Dynamics 36, 1505-1521.

D’Agostino, D.R., Scardigno, A., Lamaddalena, N., El Chami, D. (2014) Sensitivity analysis of coupled hydro-economic models: quantifying climate change uncertainty for decision-making. Water resources management 28, 4303-4318.

Darwin, R. (1999) A farmer's view of the Ricardian approach to measuring agricultural effects of climatic change. Climatic Change 41, 371-411.

Darwin, R., Tsigas, M.E., Lewandrowski, J., Raneses, A., (1995) World agriculture and climate change: Economic adaptations. United States Department of Agriculture, Economic Research Service.

Deressa, T.T., Hassan, R.M., Ringler, C., Alemu, T., Yesuf, M. (2009) Determinants of farmers' choice of adaptation methods to climate change in the Nile Basin of Ethiopia. Global Environmental Change 19, 248-255. 
Donoso, G., (2015) Water Pricing in Chile: Decentralization and Market Reforms, Water pricing experiences and innovations. Springer, pp. 83-96.

Donoso, G., Cancino, J., López de Lérida, J., Contreras, H., Rivas, W., (2010) Evaluacion de Impacto de los Programas de INDAP: Programa de Desarrollo Local -Programa de Desarrollo de Comunas Pobres, in: Ministerio_de_Agricultura (Ed.), Chile, p. 392.

Downing, T.E., Ringius, L., Hulme, M., Waughray, D. (1997) Adapting to climate change in Africa. Mitigation and Adaptation Strategies for Global Change 2, 19-44.

Dube, S., Scholes, R.J., Nelson, G.C., Mason-D'Croz, D., Palazzo, A. (2013) South African food security and climate change: Agriculture futures. Economics: The Open-Access, OpenAssessment E-Journal. Vol 7 1 -54. doi:http://dx.doi.org/10.5018/economics-ejournal.ja.201335

Easterling, W., Aggarwal, P., Batima, P., Brander, K., Erda, L., Howden, S., Kirilenko, A., Morton, J., Soussana, J., Schmidhuber, J., (2007) Food, fibre and forest products. Climate Change 2007: impacts, adaptation and vulnerability. In 'Contribution of Working Group II to the Fourth Assessment Report of the Intergovernmental Panel on Climate Change'.(Eds ML Parry, OF Canziani, JP Palutikof, PJ van der Linden, CE Hanson) pp. 273-313. Cambridge University Press: Cambridge, UK.

Espinosa, J., Uribe, H., Arumí, J., Rivera, D., Stehr, A. (2011) Vulnerabilidad del recurso hídrico respecto a actividades agrícolas en diferentes subcuencas del rio Limarí. Gestión Ambiental 22, 15-30.

Esteve, P., Varela-Ortega, C., Blanco-Gutiérrez, I., Downing, T.E. (2015) A hydro-economic model for the assessment of climate change impacts and adaptation in irrigated agriculture. Ecological Economics 120, 49-58. doi:10.1016/j.ecolecon.2015.09.017

Ewert, F., Rötter, R.P., Bindi, M., Webber, H., Trnka, M., Kersebaum, K.C., Olesen, J.E., van Ittersum, M.K., Janssen, S., Rivington, M. (2015) Crop modelling for integrated assessment of risk to food production from climate change. Environmental Modelling \& Software 72, 287303.

Falvey, M., Garreaud, R.D. (2009) Regional cooling in a warming world: Recent temperature trends in the southeast Pacific and along the west coast of subtropical South America (19792006). Journal of Geophysical Research: Atmospheres (1984-2012) 114.

Falloon, P., Betts, R. (2010) Climate impacts on European agriculture and water management in the context of adaptation and mitigation-the importance of an integrated approach. Science of the Total Environment 408, 5667-5687.

FAO, (2014a) Deep Roots. Food and Agriculture Organization of the United Nations, Rome, Italy., p. 257.

FAO, (2014b) The State of Food and Agriculture. Innovation in family farming. Food and Agriculture Organization of the United Nations, Rome, Italy., p. 139

FAOSTAT, (2015) Available at: http://faostat3.fao.org/home/E (accessed: March, 2015).

Feng, S., Fu, Q. (2013) Expansion of global drylands under a warming climate. Atmos. Chem. Phys 13, 10,081-010,094. 
Fernández, F.J., Blanco, M. (2015) Modelling the economic impacts of climate change on global and European agriculture: Review of economic structural approaches. Economics: The Open-Access, Open-Assessment E-Journal 9, 1-53.

Fernández, F.J., Ponce, R.D., Blanco, M., Rivera, D., Vásquez, F. (2016) Water variability and the economic impacts on small-scale farmers. A farm risk-based integrated modelling approach. Water resources management 30, 1357-1373. doi:10.1007/s11269-016-1227-8

FIA, (2010) El cambio climático en el sector silvoagropecuario de Chile, Fundación para la Innovación Agraria, Ministerio de Agricultura de Chile, Santiago.

Field, C.B., Barros, V.R., Mach, K., Mastrandrea, M. (2014) Climate change 2014: impacts, adaptation, and vulnerability. Contribution of Working Group II to the Fifth Assessment Report of the Intergovernmental Panel on Climate Change.

Fischer, G., Frohberg, K., Keyzer, M.A., Parikh, K.S. (1988) Linked national models: A tool for international food policy analysis. Springer Science \& Business Media.

Fischer, G., Shah, M., Tubiello, F.N., Van Velhuizen, H. (2005) Socio-economic and climate change impacts on agriculture: an integrated assessment, 1990-2080. Philosophical Transactions of the Royal Society B: Biological Sciences 360, 2067-2083. doi:http://dx.doi.org/10.1098/rstb.2005.1744

Fischer, G., Shah, M.M., Van Velthuizen, H. (2002) Climate change and agricultural vulnerability. Discussion paper, IIASA, Internat. Inst. for Applied Systems Analysis.

Foster, T., Brozović, N., Butler, A.P. (2014) Modeling irrigation behavior in groundwater systems. Water resources research 50, 6370-6389.

Foster, W., Valdés, A., (2013) ¿Cuál es el tamaño económico del sector silvoagropecuario? Cálculo para el año 2008 considerando sus encadenamientos., in: Ministerio_de_Agricultura (Ed.). Ministerio de Agricultura, Chile, p. 63.

Frank, S., Witzke, H.-P., Zimmermann, A., Havlík, P., Ciaian, P., (2014) Climate change impacts on European agriculture: a multi model perspective, XIVth EAAE Congress" AgriFood and Rural Innovations for Healthier Societies". Ljubbljana, Slovenia.

Fraser, E.D., Mabee, W., Figge, F. (2005) A framework for assessing the vulnerability of food systems to future shocks. Futures 37, 465-479.

Freeman, A. (1993) The measurement of environmental and resource values resources for the future. Washington, DC.

Graveline, N., Majone, B., Van Duinen, R., Ansink, E. (2014) Hydro-economic modeling of water scarcity under global change: an application to the Gállego river basin (Spain). Regional environmental change 14, 119-132.

Gutowski, W.J., Decker, S.G., Donavon, R.A., Pan, Z., Arritt, R.W., Takle, E.S. (2003) Temporal-spatial scales of observed and simulated precipitation in central US climate. Journal of Climate 16, 3841-3847.

Hannah, L., Roehrdanz, P.R., Ikegami, M., Shepard, A.V., Shaw, M.R., Tabor, G., Zhi, L., Marquet, P.A., Hijmans, R.J. (2013) Climate change, wine, and conservation. Proceedings of the National Academy of Sciences 110, 6907-6912. doi:http://dx.doi.org/10.1073/pnas.1210127110 
Harou, J.J., Pulido-Velazquez, M., Rosenberg, D.E., Medellín-Azuara, J., Lund, J.R., Howitt, R.E. (2009) Hydro-economic models: Concepts, design, applications, and future prospects. Journal of Hydrology 375, 627-643.

Harvey, C.A., Rakotobe, Z.L., Rao, N.S., Dave, R., Razafimahatratra, H., Rabarijohn, R.H., Rajaofara, H., MacKinnon, J.L. (2014) Extreme vulnerability of smallholder farmers to agricultural risks and climate change in Madagascar. Philosophical Transactions of the Royal Society B: Biological Sciences 369, 20130089.

Hassan, R., Nhemachena, C. (2008) Determinants of African farmers' strategies for adapting to climate change: Multinomial choice analysis. African Journal of Agricultural and Resource Economics 2, 83-104.

Hazell, P.B. (2005) Is there a future for small farms? Agricultural Economics 32, 93-101.

Hazell, P.B., Norton, R.D., Hazell, P.B.R., Hazell, P.B.R. (1986) Mathematical programming for economic analysis in agriculture. Macmillan Publishing Company, New York.

Heinz, I., Pulido-Velazquez, M., Lund, J., Andreu, J. (2007) Hydro-economic modeling in river basin management: implications and applications for the European water framework directive. Water resources management 21, 1103-1125.

Hertel, T., Randhir, T. (1999) Trade liberalization as a vehicle for adapting to global warming.

Hertel, T.W., Burke, M.B., Lobell, D.B. (2010) The poverty implications of climate-induced crop yield changes by 2030. Global Environmental Change 20, 577-585. doi:http://dx.doi.org/10.1016/j.gloenvcha.2010.07.001

Hertel, T.W., Rosch, S.D. (2010) Climate change, agriculture, and poverty. Applied Economic Perspectives and Policy, ppq016. doi:http://dx.doi.org/10.1093/aepp/ppq016

Holden, S., Shiferaw, B., Pender, J. (2004) Non-farm income, household welfare, and sustainable land management in a less-favoured area in the Ethiopian highlands. Food Policy 29, 369-392. doi:http://dx.doi.org/10.1016/j.foodpol.2004.07.007

Howitt, R.E. (1995) Positive mathematical programming. American journal of agricultural economics 77, 329-342.

Howitt, R.E. (2005) Agricultural and environmental policy models: Calibration, estimation and optimization. Davis: University of California, Davis. Available online at< http://www. agecon. ucdavis. edu/people/faculty/facultydocs/howitt/master. pdf

Hurd, B.H., Coonrod, J. (2012) Hydro-economic consequences of climate change in the upper Rio Grande. Climate Research 53, 103.

Iglesias, A., Garrote, L., Quiroga, S., Moneo, M. (2009) Impacts of climate change in agriculture in Europe. PESETA-Agriculture study. Institute for Prospective Technological Studies, Joint Research Centre, European Commission.

Iglesias, A., Schlickenrieder, J., Pereira, D., Diz, A. (2011) From the farmer to global food production: use of crop models for climate change impact assessment. Handbook on Climate Change and Agriculture, 49.

Ignaciuk, A., Mason-D'Croz, D., (2014) Modelling adaptation to climate change in agriculture, OECD Food, Agriculture and Fisheries Papers. OECD Publishing. doi:http://dx.doi.org/10.1787/5jxrclljnbxq-en 
INE, (2007) Censo Agropecuario, Chile.

INE, (2009) Informe Anual de Estadísticas Agropecuarias, in: Estadísticas, I.N.d. (Ed.), Santiago de Chile, p. 178.

INE, (2010) Informe Anual de Estadísticas Agropecuarias, in: Estadísticas, I.N.d. (Ed.), Santiago de Chile, p. 172.

INE, (2013) Informe Anual de Estadísticas Agropecuarias, Instituto Nacional de Estadística, Chile.

IPCC, (2014) Summary for policymakers, Climate Change 2014: Impacts, Adaptation, and Vulnerability. Part A: Global and Sectoral Aspects. Contribution of Working Group II to the Fifth Assessment Report of the Intergovernmental Panel on Climate Change [Field, C.B., V.R. Barros, D.J. Dokken, K.J. Mach, M.D. Mastrandrea, T.E. Bilir, M. Chatterjee, K.L. Ebi, Y.O. Estrada, R.C. Genova, B. Girma, E.S. Kissel, A.N. Levy, S. MacCracken, P.R. Mastrandrea, and L.L.White (eds.)]. Cambridge University Press, Cambridge, United Kingdom and New York, NY, USA, pp. 1-32.

Jara-Rojas, R., Osorio, J.D., Manríquez, P., Rojas, Á. (2012) Classification criteria and commercial profile re-definition of the Family Farm Agriculture in Chile, Maule region. Revista de la Facultad de Ciencias Agrarias 44, 143-156.

Jeuland, M. (2010) Economic implications of climate change for infrastructure planning in transboundary water systems: An example from the Blue Nile. Water resources research 46.

Jiang, Q., Grafton, R.Q. (2012) Economic effects of climate change in the Murray-Darling Basin, Australia. Agricultural Systems 110, 10-16.

Jones, J.W., Bartels, W., Fraisse, C., Boote, K.J., Ingram, K.T., Hoogenboom, G., (2011) Use of Crop Models for Climate-Agricultural Decisions, Handbook of Climate Change and Agroecosystems. ICP Series on Climate Change Impacts, Adaptation, and Mitigation,. Imperial College Press, London, pp. 131-157.

Jones, P.G., Thornton, P.K. (2003) The potential impacts of climate change on maize production in Africa and Latin America in 2055. Global Environmental Change 13, 51-59. doi:http://dx.doi.org/10.1016/S0959-3780(02)00090-0

Kaiser, H.M., Riha, S.J., Wilks, D.S., Rossiter, D.G., Sampath, R. (1993) A farm-level analysis of economic and agronomic impacts of gradual climate warming. American journal of agricultural economics 75, 387-398.

Kane, S., Reilly, J., Tobey, J. (1992) An empirical study of the economic effects of climate change on world agriculture. Climatic Change 21, 17-35. doi:http://dx.doi.org/10.1007/BF00143251

Kanellopoulos, A., Berentsen, P., Heckelei, T., Van Ittersum, M., Lansink, A.O. (2010) Assessing the Forecasting Performance of a Generic Bio-Economic Farm Model Calibrated With Two Different PMP Variants. Journal of Agricultural Economics 61, 274-294.

Kanellopoulos, A., Reidsma, P., Wolf, J., Van Ittersum, M. (2014) Assessing climate change and associated socio-economic scenarios for arable farming in the Netherlands: an application of benchmarking and bio-economic farm modelling. European Journal of Agronomy 52, 69-80.

Karfakis, P., Lipper, L., Smulders, M., Meybeck, A., Lankoski, J., Redfern, S., Azzu, N., Gitz, V., (2012) The assessment of the socioeconomic impacts of climate change at household level 
and policy implications, Building resilience for adaptation to climate change in the agriculture sector. Proceedings of a Joint FAO/OECD Workshop, Rome, Italy, 23-24 April 2012. Food and Agriculture Organization of the United Nations (FAO), pp. 133-150.

Katz, R.W., Parlange, M.B., Naveau, P. (2002) Statistics of extremes in hydrology. Advances in water resources $25,1287-1304$.

Koohafkan, P., Stewart, B.A., (2008) Drylands, People and Land Use, Water and cereals in drylands. FAO, pp. 5-15.

Kriegler, E., O’Neill, B.C., Hallegatte, S., Kram, T., Lempert, R.J., Moss, R.H., Wilbanks, T. (2012) The need for and use of socio-economic scenarios for climate change analysis: a new approach based on shared socio-economic pathways. Global Environmental Change 22, 807822.

Kurukulasuriya, P., Mendelsohn, R., Hassan, R., Benhin, J., Deressa, T., Diop, M., Eid, H.M., Fosu, K.Y., Gbetibouo, G., Jain, S. (2006) Will African agriculture survive climate change? The World Bank Economic Review 20, 367-388.

Kurukulasuriya, P., Rosenthal, S. (2013) Climate change and agriculture: A review of impacts and adaptations. World Bank, Washington, DC.

Lavalle, C., Micale, F., Houston, T.D., Camia, A., Hiederer, R., Lazar, C., Conte, C., Amatulli, G., Genovese, G. (2009) Climate change in Europe. 3. Impact on agriculture and forestry. A review. Agronomy for sustainable Development 29, 433-446.

Leggett, J., Pepper, W.J., Swart, R.J., Edmonds, J., Meira Filho, L., Mintzer, I., Wang, M. (1992) Emissions scenarios for the IPCC: an update. Climate change, 69-95.

Lindoso, D.P., Rocha, J.D., Debortoli, N., Parente, I.I., Eiró, F., Bursztyn, M., Rodrigues-Filho, S. (2014) Integrated assessment of smallholder farming's vulnerability to drought in the Brazilian Semi-arid: a case study in Ceará. Climatic Change 127, 93-105.

Lobell, D., Burke, M., (2010a) Global and Regional Assessments, Climate Change and Food Security. Springer, pp. 177-192. doi:http://dx.doi.org/10.1007/978-90-481-2953-9_10

Lobell, D., Burke, M. (2010b) On the use of statistical models to predict crop yield responses to climate change. Agricultural and forest meteorology 150, 1443-1452.

Louhichi, K., Gomez y Paloma, S. (2014) A farm household model for agri-food policy analysis in developing countries: Application to smallholder farmers in Sierra Leone. Food Policy 45, 1 13. doi:http://dx.doi.org/10.1016/j.foodpol.2013.10.012

Louhichi, K., Gomez y Paloma, S., Belhouchette, H., Allen, T., Fabre, J., Blanco-Fonseca, M., Chenoune, R., Acs, S., Flichman, G. (2013) Modelling Agri-Food Policy Impact at Farmhousehold Level in Developing Countries (FSSIM-Dev). Application to Sierra Leone. Joint Research Centre. JRC Scientific and Policy Reports.

Maneta, M., Torres, M., Vosti, S.A., Wallender, W.W., Allen, S., Bassoi, L.H., Bennett, L., Howitt, R., Rodrigues, L., Young, J. (2009a) Assessing agriculture-water links at the basin scale: hydrologic and economic models of the São Francisco River Basin, Brazil. Water International 34, 88-103.

Maneta, M., Torres, M.d.O., Wallender, W., Vosti, S., Howitt, R., Rodrigues, L., Bassoi, L., Panday, S. (2009b) A spatially distributed hydroeconomic model to assess the effects of drought on land use, farm profits, and agricultural employment. Water resources research 45 . 
Medellín-Azuara, J., Mendoza-Espinosa, L., Lund, J., Harou, J., Howitt, R. (2009) Virtues of simple hydro-economic optimization: Baja California, Mexico. Journal of environmental management 90, 3470-3478.

Mendelsohn, R., Dinar, A. (2003) Climate, water, and agriculture. Land economics 79, 328-341.

Mendelsohn, R., Nordhaus, W., Shaw, D. (1996) Climate impacts on aggregate farm value: accounting for adaptation. Agricultural and forest meteorology 80, 55-66.

Mendelsohn, R., Nordhaus, W.D., Shaw, D. (1994) The impact of global warming on agriculture: a Ricardian analysis. The American Economic Review, 753-771.

MMA, (2016) National Climate Change Action Plan 2017 - 2022. Ministry for the Environment, Santiago, Chile, p. 52.

Mortimore, M., Anderson, S., Cotula, L., Davies, J., Faccer, K., Hesse, C., Morton, J.F., Nyangena, W., Skinner, J., Wolfangel, C. (2009) Dryland Opportunities: A new paradigm for people, ecosystems and development. by: IUCN, Gland, Switzerland, IIED, London, UK and UNDP, New York, USA.

Morton, J.F. (2007) The impact of climate change on smallholder and subsistence agriculture. Proc Natl Acad Sci U S A 104, 19680-19685. doi:10.1073/pnas.0701855104

Müller, C., Bondeau, A., Popp, A., Waha, K., Fader, M. (2010) Climate change impacts on agricultural yields.

Nagayets, O. (2005) Small farms: current status and key trends. The future of small farms, 355.

Nakicenovic, N., Alcamo, J., Davis, G., De Vries, B., Fenhann, J., Gaffin, S., Gregory, K., Grübler, A., Jung, T.Y., Kram, T., La Rovere, E.L., Michaelis, L., Mori, S., Morita, T., Pepper, W., Pitcher, H., Price, L., Raihi, K., Roehrl, A., Rogner H-, H., Sankovski, A., Schlesinger, M., Shukla, P., Smith, S., Swart, R., van Rooijen, S., Victor, N., Dadi, Z. (2000) Special Report on Emissions Scenarios. Cambridge University Press, Cambridge, UK.

Nelson, G.C., Mensbrugghe, D., Ahammad, H., Blanc, E., Calvin, K., Hasegawa, T., Havlik, P., Heyhoe, E., Kyle, P., Lotze-Campen, H., von Lampe, M., d'Croz, D., van Meijl, H., Müller, C., Reilly, J., Robertson, R., Sands, R., Schmitz, C., Tabeau, A., Takahashi, K., Valin, H., Willenbockel, D. (2014a) Agriculture and climate change in global scenarios: why don't the models agree. Agricultural Economics 45, 85-101. doi:http://dx.doi.org/10.1111/agec.12091

Nelson, G.C., Rosegrant, M.W., Koo, J., Robertson, R., Sulser, T., Zhu, T., Ringler, C., Msangi, S., Palazzo, A., Batka, M. (2009) Climate change: Impact on agriculture and costs of adaptation. Intl Food Policy Res Inst.

Nelson, G.C., Rosegrant, M.W., Palazzo, A., Gray, I., Ingersoll, C., Robertson, R., Tokgoz, S., Zhu, T., Sulser, T.B., Ringler, C. (2010) Food security, farming, and climate change to 2050: Scenarios, results, policy options. Intl Food Policy Res Inst

Nelson, G.C., Valin, H., Sands, R.D., Havlík, P., Ahammad, H., Deryng, D., Elliott, J., Fujimori, S., Hasegawa, T., Heyhoe, E. (2014b) Climate change effects on agriculture: Economic responses to biophysical shocks. Proceedings of the National Academy of Sciences $111,3274-3279$.

Newton, A.C., Tejedor, N. (2011) Principles and practice of forest landscape restoration: case studies from the drylands of Latin America. IUCN. 
ODEPA, (2010) Estimación del impacto socioeconómico del cambio climático en el Sector Silvoagropecuario de Chile, Oficina de Estudios y Políticas Agrarias (ODEPA).

ODEPA, (2015) Chilean agriculture overview Agrarian Policies and Studies Bureau, Chilean Ministry of Agriculture, Chile.

OECD (2008) OECD Review of Agricultural Policies: Chile 2008. OECD Publishing, Paris.

OECD/ECLAC (2016) OECD Environmental Performance Reviews: Chile 2016. OECD Publishing.

Olesen, J.E., Bindi, M. (2002) Consequences of climate change for European agricultural productivity, land use and policy. European Journal of Agronomy 16, 239-262.

Olesen, J.E., Trnka, M., Kersebaum, K., Skjelvåg, A., Seguin, B., Peltonen-Sainio, P., Rossi, F., Kozyra, J., Micale, F. (2011) Impacts and adaptation of European crop production systems to climate change. European Journal of Agronomy 34, 96-112.

Olsson, L., Opondo, M., Tschakert, P., Agrawal, A., Eriksen, S., Ma, S., Perch, L., Zakieldeen, S., (2014) Livelihoods and poverty, Climate change 2014: impacts, adaptation, and vulnerability. Part A: global and sectoral aspects. Contribution of Working Group II to the Fifth Assessment Report of the Intergovernmental Panel on Climate Change [Field, C.B., V.R. Barros, D.J. Dokken, K.J. Mach, M.D. Mastrandrea, T.E. Bilir, M. Chatterjee, K.L. Ebi, Y.O. Estrada, R.C. Genova, B. Girma, E.S. Kissel, A.N. Levy, S. MacCracken, P.R. Mastrandrea, and L.L. White (eds.)]. Cambridge University Press, Cambridge, United Kingdom and New York, NY, USA, pp. 793-832.

Pandey, R., Kala, S., Pandey, V.P. (2015) Assessing climate change vulnerability of water at household level. Mitigation and Adaptation Strategies for Global Change 20, 1471-1485.

Parry, M., Canziani, O.F., Palutikof, J.P., van der Linden, P.J., Hanson, C.E., (2007) IPCC, 2007: climate change 2007: impacts, adaptation and vulnerability. Contribution of working group II to the fourth assessment report of the intergovernmental panel on climate change. Cambridge University Press, Cambridge.

Parry, M., Rosenzweig, C., Iglesias, A., Fischer, G., Livermore, M. (1999) Climate change and world food security: a new assessment. Global Environmental Change 9, S51-S67.

Parry, M.L., Rosenzweig, C., Iglesias, A., Livermore, M., Fischer, G. (2004) Effects of climate change on global food production under SRES emissions and socio-economic scenarios. Global Environmental Change 14, 53-67.

Peña-Haro, S., Llopis-Albert, C., Pulido-Velazquez, M., Pulido-Velazquez, D. (2010) Fertilizer standards for controlling groundwater nitrate pollution from agriculture: El Salobral-Los Llanos case study, Spain. Journal of Hydrology 392, 174-187.

Peña-Haro, S., Pulido-Velazquez, M., Llopis-Albert, C. (2011) Stochastic hydro-economic modeling for optimal management of agricultural groundwater nitrate pollution under hydraulic conductivity uncertainty. Environmental Modelling \& Software 26, 999-1008.

Perch, L. (2011) Mitigation of what and by what? Adaptation by whom and for whom? Dilemmas in delivering for the poor and the vulnerable in international climate policy, Working Paper, International Policy Centre for Inclusive Growth. No. 79.

Petsakos, A., Rozakis, S. (2015) Calibration of agricultural risk programming models. European Journal of Operational Research 242, 536-545. 
Ponce, R., Blanco Fonseca, M., Giupponi, C. (2014) The Economic Impacts Of Climate Change On The Chilean Agricultural Sector: A non-linear agricultural supply model. Chilean Journal of Agricultural Research 74, 404-412. doi:org/10.4067/S0718-58392014000400005

Ponce, R., Blanco, M., Giupponi, C. (2015) Welfare Effects of Water Variability in Agriculture. Insights from a Multimarket Model. Water 7, 2908-2923.

Porter, J.R., Xie, L., Challinor, A.J., Cochrane, K., Howden, S.M., Iqbal, M.M., Lobell, D.B., Travasso, M.I., Netra Chhetri, N.C., Garrett, K., (2014) Food security and food production systems, Climate Change 2014: Impacts, Adaptation, and Vulnerability. Part A: Global and Sectoral Aspects. Contribution of Working Group II to the Fifth Assessment Report of the Intergovernmental Panel on Climate Change. Cambridge University Press, Cambridge, United Kingdom and New York, NY, USA, pp. 485-533.

Quinn, N.W., Brekke, L.D., Miller, N.L., Heinzer, T., Hidalgo, H., Dracup, J.A. (2004) Model integration for assessing future hydroclimate impacts on water resources, agricultural production and environmental quality in the San Joaquin Basin, California. Environmental Modelling \& Software 19, 305-316.

Quiroga, S., Iglesias, A. (2009) A comparison of the climate risks of cereal, citrus, grapevine and olive production in Spain. Agricultural Systems 101, 91-100.

Qureshi, M., Qureshi, S., Bajracharya, K., Kirby, M. (2008) Integrated Biophysical and Economic ModellingFramework to Assess Impacts of Alternative Groundwater Management Options. Water resources management 22, 321-341.

Qureshi, M.E., Hanjra, M.A., Ward, J. (2013) Impact of water scarcity in Australia on global food security in an era of climate change. Food Policy 38, 136-145.

Ravallion, M., Datt, G. (2002) Why has economic growth been more pro-poor in some states of India than others? Journal of development economics 68, 381-400.

Reed, S.C., Coe, K.K., Sparks, J.P., Housman, D.C., Zelikova, T.J., Belnap, J. (2012) Changes to dryland rainfall result in rapid moss mortality and altered soil fertility. Nature Climate Change 2, 752-755.

Reidsma, P., Ewert, F., Lansink, A.O. (2007) Analysis of farm performance in Europe under different climatic and management conditions to improve understanding of adaptive capacity. Climatic Change 84, 403-422.

Reidsma, P., Ewert, F., Lansink, A.O., Leemans, R. (2009) Vulnerability and adaptation of European farmers: a multi-level analysis of yield and income responses to climate variability. Regional environmental change 9, 25.

Reidsma, P., Ewert, F., Lansink, A.O., Leemans, R. (2010) Adaptation to climate change and climate variability in European agriculture: the importance of farm level responses. European Journal of Agronomy 32, 91-102.

Reidsma, P., Wolf, J., Kanellopoulos, A., Schaap, B.F., Mandryk, M., Verhagen, J., van Ittersum, M.K. (2015) Climate change impact and adaptation research requires integrated assessment and farming systems analysis: a case study in the Netherlands. Environmental Research Letters 10, 045004.

Reilly, J., Hohmann, N. (1993) Climate change and agriculture: the role of international trade. The American Economic Review 83, 306-312. 
Reilly, J., Hohmann, N., Kane, S. (1994) Climate change and agricultural trade: who benefits, who loses? Global Environmental Change 4, 24-36.

Reilly, J., Tubiello, F., McCarl, B., Abler, D., Darwin, R., Fuglie, K., Hollinger, S., Izaurralde, C., Jagtap, S., Jones, J. (2003) US agriculture and climate change: new results. Climatic Change 57, 43-67.

Reinsborough, M.J. (2003) A Ricardian model of climate change in Canada. Canadian Journal of Economics/Revue canadienne d'économique 36, 21-40.

Reynolds, J.F., Smith, D.M.S., Lambin, E.F., Turner, B., Mortimore, M., Batterbury, S.P., Downing, T.E., Dowlatabadi, H., Fernández, R.J., Herrick, J.E. (2007) Global desertification: building a science for dryland development. science $316,847-851$.

Ringler, C., Bryan, E., Hassan, R., Alemu, T., Hillesland, M. (2011) How can African agriculture adapt to climate change?: insights from Ethiopia and South Africa. Research BriefInternational Food Policy Research Institute (USA) eng no. 15.

Rivano, F., Jara, J. (2005) Estimación de la evapotranspiración de referencia en la localidad de Remehue-Osorno, X región. Agro sur 33, 49-61.

Roco, L., Engler, A., Bravo-Ureta, B., Jara-Rojas, R. (2014) Farm level adaptation decisions to face climatic change and variability: evidence from Central Chile. Environmental Science \& Policy 44, 86-96.

Roco, L., Engler, A., Bravo-Ureta, B.E., Jara-Rojas, R. (2015) Farmers' perception of climate change in mediterranean Chile. Regional environmental change 15, 867-879.

Rojas, M., (2012) Estado del arte de modelos para la investigación del calentamiento global. Informe para Opciones de Mitigación para enfrentar el Cambio Climático. MAPS Chile, Chile.

Rosegrant, M.W., Hazell, P.B. (2000) Transforming the rural Asian economy: The unfinished revolution. Oxford University Press, Oxford.

Rosenzweig, C., Elliott, J., Deryng, D., Ruane, A.C., Müller, C., Arneth, A., Boote, K.J., Folberth, C., Glotter, M., Khabarov, N. (2014) Assessing agricultural risks of climate change in the 21st century in a global gridded crop model intercomparison. Proceedings of the National Academy of Sciences 111, 3268-3273.

Rosenzweig, C., Parry, M.L. (1994) Potential impact of climate change on world food supply. Nature 367, 133-138.

Rosenzweig, M.R., Binswanger, H.P. (1992) Wealth, weather risk, and the composition and profitability of agricultural investments. World Bank Publications, Washington, DC.

Salinas, C.X., Mendieta, J. (2013a) The cost of mitigation strategies for agricultural adaptation to global change. Mitigation and Adaptation Strategies for Global Change 18, 933-941.

Salinas, C.X., Mendieta, J. (2013b) Mitigation and adaptation investments for desertification and climate change: an assessment of the socioeconomic return. Mitigation and Adaptation Strategies for Global Change 18, 659-672.

Samaniego, J., De Miguel, C.J., Galindo, L.M., Gómez, J.J., Martínez, K., Cetrángolo, O. (2009) La economía del cambio climático en Chile: síntesis. Naciones Unidas, Santiago. 
Santibáñez, F., Santibáñez, P., Cabrera, R., Solis, L., Quiroz, M., Hernandez, J., (2008) Impactos productivos en el sector silvoagropecuario de Chile frente a escenarios de Cambio Climático, Análisis de vulnerabilidad del sector silvoagropecuario, recursos hídricos y edáficos de Chile frente a escenarios de Cambio Climático. Gobierno de Chile, Santiago, pp. 1-181.

Schimmelpfennig, D., Lewandrowski, J., Reilly, J., Tsigas, M., Parry, I., Mendelsohn, R., Mount, T. (1996) Agricultural adaptation to climate change. Economic Research Service, USDA, Agricultural Economic Report. URL http://www. ers. usda. gov/media/490977/aer740a_1_.pdf

Schmidhuber, J., Tubiello, F.N. (2007) Global food security under climate change. Proceedings of the National Academy of Sciences 104, 19703-19708.

Schmitz, C., van Meijl, H., Kyle, P., Nelson, G.C., Fujimori, S., Gurgel, A., Havlik, P., Heyhoe, E., d'Croz, D.M., Popp, A. (2014) Land-use change trajectories up to 2050: insights from a global agro-economic model comparison. Agricultural Economics 45, 69-84.

Schwanitz, V.J. (2013) Evaluating integrated assessment models of global climate change. Environmental Modelling \& Software 50, 120-131.

Seo, S.N., Mendelsohn, R. (2008) A Ricardian analysis of the impact of climate change on South American farms.

Shrestha, S., Ciaian, P., Himics, M., Van Doorslaer, B. (2013) Impacts of climate change on EU agriculture. Review of Agricultural and Applied Economics 16, 24-39.

Skjeflo, S. (2013) Measuring household vulnerability to climate change-Why markets matter. Global Environmental Change 1694-1701. doi:http://dx.doi.org/10.1016/j.gloenvcha.2013.08.011

Skjeflo, S.W., (2014) Measuring Household Vulnerability to Climate Change, in: Chen, W.-Y., Suzuki, T., Lackner, M. (Eds.), Handbook of Climate Change Mitigation and Adaptation. Springer New York, New York, NY, pp. 1-12. doi:http://dx.doi.org/10.1007/978-1-4614-64310_74-1

Stehr, A., Aguayo, M., Link, O., Parra, O., Romero, F., Alcayaga, H. (2010a) Modelling the hydrologic response of a mesoscale Andean watershed to changes in land use patterns for environmental planning. Hydrology and Earth System Sciences 14, 1963-1977. doi:10.5194/hess-14-1963-2010

Stehr, A., Debels, P., Arumi, J., Alcayaga, H., Romero, F. (2010b) Modeling the hydrological response to climate change: experiences from two south-central Chilean watersheds. Tecnologia y Ciencias del Agua 1, 37-58.

Stehr, A., Debels, P., Romero, F., Alcayaga, H. (2008) Hydrological modelling with SWAT under conditions of limited data availability: evaluation of results from a Chilean case study. Hydrological Sciences Journal 53, 588-601. doi:10.1623/hysj.53.3.588

Stocker, T.F., Qin, D., Plattner, G.-K., Tignor, M., Allen, S.K., Boschung, J., Nauels, A., Xia, Y., Bex, V., Midgley, P.M. (2013) Climate change 2013: The physical science basis. Contribution of Working Group I to the Fifth Assessment Report of the Intergovernmental Panel on Climate Change. Cambridge University Press, Cambridge, UK and New York.

Stott, P.A., Jones, G.S., Lowe, J.A., Thorne, P., Durman, C., Johns, T.C., Thelen, J.-C. (2006) Transient climate simulations with the HadGEM1 climate model: causes of past warming and future climate change. Journal of Climate 19, 2763-2782. 
Tanaka, S.K., Zhu, T., Lund, J.R., Howitt, R.E., Jenkins, M.W., Pulido, M.A., Tauber, M., Ritzema, R.S., Ferreira, I.C. (2006) Climate warming and water management adaptation for California. Climatic Change 76, 361-387.

Tobey, J., Reilly, J., Kane, S. (1992) Economic implications of global climate change for world agriculture. Journal of Agricultural and Resource Economics, 195-204.

Tol, R.S., Downing, T.E., Kuik, O.J., Smith, J.B. (2004) Distributional aspects of climate change impacts. Global Environmental Change 14, 259-272.

Tongeren, F., Meijl, H., Surry, Y. (2001) Global models applied to agricultural and trade policies: a review and assessment. Agricultural Economics 26, 149-172.

Tonhasca, A., Byrne, D.N. (1994) The effects of crop diversification on herbivorous insects: a meta-analysis approach. Ecological Entomology 19, 239-244.

Torres, M.d.O., Maneta, M., Howitt, R., Vosti, S.A., Wallender, W.W., Bassoi, L.H., Rodrigues, L.N. (2012) Economic impacts of regional water scarcity in the São Francisco River Basin, Brazil: an application of a linked hydro-economic model. Environment and Development Economics 17, 227-248.

Torres, R., Azócar, G., Rojas, J., Montecinos, A., Paredes, P. (2015) Vulnerability and resistance to neoliberal environmental changes: An assessment of agriculture and forestry in the Biobio region of Chile (1974-2014). Geoforum 60, 107-122. doi:10.1016/j.geoforum.2014.12.013

Traub, A., (2014) Análisis macrosectorial: PIB 2013 y agricultura, in: AGRARIA, O.D.E.Y.P. (Ed.). ODEPA, Santiago.

Tubiello, F.N., Amthor, J.S., Boote, K.J., Donatelli, M., Easterling, W., Fischer, G., Gifford, R.M., Howden, M., Reilly, J., Rosenzweig, C. (2007) Crop response to elevated CO 2 and world food supply: a comment on "Food for Thought..." by Long et al., Science 312: 19181921, 2006. European Journal of Agronomy 26, 215-223.

UNDP, (2008) Desarrollo humano en Chile rural: Seis millones por nuevos caminos. United Nations Development Programme, Santiago, Chile.

Uthes, S., Fricke, K., König, H., Zander, P., van Ittersum, M., Sieber, S., Helming, K., Piorr, A., Müller, K. (2010) Policy relevance of three integrated assessment tools-a comparison with specific reference to agricultural policies. Ecological Modelling 221, 2136-2152.

Van Ittersum, M., Donatelli, M., (2003) Modelling cropping systems-highlights of the symposium and preface to the special issues. Elsevier.

Van Passel, S., Massetti, E., Mendelsohn, R. (2012) A Ricardian analysis of the impact of Climate Change on European agriculture. Environmental and Resource Economics, 1-36.

van Vuuren, D.P., Carter, T.R. (2014) Climate and socio-economic scenarios for climate change research and assessment: reconciling the new with the old. Climatic Change 122, 415-429.

Van Vuuren, D.P., Edmonds, J., Kainuma, M., Riahi, K., Thomson, A., Hibbard, K., Hurtt, G.C., Kram, T., Krey, V., Lamarque, J.-F. (2011) The representative concentration pathways: an overview. Climatic Change 109, 5. 
van Wijk, M.T.v., Rufino, M.C., Enahoro, D., Parsons, D., Silvestri, S., Valdivia, R.O., Herrero, M. (2012) A review on farm household modelling with a focus on climate change adaptation and mitigation.

Varela-Ortega, C., Blanco-Gutiérrez, I., Swartz, C.H., Downing, T.E. (2011) Balancing groundwater conservation and rural livelihoods under water and climate uncertainties: An integrated hydro-economic modeling framework. Global Environmental Change 21, 604-619.

von Lampe, M., Willenbockel, D., Ahammad, H., Blanc, E., Cai, Y., Calvin, K., Fujimori, S., Hasegawa, T., Havlik, P., Heyhoe, E. (2014) Why do global long-term scenarios for agriculture differ? An overview of the AgMIP Global Economic Model Intercomparison. Agricultural Economics 45, 3-20.

Von Neumann, J., Morgenstern, O. (1944) Theory of games and economic behavior. Princeton university press, Princeton.

Wang, J., Huang, X., Zhong, T., Chen, Z. (2013) Climate change impacts and adaptation for saline agriculture in north Jiangsu Province, China. Environmental Science \& Policy 25, 83-93.

Wang, J., Mendelsohn, R., Dinar, A., Huang, J., Rozelle, S., Zhang, L. (2009) The impact of climate change on China's agriculture. Agricultural Economics 40, 323-337.

Ward, F.A., Pulido-Velazquez, M. (2012) Economic costs of sustaining water supplies: findings from the Rio Grande. Water resources management 26, 2883-2909.

Watson, R.T., Zinyowera, M.C., Moss, R.H. (1996) Climate Change 1995 impacts, adaptations and mitigation of climate change: Scientific-technical analysis. Cambridge University Press.

Wheeler, T., Von Braun, J. (2013) Climate change impacts on global food security. science 341, 508-513.

White, J.W., Hoogenboom, G., Kimball, B.A., Wall, G.W. (2011) Methodologies for simulating impacts of climate change on crop production. Field Crops Research 124, 357-368.

Witzke, H.-P., Ciaian, P., Delince, J. (2014) CAPRI long-term climate change scenario analysis: The AgMIP approach. JRC Scientific and Policy Reports. European Commission.

Wood, S.A., Jina, A.S., Jain, M., Kristjanson, P., DeFries, R.S. (2014) Smallholder farmer cropping decisions related to climate variability across multiple regions. Global Environmental Change 25, 163-172.

World Bank (2008) World Development Report-“Agriculture for development”. World Bank, Washington DC. doi:10.1596/978-0-8213-7235-7

Yang, Y.-C.E., Brown, C.M., Yu, W.H., Savitsky, A. (2013) An introduction to the IBMR, a hydro-economic model for climate change impact assessment in Pakistan's Indus River basin. Water International 38, 632-650.

Yates, D.N., Strzepek, K.M. (1998) An assessment of integrated climate change impacts on the agricultural economy of Egypt. Climatic Change 38, 261-287. 


\section{Annexes}




\section{Annex 1. Global and EU regional economic assessments previous to RCPs and SSPs scenarios}

\begin{tabular}{|c|c|c|c|c|c|c|c|}
\hline Reference & $\begin{array}{l}\text { GCMs } \\
\text { Emission scenarios } \\
\text { Climate projections }\end{array}$ & $\begin{array}{l}\text { Biophysical model } \\
\text { (estimation of potential changes } \\
\text { in crop yields) }\end{array}$ & $\begin{array}{l}\text { Economic } \\
\text { model }\end{array}$ & $\begin{array}{l}\text { Regional } \\
\text { Scope }\end{array}$ & $\begin{array}{l}\mathrm{CO2} \\
\text { fertilization }\end{array}$ & $\begin{array}{l}\text { Time } \\
\text { Horizon }\end{array}$ & $\begin{array}{l}\text { Farm-level } \\
\text { Adaptation } \\
\text { measures }\end{array}$ \\
\hline \multicolumn{8}{|c|}{ Global economic impact assessments } \\
\hline \multicolumn{8}{|c|}{ IPCC FAR (1990) } \\
\hline Tobey et al. (1992) & & $\begin{array}{l}\text { Crop responses to climate change } \\
\text { obtained from external studies }\end{array}$ & $\begin{array}{l}\text { SWOPSIM } \\
(\mathrm{PE})\end{array}$ & $\begin{array}{l}\text { Global } \\
(13 \\
\text { regions })\end{array}$ & No & & No \\
\hline Kane et al. (1992) & & $\begin{array}{l}\text { Crop responses to climate change } \\
\text { obtained from external studies }\end{array}$ & $\begin{array}{l}\text { SWOPSIM } \\
(\mathrm{PE})\end{array}$ & $\begin{array}{l}\text { Global } \\
(13 \\
\text { regions })\end{array}$ & No & & No \\
\hline $\begin{array}{l}\text { Rosenzweig and Parry } \\
\text { (1994) }\end{array}$ & $\begin{array}{l}3 \text { Low resolution GCMs (GISS; GFDL; } \\
\text { UKMO) }\end{array}$ & $\begin{array}{l}\text { Crop models and a decision support } \\
\text { system developed by IBSNAT* } \\
\text { (1989) (DSSAT v2.1) }\end{array}$ & BLS & $\begin{array}{l}\text { Global } \\
(34 \\
\text { regions })\end{array}$ & Yes & 2060 & Yes \\
\hline \multicolumn{8}{|c|}{$\begin{array}{l}\text { IPCC SAR (1995) } \\
\text { Special Report on Regional Impacts of Climate Change (IPCC, 1997) }\end{array}$} \\
\hline Parry et al. (1999) & $\begin{array}{l}5 \text { Higher resolution GCMs } \\
1 \text { emission scenario } \\
2 \text { climate change scenarios } \\
\text { - HadCM2- IS92a (four ensemble } \\
\text { - members) } \\
\text { - HadCM3 -IS92a }\end{array}$ & DSSAT (v2.1) & BLS & $\begin{array}{l}\text { Global } \\
(34 \\
\text { regions })\end{array}$ & Yes & $\begin{array}{l}2020 \\
2050 \\
2080\end{array}$ & Yes \\
\hline \multicolumn{8}{|c|}{ IPCC TAR (2001) } \\
\hline Fischer et al. (2002) & 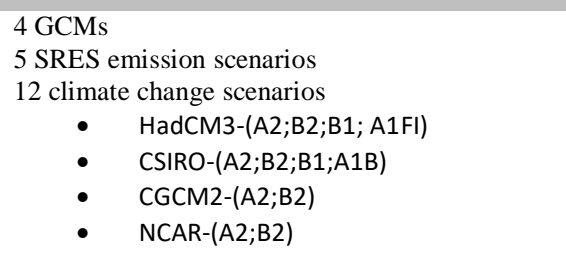 & Agro-ecological zones (AEZ) MODEL & BLS & & Yes & 2080 & Yes \\
\hline
\end{tabular}




\begin{tabular}{|c|c|c|c|c|c|c|c|}
\hline Reference & $\begin{array}{l}\text { GCMs } \\
\text { Emission scenarios } \\
\text { Climate projections }\end{array}$ & $\begin{array}{l}\text { Biophysical model } \\
\text { (estimation of potential changes } \\
\text { in crop yields) }\end{array}$ & $\begin{array}{l}\text { Economic } \\
\text { model }\end{array}$ & $\begin{array}{l}\text { Regional } \\
\text { Scope }\end{array}$ & $\begin{array}{l}\mathrm{CO2} \\
\text { fertilization }\end{array}$ & $\begin{array}{l}\text { Time } \\
\text { Horizon }\end{array}$ & $\begin{array}{l}\text { Farm-level } \\
\text { Adaptation } \\
\text { measures }\end{array}$ \\
\hline Parry et al. (2004) & $\begin{array}{l}1 \text { GCMs } \\
4 \text { SRES emission scenarios } \\
7 \text { climate change scenarios } \\
\text { - HadCM3- } A 1 F I \\
\text { - HadCM3-A2 with } 3 \text { ensemble } \\
\text { - } \text { members }^{+}(a, b, c) \\
\text { - HadCM3- } B 1 a, \\
\quad \text { HadCM3-B2 with } 2 \text { ensemble } \\
\text { members }(a ; b)\end{array}$ & DSSAT (v2.1) & BLS & $\begin{array}{l}\text { Global }(34 \\
\text { regions) }\end{array}$ & Yes & $\begin{array}{l}2020 \\
2050 \\
2080\end{array}$ & Yes \\
\hline Fisher et al. (2005) & $\begin{array}{l}5 \text { GCMs } \\
5 \text { SRES emission scenarios } \\
14 \text { climate change scenarios } \\
\text { - } \quad \text { HadCM3-(A2;B2;B1;A1FI) } \\
\text { - } \quad \text { ECHAM-(A2;B2) } \\
\text { - } \quad \text { CGIRO-(A2;B2;B1;A1B) } \\
\text { - } \quad N C A R-(A 2 ; B 2)\end{array}$ & $\begin{array}{l}\text { FAO/IIASA } \\
\text { model (AEZ) }\end{array}$ & BLS & Global & Yes & 2080 & Yes \\
\hline \multicolumn{8}{|c|}{ IPCC AR4 (2007) } \\
\hline Nelson et al. (2009) & $\begin{array}{l}2 \text { GCMs } \\
1 \text { SRES emission scenario } \\
2 \text { climate change scenarios (with and without } \\
\text { CO2 fertilization) } \\
\text { - NCAR-A2 } \\
\text { - CSIRO-A2 }\end{array}$ & DSSAT (v4.0) & IMPACT (PE) & $\begin{array}{l}\text { Global } \\
\text { (281 } \\
\text { FPUs) }\end{array}$ & Yes & 2050 & Yes \\
\hline Nelson et al. (2010) & $\begin{array}{l}2 \mathrm{GCMs} \\
2 \mathrm{SRES} \\
4 \text { climate change scenarios } \\
\qquad \quad \text { CSIRO-(A1B;B1) } \\
\quad \quad \text { MIROC-(A1B;B1) }\end{array}$ & DSSAT (v4.5) & IMPACT (PE) & $\begin{array}{l}\text { Global } \\
(281 \\
\text { FPUs })\end{array}$ & No & 2050 & Yes \\
\hline Hertel et al. (2010) & - & $\begin{array}{l}\text { Synthesis of values from the literature } \\
\text { for the GTAP regions and six } \\
\text { commodities }\end{array}$ & GTAP (CGE) & $\begin{array}{l}\text { Global }(34 \\
\text { regions) }\end{array}$ & Yes & 2030 & No \\
\hline
\end{tabular}




\begin{tabular}{|c|c|c|c|c|c|c|c|}
\hline Reference & $\begin{array}{c}\text { GCMs } \\
\text { Emission scenarios } \\
\text { Climate projections }\end{array}$ & $\begin{array}{c}\text { Biophysical model } \\
\text { (estimation of potential changes } \\
\text { in crop yields) }\end{array}$ & $\begin{array}{l}\text { Economic } \\
\text { model }\end{array}$ & $\begin{array}{l}\text { Regional } \\
\text { Scope }\end{array}$ & $\begin{array}{l}\mathrm{CO2} \\
\text { fertilization }\end{array}$ & $\begin{array}{l}\text { Time } \\
\text { Horizon }\end{array}$ & $\begin{array}{l}\text { Farm-level } \\
\text { Adaptation } \\
\text { measures }\end{array}$ \\
\hline Calzadilla et al. (2013) & $\begin{array}{l}\text { Climate changes data from Falloon and Betts } \\
\text { (2006) and Stott et al. (2006). Based on } \\
\text { 1GCM } \\
\text { 2 SRES emission scenarios } \\
\text { HadGEM1-TRIP-(A1B;A2) } \\
6 \text { scenarios: } \\
\text { - Precipitation-only } \\
\text { - Precipitation-CO2 } \\
\text { - Precipitation-temperature-CO2 } \\
\text { - Water-only } \\
\text { - All-factors }\end{array}$ & $\begin{array}{l}\text { Regional crop yield responses to } \\
\text { changes in precipitation and } \\
\text { temperature are based on } \\
\text { Rosenzweig and Iglesias (1994) } \\
\text { CO2 fertilization effect on crop yields } \\
\text { are based on information } \\
\text { presented by Tubiello et al. (2007) } \\
\text { Runoff elasticities of water supply } \\
\text { estimated by Darwin et al. (1995) }\end{array}$ & $\begin{array}{l}\text { GTAP-W } \\
\text { (CGE) }\end{array}$ & $\begin{array}{l}\text { Global }(34 \\
\text { regions) }\end{array}$ & Yes & $\begin{array}{l}2020 \\
2050\end{array}$ & No \\
\hline \multicolumn{8}{|c|}{ European regional economic impact assessments } \\
\hline Ciscar (2009) & $\begin{array}{l}2 \mathrm{GCMs} \\
\text { 3RCMs } \\
2 \text { SRES (A2 and B2) } \\
5 \text { climate change scenarios: } \\
1 \text { scenario for } 2020 \text { : } \\
\text { • RCA driven by ECHAM4 (A2) } \\
4 \text { scenarios for 2080: } \\
\text { - HIRHAM driven by HadAM3h (A2;B2) } \\
\text { - RCAO driven by ECHAM4 (A2;B2) }\end{array}$ & $\begin{array}{l}\text { DSSAT - for Europe } \\
\text { World yield changes based on Parry et } \\
\text { al } 2004\end{array}$ & $\begin{array}{l}\text { GTAP and } \\
\text { GEM-E3 } \\
\text { (CGE) }\end{array}$ & $\begin{array}{l}\text { Europe }(5 \\
\text { regions) }\end{array}$ & Yes & $\begin{array}{l}2020 \\
2080\end{array}$ & Yes \\
\hline \multirow[t]{2}{*}{ Ciscar et al. (2011) } & $\begin{array}{l}2 \text { GCMs } \\
2 \text { RCMs } \\
2 \text { SRES } \\
4 \text { climate change scenarios } \\
\quad \text { HIRHAM driven by HadAM } 3 h(A 2 ; B 2) \\
\quad-\quad \text { RCAO driven by ECHAM4 (A2;B2) }\end{array}$ & DSSAT & $\begin{array}{l}\text { GEM-E3 } \\
\text { (CGE) }\end{array}$ & $\begin{array}{l}\text { Europe }(5 \\
\text { regions) }\end{array}$ & Yes & $\begin{array}{l}2080 \\
(2010) * *\end{array}$ & Yes \\
\hline & $\begin{array}{l}\text { All climate data come from PRUDENCE } \\
\text { project }\end{array}$ & & & & & & \\
\hline Shrestha et al. (2013) & $\begin{array}{l}2 \mathrm{GCMs} \\
2 \mathrm{RCMs} \\
1 \text { SRES } \\
2 \text { Climate change scenarios: } \\
\qquad \text { HadRM } 3 Q 0 \text { driven by HadCM3 (A1B) } \\
\qquad \text { HIRHAM5 driven by ECHAM5 (A1B) }\end{array}$ & BIOMA platform & CAPRI (PE) & $\begin{array}{l}\text { Europe } \\
(280 \\
\text { NUTS } 2 \\
\text { region } \\
\text { Global } \\
\text { ( } 77 \\
\text { countries }\end{array}$ & Yes & 2020 & Yes \\
\hline
\end{tabular}




\begin{tabular}{|c|c|c|c|c|c|c|c|}
\hline Reference & $\begin{array}{l}\text { GCMs } \\
\text { Emission scenarios } \\
\text { Climate projections }\end{array}$ & $\begin{array}{c}\text { Biophysical model } \\
\text { (estimation of potential changes } \\
\text { in crop yields) }\end{array}$ & $\begin{array}{l}\text { Economic } \\
\text { model }\end{array}$ & $\begin{array}{l}\text { Regional } \\
\text { Scope }\end{array}$ & $\begin{array}{l}\mathrm{CO2} \\
\text { fertilization }\end{array}$ & $\begin{array}{l}\text { Time } \\
\text { Horizon }\end{array}$ & $\begin{array}{l}\text { Farm-level } \\
\text { Adaptation } \\
\text { measures }\end{array}$ \\
\hline Blanco et al. (2014a) & $\begin{array}{l}\text { 2GCMs } \\
\text { 2RCMs } \\
\text { 1SRES } \\
2 \text { Climate change scenarios: } \\
\text { • HadRM3 driven by HadCM3 (A1B) } \\
\text { - HIRHAM5 driven by ECHAM5 (A1B) }\end{array}$ & WOFOST (BIOMA platform) & CAPRI (PE) & $\begin{array}{l}\text { in } 40 \text { trade } \\
\text { blocks } \\
\text { Europe } \\
(280 \\
\text { NUTS } 2 \\
\text { regions } \\
\text { Global } \\
\text { ( } 77 \\
\text { countries } \\
\text { in } 40 \text { trade } \\
\text { blocks } \\
\end{array}$ & Yes & 2030 & No \\
\hline
\end{tabular}


Annex 1. Global and EU regional economic assessments post RCPs and SSPs scenarios

\begin{tabular}{|c|c|c|c|c|c|c|}
\hline Reference & $\begin{array}{c}\text { GCMs/RCMs } \\
\text { Emission scenarios } \\
\text { Climate projections }\end{array}$ & Biophysical model & $\begin{array}{l}\text { Economic } \\
\text { model }\end{array}$ & $\begin{array}{l}\text { Regional } \\
\text { Scope }\end{array}$ & $\begin{array}{l}\text { CO2 } \\
\text { fertilization }\end{array}$ & $\begin{array}{l}\text { Time } \\
\text { Horizon }\end{array}$ \\
\hline \multicolumn{7}{|c|}{ Global economic impact assessments } \\
\hline Nelson et al. (2013) & $\begin{array}{l}2 \mathrm{GCMs} \\
1 \text { RCP } \\
2 \text { Climate change scenarios: } \\
\qquad \quad \text { HadGEM2-ES (RCP8.5) } \\
\text { - IPSL-CM5A-LR (RCP8.5) }\end{array}$ & $\begin{array}{cl}5 \text { Crop growth models } \\
\text { - } & \text { DSSAT } \\
- & \text { EPIC } \\
\text { - } & \text { LPJmL } \\
\text { - } & \text { PDSSAT } \\
\text { - } & \text { PEGASUS }\end{array}$ & 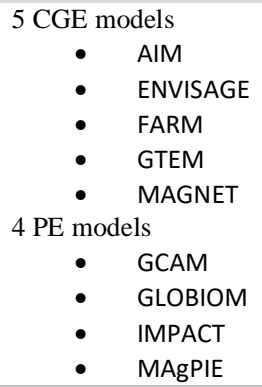 & Global & No & 2050 \\
\hline \multicolumn{7}{|c|}{ IPCC AR5 } \\
\hline Nelson et al. (2014) & $\begin{array}{l}2 \mathrm{GCMs} \\
1 \text { RCP } \\
2 \text { Climate change scenarios: } \\
\bullet \quad \text { HadGEM2-ES (RCP8.5) } \\
\text { - IPSL-CM5A-LR (RCP8.5) }\end{array}$ & $\begin{array}{cc}2 \text { Crop growth models } \\
\qquad \quad \text { DSSAT } \\
-\quad \text { LPJmL }\end{array}$ & $\begin{array}{cl}5 \text { CGE models } \\
\bullet & \text { AIM } \\
\bullet & \text { ENVISAGE } \\
\bullet & \text { FARM } \\
\bullet & \text { GTEM } \\
\bullet & \text { MAGNET } \\
4 \mathrm{PE} \text { models } \\
\bullet \quad \text { GCAM } \\
\bullet \quad \text { GLOBIOM } \\
\bullet \quad \text { IMPACT } \\
\bullet \quad \text { MAgPIE }\end{array}$ & Global & No & 2050 \\
\hline
\end{tabular}




\begin{tabular}{|c|c|c|c|c|c|c|}
\hline Reference & $\begin{array}{c}\text { GCMs/RCMs } \\
\text { Emission scenarios } \\
\text { Climate projections } \\
\end{array}$ & Biophysical model & $\begin{array}{l}\text { Economic } \\
\text { model }\end{array}$ & $\begin{array}{l}\text { Regional } \\
\text { Scope }\end{array}$ & $\begin{array}{l}\text { CO2 } \\
\text { fertilization }\end{array}$ & $\begin{array}{l}\text { Time } \\
\text { Horizon }\end{array}$ \\
\hline Von Lampe et al. (2014) & $\begin{array}{l}\text { 2GCMs } \\
\text { 1RCP } \\
2 \text { Climate change scenarios: } \\
\qquad \quad \text { HadGEM2-ES (RCP8.5) } \\
\text { - IPSL-CM5A-LR (RCP8.5) }\end{array}$ & $\begin{array}{cc}2 \text { Crop growth models } \\
\qquad \quad \text { DSSAT } \\
\bullet \quad \text { LPJmL }\end{array}$ & 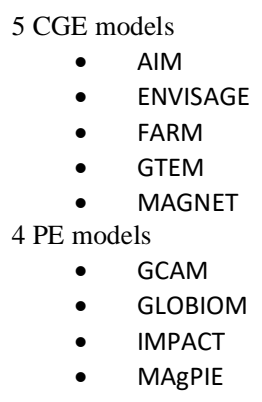 & Global & No & 2050 \\
\hline Witzke et al. (2014) & $\begin{array}{l}\text { 2GCMs } \\
\text { 1RCP } \\
2 \text { Climate change scenarios: } \\
\qquad \quad \text { HadGEM2-ES (RCP8.5) } \\
\text { - IPSL-CM5A-LR (RCP8.5) }\end{array}$ & $\begin{array}{cc}2 \text { Crop growth models } \\
\qquad \quad \text { DSSAT } \\
\bullet \quad \text { LPJmL }\end{array}$ & 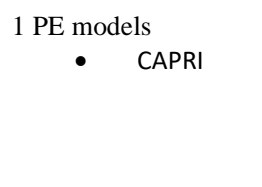 & Global & No & 2050 \\
\hline \multicolumn{7}{|c|}{ European regional economic impact assessments } \\
\hline Blanco et al. (2014b) & $\begin{array}{l}3 \mathrm{GCMs} \\
1 \mathrm{RCP} \\
3 \text { Climate change scenarios } \\
\text { (with and without CO2): } \\
\text { - HadGEM2-ES (RCP8.5) } \\
\text { - } \quad \text { IPSL-CM5A-LR (RCP8.5) } \\
\text { - MIROC (RCP8.5) }\end{array}$ & $\begin{array}{ll}\text { - } & \text { LPJmL (Global) } \\
& \text { WOFOST (EU) }\end{array}$ & $\begin{array}{l}1 \mathrm{PE} \text { models } \\
\bullet \quad \text { CAPRI }\end{array}$ & $\begin{array}{l}\text { Europe } \quad(280 \\
\text { NUTS } 2 \\
\text { region } \\
\text { Global } \quad 77 \\
\text { countries in } \\
40 \quad \text { trade } \\
\text { blocks }\end{array}$ & Yes & 2030 \\
\hline Frank et al. (2014) & $\begin{array}{l}\text { 2GCMs } \\
\text { 1RCP } \\
2 \text { Climate change scenarios: } \\
\text { • HadGEM2-ES (RCP8.5) } \\
\text { - IPSL-CM5A-LR (RCP8.5) }\end{array}$ & $\begin{array}{ll}\text { - } & \text { DSSAT } \\
\text { - } & \text { LPJmL }\end{array}$ & $\begin{aligned} & 2 \text { PE models } \\
&$\[ \]$ \text { CAPRI } \\
& \bullet \text { GLOBIOM } \\
&-E U\end{aligned}$ & $\begin{array}{l}\text { GLOBAL - } \\
\text { EUROPE }\end{array}$ & No & 2050 \\
\hline
\end{tabular}


Annex 3. Main features and differences between market models used for the assessment of climate change impact on agriculture.

\begin{tabular}{|c|c|c|c|}
\hline & PE model & BLS trade model & GE model \\
\hline Scope of application & Agricultural Sector & Regional subset of economies & Global Economy \\
\hline $\begin{array}{l}\text { Underlying economic } \\
\text { theory }\end{array}$ & Partial equilibrium (agri-markets) & $\begin{array}{l}\text { General equilibrium highly focused on } \\
\text { agriculture }\end{array}$ & General Equilibrium \\
\hline Exogenous variables & Policy, Behavioural parameters & $\begin{array}{l}\text { Policy, Macroeconomic variables, Technical } \\
\text { Progress, Shifts in lifestyles. }\end{array}$ & Policy, Macroeconomic variables \\
\hline Model Outputs & $\begin{array}{l}\text { Production consumption, prices and trade in some } \\
\text { markets }\end{array}$ & $\begin{array}{l}\text { Food Production, Food prices, Number of } \\
\text { people at risk of hunger }\end{array}$ & $\begin{array}{l}\text { Production, consumption, prices, trade levels } \\
\text { and welfare }\end{array}$ \\
\hline $\begin{array}{l}\text { Representation of } \\
\text { differences between } \\
\text { economies }\end{array}$ & Parametric differences between regions & $\begin{array}{l}\text { Linked individual country models } \\
\text { Differences in parameters for models with } \\
\text { common structure }\end{array}$ & Parametric differences between regions \\
\hline Strengths & $\begin{array}{l}\text { Provides much product detail than BLS and GE } \\
\text { models. } \\
\text { Ability to flexibly integrate a wide range of policy } \\
\text { instruments } \\
\text { Facilitates both the data-handling aspects as well as } \\
\text { the interpretation of results. }\end{array}$ & $\begin{array}{l}\text { Can capture more regional economic and } \\
\text { institutional details than GE models (National } \\
\text { models account with greater commodity } \\
\text { detail). }\end{array}$ & $\begin{array}{l}\text { Complete representation of national economies } \\
\text { Takes in to account the interactions between } \\
\text { the agricultural sector and the rest of the } \\
\text { economy. } \\
\text { important in a context where linkages from the } \\
\text { farm to the non-farm sectors are significant }\end{array}$ \\
\hline Weaknesses & $\begin{array}{l}\text { Limited capability to handle structural differences } \\
\text { between economies } \\
\text { Only suites for policy analysis when the linkages } \\
\text { with the rest of the economy are small }\end{array}$ & $\begin{array}{l}\text { Individual country models may make it } \\
\text { difficult to disentangle model results into the } \\
\text { effects of exogenous events on the one hand } \\
\text { and differences in theories on the other hand. } \\
\begin{array}{l}\text { Difficulties in terms of consistency and } \\
\text { maintenance. }\end{array}\end{array}$ & $\begin{array}{l}\text { Limited capability to handle structural } \\
\text { differences between economies } \\
\text { Often highly aggregated } \\
\text { Rough representation of policies }\end{array}$ \\
\hline
\end{tabular}




\section{Annex 4. National Institute for Agricultural Development Survey}

\begin{tabular}{|c|c|c|}
\hline \multirow{2}{*}{ Versión:00 } & Programa de Desarrollo de Acción Local & División de Fomento \\
\hline & FORMULARIO: F-Fo-ProDESAL-01 & Fecha: 7 de Junio de 2011 \\
\hline
\end{tabular}

\begin{tabular}{|c|c|c|c|c|c|c|c|c|c|}
\hline 1.- INFORMACIÓN GENERAL & & & & & & \multicolumn{2}{|c|}{ Coordenadas SIG } & & \\
\hline Fecha & & & & & & \multicolumn{2}{|l|}{ Datum } & & \\
\hline Nombre encuestador & & & & & & \multicolumn{2}{|l|}{ Huso } & & \\
\hline Nombre Unidad Operativa & & & & & & \multicolumn{2}{|c|}{ Coordenada este } & & \\
\hline Año Inicio & & & & & & \multicolumn{2}{|c|}{ Coordenada norte } & & \\
\hline & & & & & & & & & \\
\hline 1.1 Usuario & & & & & & & & & \\
\hline Rut Usuario & \multicolumn{5}{|c|}{ Nombre de Comunidad/asociación/agrupación } & & & & \\
\hline Nombre Usuario & & & & & Etnia & & & & \\
\hline Iniciación de Actividades & (Si/No) & Fecha & & Régimen conyugal & & & & & \\
\hline \multicolumn{2}{|c|}{ Objetivo que busca al participar del Programa: } & \multicolumn{2}{|c|}{ Producción para autoconsumo } & \multicolumn{3}{|c|}{ Generar excedentes para la venta } & \multicolumn{3}{|c|}{ Desarrollar un negocio } \\
\hline & & & & & & & & & \\
\hline \multicolumn{10}{|l|}{ 1.2 Predio } \\
\hline \multicolumn{10}{|l|}{ Dirección } \\
\hline \multirow{2}{*}{\multicolumn{2}{|c|}{ Localidad Sector }} & & & & & & & & \\
\hline & & Comuna & Provincia & \multicolumn{2}{|c|}{ Región } & \multicolumn{2}{|c|}{ RolPredio } & & \\
\hline \multirow{2}{*}{ Tenencia } & & & & & & & \multirow[b]{2}{*}{ Mediería } & & \\
\hline & Propietario & Sucesión & Arrendatario & & Usufructuario & & & & \\
\hline & Comunero & individual & & & & & & & \\
\hline & & & & & & & & & \\
\hline \multicolumn{9}{|l|}{ Distribución de la superficie (ha) } & \\
\hline Total & Regada & Secano & Uso Agrícola & & Uso Forestal & \multicolumn{2}{|r|}{$\begin{array}{l}\text { Clase de Uso } \\
\text { de suelo }\end{array}$} & & \\
\hline \multirow[t]{4}{*}{ Recurso Hidrico para Riego } & Fuente de agua & $\begin{array}{l}\text { Suficiente } \\
\text { [Síno] }\end{array}$ & $\begin{array}{l}\text { Cantidad de Derechos de } \\
\text { Agua }\end{array}$ & \multicolumn{5}{|c|}{ Situación Jurídica del Água } & \\
\hline & & & & Inserita & & No inscrita & & En trámite & \\
\hline & & & & Inserita & & No inserita & & En trámite & \\
\hline & & & & & & & & & \\
\hline
\end{tabular}




\begin{tabular}{|c|c|c|}
\hline $3 x=$ & Programa de Desarrollo de Acción Local & División de fomento \\
\hline \multirow{2}{*}{ versión: 00} & FORMULARIO: F-FO-PRODESAL-01 & \multirow{2}{*}{ Fecha: 7 de Junio de 2011} \\
\hline & Encuesta de Diagnóstico de Usuarios & \\
\hline
\end{tabular}

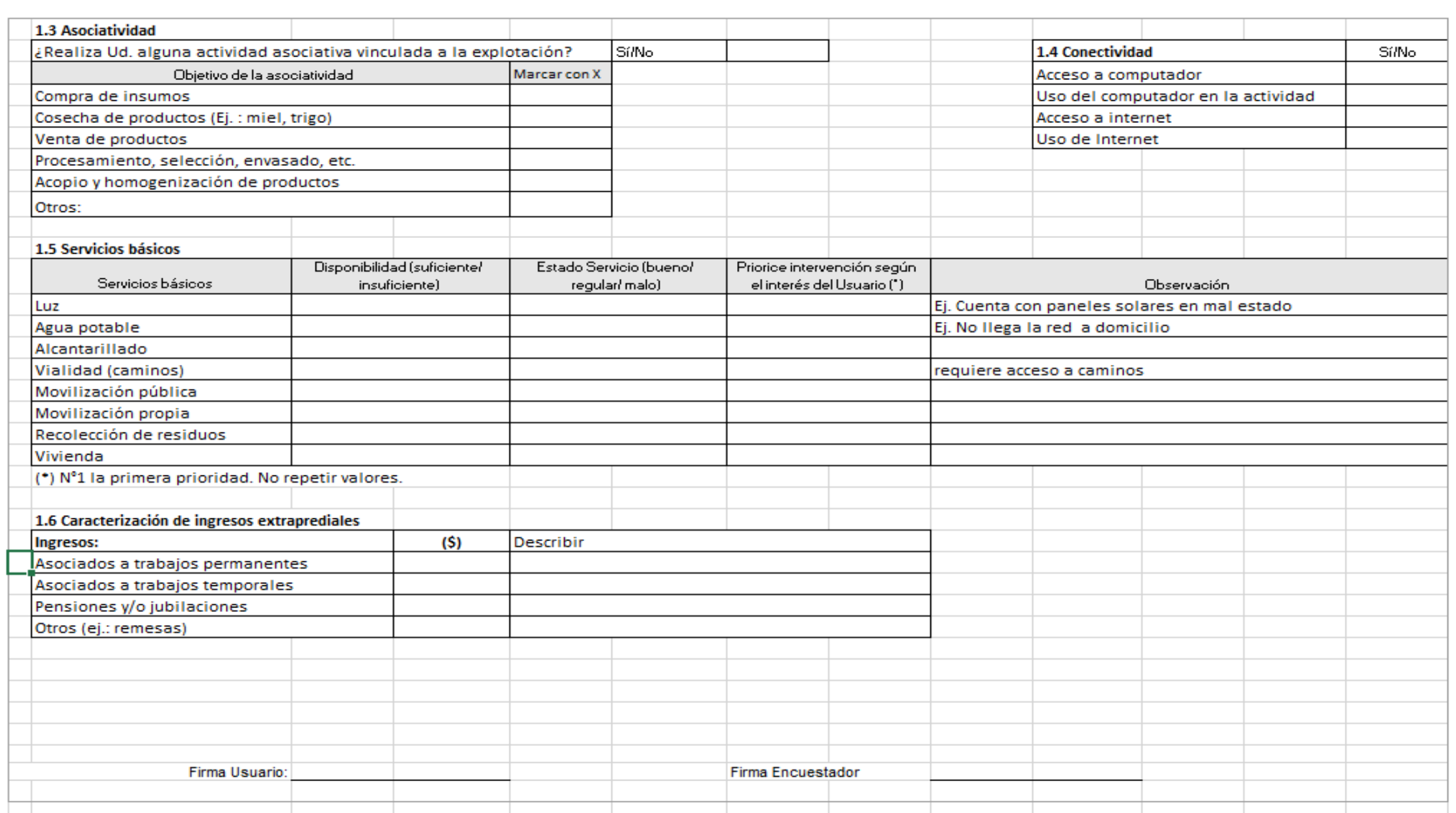




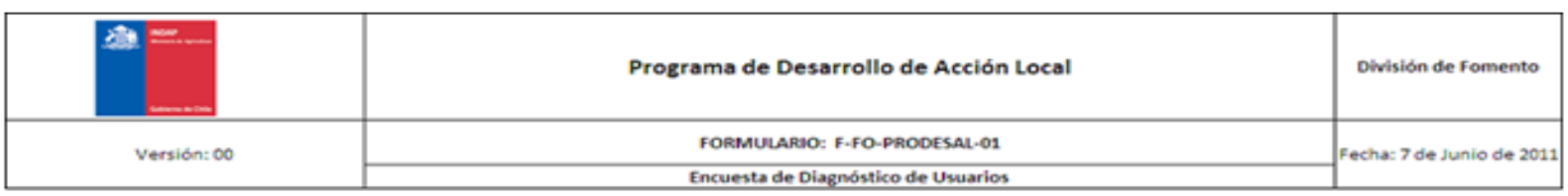

\section{MULTIACTIVIDAD}

2.1Caracterización de la producción

\begin{tabular}{|l|l|l|l|}
\hline & Rubro & Nombre especie & $\begin{array}{c}\text { Superficie } \\
\text { (halo } \\
\text { cantidad }\end{array}$ \\
\hline Cultivo Principal 1 & Hortalizas & Lechuga & \\
\hline Cultivo Principal 2 & Hortalizas & Tomates & \\
\hline Cultivo Principal 3 & Hortalizas & Cebolla & \\
\hline Cultivo Principal 4 & Chacra & Papa & \\
\hline & & & \\
\hline & & & \\
\hline & & & \\
\hline & & & \\
\hline & & & \\
\hline & & & \\
\hline
\end{tabular}

Gcuesta de Diagrósthe de ur

Cechas 7 de Junio de 201

") colocar la unidad relacionada al producto indicada en ane

2.2 Estimación de Ingresos

\begin{tabular}{|c|c|c|c|c|c|c|c|c|c|}
\hline Especie & $\begin{array}{c}\text { Cantidad } \\
\text { producida } \\
\text { (") }\end{array}$ & $\begin{array}{l}\text { Unidad de } \\
\text { medida }\end{array}$ & $\begin{array}{c}\text { Estimación } \\
\text { Precio } \\
\text { unitario }\end{array}$ & $\begin{array}{l}\text { Estimación } \\
\text { valor de la } \\
\text { producción }\end{array}$ & $\begin{array}{c}\text { Porcentaje } \\
\text { consumnido } \\
\text { yro } \\
\text { intercambiado }\end{array}$ & \begin{tabular}{|} 
Valorización \\
consumido yło \\
intercambiado
\end{tabular} & Valor total & $\begin{array}{c}\text { Calidad } \\
\text { (Evennot Ficulart } \\
\text { Mala) }\end{array}$ & Identifique el problema \\
\hline Lechuga & 100 & & & o & & 0 & & & \\
\hline \begin{tabular}{|l|} 
Tomates \\
\end{tabular} & & & & 0 & & 0 & & & \\
\hline Cebolla & & & & 0 & & 0 & & & \\
\hline Papa & & & & o & & o & & & \\
\hline Total & & & & 0 & & & c & & \\
\hline
\end{tabular}

Toral

(") colocar la unidad relacionada ol producto indicada en anexo 1

2. 3 Costos (M\$)

Insumos

1

Mano de obrafamiliar

Mano de obra Externa

Maquinariay servicios

Total 0

2.4 Gestión
\begin{tabular}{|l|c|l|}
\hline Actividad & [SilNo) & Describa \\
\hline ¿Realiza manejo orgánico? & & \\
\hline ¿Realiza control de malezas? & & \\
\hline ¿Realiza control de plagas y enfermedad & & \\
\hline
\end{tabular} 


\begin{tabular}{|c|c|c|}
\hline$a=$ & Programa de Desarrollo de Acción Local & División de fomento \\
\hline \multirow{2}{*}{ versión: 00} & FORMMULARIO: F-FO-PRODESAL-01 & \multirow[t]{2}{*}{ Fecha: 7 de Junio de 201} \\
\hline & Encuesta de Diagnnóstico de Usuarios & \\
\hline
\end{tabular}

3. ESPECIALIDADES CAMPESINAS

3.1 Caracterización de la Producción

\begin{tabular}{|c|c|c|c|c|c|c|c|c|c|}
\hline \multicolumn{3}{|c|}{ 3.1 Caracterización de la Producción } & \multicolumn{2}{|c|}{ Producción anual } & \multirow[b]{2}{*}{$\begin{array}{l}\text { Mes inicio } \\
\text { producción }\end{array}$} & \multirow[b]{2}{*}{$\begin{array}{c}\text { Mes } \\
\text { finalización } \\
\text { producción }\end{array}$} & \multirow[b]{2}{*}{$\begin{array}{c}\text { Calidad } \\
\text { (Bueno/ } \\
\text { Regular/Malo) }\end{array}$} & \multirow{2}{*}{\multicolumn{2}{|c|}{ Identifique a el problema }} \\
\hline Especie & Subproducto & $\begin{array}{c}\text { Año de inicio del } \\
\text { negocio }\end{array}$ & $\begin{array}{l}\text { Cantidad total } \\
\text { producida/año }\end{array}$ & $\begin{array}{l}\text { Unidad de } \\
\text { medida } \\
\text { (kg o lt) }\end{array}$ & & & & & \\
\hline Durazno conservero & conservas & & & & & & & & \\
\hline Ovinos & Queso & & & & & & & & \\
\hline \multicolumn{10}{|l|}{ Harina de avellanas } \\
\hline \multicolumn{10}{|c|}{ Hiebas condimentarias } \\
\hline \multirow{2}{*}{\multicolumn{10}{|c|}{\begin{tabular}{|l} 
Chicha de Menzanas \\
TOTAL
\end{tabular}}} \\
\hline & & & & & & & & & \\
\hline Durazno conservero & conservas & & & & & $\mathrm{c}$ & & 0 & $\mathrm{c}$ \\
\hline Ovinos & Queso & & & & & c & & 0 & $\mathrm{c}$ \\
\hline \multirow[t]{3}{*}{ Abejas } & miel & envase $1 \mathrm{~kg}$ & & & & $\mathrm{c}$ & & 0 & $c 0$ \\
\hline & Jabòn & & & & & c & & 0 & $\mathrm{c}$ \\
\hline & Manjar & & & & & $\mathrm{c}$ & & 0 & co \\
\hline
\end{tabular}

3.3 Costos (MS)

Insumos

Mano de obra familiar

Mano de obra Externa

Maquinaria y servicios

Total

\begin{tabular}{|l|l|l|}
\hline 3.4 Gestión \\
\hline Actividad & (Si/No) & Drecriba \\
\hline cLleva registros de producción? & & \\
\hline cLleva registros de labores? & & \\
\hline
\end{tabular}

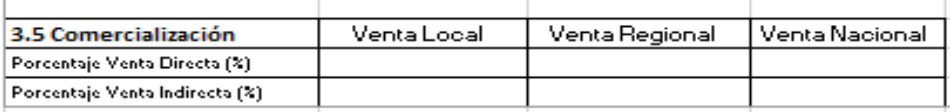

Encuesta_Diagnóstico_PRODESAL (002)

3. Especialidades Campesinas 


\begin{tabular}{|c|c|c|}
\hline$a=1$ & Programa de Desarrollo de Acción Local & Owision de fomento \\
\hline \multirow{2}{*}{ version: $\infty$} & FORMULARIO: F.FO-PRODESAL.01 & \\
\hline & Encuesta de Diagnóstiko de Usuarios & \\
\hline
\end{tabular}

7. CULTIVOS: HORATLIZAS Y CHACRAS, CULTIVOS INDUSTRIALES, PRODUCCIÓN DE SEMILLAS, CULTIVOS EN INVERNADERO, FRUTALES, CEREALES, LEGUMINOSAS, FLORICULTURA Y HIERBAS MEDICINALES

\begin{tabular}{|c|c|c|c|c|c|c|c|c|c|}
\hline \multicolumn{10}{|c|}{ 7.1Caracterización de la producción } \\
\hline & Rubro & $\begin{array}{l}\text { Nombre } \\
\text { especie }\end{array}$ & $\begin{array}{l}\text { Invernader } \\
\text { ol Aire libre }\end{array}$ & $\begin{array}{l}\text { Superficie } \\
\text { (ha) }\end{array}$ & $\begin{array}{l}\text { Rendimient } \\
\text { ol ha. (") }\end{array}$ & $\begin{array}{c}\text { ¿Posee } \\
\text { semilla } \\
\text { certificada? } \\
\text { [Sil No) }\end{array}$ & Riego (SillNo) & $\begin{array}{c}\text { Riego } \\
\text { Tecrificado } \\
\text { (SilNo) }\end{array}$ & $\begin{array}{l}\text { Identifique el Problema } \\
\text { (plagas o enfermedadesi malezas' nutrición) }\end{array}$ \\
\hline \begin{tabular}{|l|} 
Cultivo Principal1 \\
\end{tabular} & Hortalizas & Lechuga & & & & & & & \\
\hline \begin{tabular}{|l|l|} 
Culivo Principal2 \\
\end{tabular} & Frutales & Durazno & & & & & & & \\
\hline \begin{tabular}{|l} 
Cultivo Principal 3 \\
\end{tabular} & Flores & Alstroemeria & & & & & & & \\
\hline \begin{tabular}{|l|} 
Cultivo Principal 4 \\
\end{tabular} & & & & & & & & & \\
\hline
\end{tabular}

Cultivo Principal 4 colocar la unidad relacionada al producto indicada en aneso

\begin{tabular}{|c|c|c|c|c|c|c|c|c|c|c|}
\hline 7.2 Estimación & & & & & & & & & & \\
\hline Especie & $\begin{array}{c}\text { Cantidad } \\
\text { producida } \\
{["]}\end{array}$ & $\begin{array}{l}\text { Unidad de } \\
\text { medida }\end{array}$ & $\begin{array}{l}\text { Cantidad } \\
\text { vendida }\end{array}$ & $\begin{array}{c}\text { Precio } \\
\text { unitario } \\
\text { promedio }\end{array}$ & $\begin{array}{l}\text { Ingresos } \\
\text { por venta }\end{array}$ & $\begin{array}{c}\text { Porcentaje } \\
\text { consumido } \\
\text { y/o } \\
\text { intercambiado }\end{array}$ & $\begin{array}{l}\text { Valorización } \\
\text { consumido ylo } \\
\text { intercambiado }\end{array}$ & Valor total & $\begin{array}{l}\text { Calidad (Buenol) } \\
\text { Regularl'Malo) }\end{array}$ & Identifique el Problema \\
\hline Lechuga & 100 & & & & & & & & & \\
\hline Damascos & & & & & & & & & & \\
\hline & & & & & & & & & & \\
\hline & & & & & & & & & & \\
\hline tal & & & & & & & & & & \\
\hline
\end{tabular}

Total 1 colocar la unidad relacionada al producto indicada en anexo 1

\begin{tabular}{|l|c|c|c|c|}
\hline 7.3 Costos (M\$) & \multicolumn{1}{|c|}{ Total } \\
\hline Insumos & Mano de obrafamiliar & Mano de obra Esterna & Maquinariay servicios & . \\
\hline
\end{tabular}

7.4 Gestión
\begin{tabular}{|l|l|l|}
\hline Actividad & [SilNo] & Drecriba \\
\hline
\end{tabular}

¿Riealiza manejo orgánico?

¿Realiza control de plagas y enfermedades?

¿Lleva registros delabores?

\begin{tabular}{|l|l|l|c|}
\hline 7.5 Comercialización & Venta Local & $\begin{array}{c}\text { Venta } \\
\text { Riegional }\end{array}$ & $\begin{array}{c}\text { Venta } \\
\text { Nacional }\end{array}$ \\
\hline Porcentoje Yents Dircects (") & & & \\
\hline Porcentoj: & & & \\
\hline
\end{tabular}

7.6 Mercado de destino por producto

\begin{tabular}{|l|l|l|}
\hline Producto & & \\
\hline Meroado & & \\
\hline
\end{tabular}

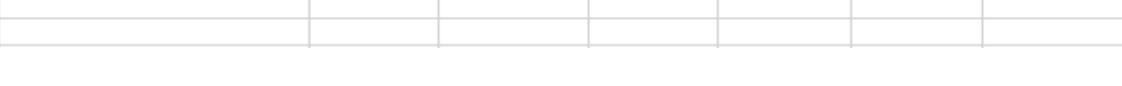




\begin{tabular}{|c|c|c|}
\hline$a=-$ & Programa de Desarrollo de Acción Local & División de fomento \\
\hline \multirow{2}{*}{ version: 00} & FORMULARIO: F-FO-PRODESAL-01 & \multirow{2}{*}{ Fecha: 7 de Junio de 201} \\
\hline & Encuesta de Diagnóstico de Usuatios & \\
\hline
\end{tabular}

9. PRADERAS

9.1 Caracterización de la producción

\begin{tabular}{|c|c|c|c|c|c|c|c|c|c|c|}
\hline \multicolumn{11}{|c|}{9.1 Caracterización de la producción } \\
\hline Rubro & $\begin{array}{c}\text { Tipo pradera } \\
\text { (Natural/Natural } \\
\text { Mejorada/ } \\
\text { Artificial/ } \\
\text { Suplementaria) }\end{array}$ & $\begin{array}{c}\text { Si es artificial: } \\
\text { Origen semilla } \\
\text { (Propia/ } \\
\text { Certificada/ } \\
\text { Corriente) }\end{array}$ & $\begin{array}{c}\text { Especie o Mezcla o } \\
\text { Especie } \\
\text { predominante }\end{array}$ & Superficie (ha) & $\begin{array}{c}\text { Tipo de uso de } \\
\text { (Heno/Pastoreo } \\
\text { directo/Ensilado/ } \\
\text { Otro) }\end{array}$ & $\begin{array}{c}\text { Unidad de medida } \\
\text { ( Fardos/Ton. de } \\
\text { materia seca/ } \\
\text { Ton. de materia } \\
\text { verde) }\end{array}$ & Riego o Secano & $\begin{array}{l}\text { Si es regada: } \\
\text { ¿Posee riego } \\
\text { tradicional o } \\
\text { tecnificado? }\end{array}$ & $\begin{array}{l}\text { Estado de la } \\
\text { pradera (Bueno/ } \\
\text { Regular/Malo) }\end{array}$ & $\begin{array}{l}\text { Identifique el Problema } \\
\text { (estado sanitario/ } \\
\text { malezas/fertilización) }\end{array}$ \\
\hline \multirow{2}{*}{\multicolumn{11}{|c|}{$\begin{array}{l}\text { Pradera } 1 \\
\text { Pradera } 2\end{array}$}} \\
\hline & & & & & & & & & & \\
\hline \multicolumn{11}{|l|}{$\begin{array}{l}\text { Pradera } 2 \\
\text { Pradera } \\
\end{array}$} \\
\hline Pradera 4 & & & & & & & & & & \\
\hline
\end{tabular}

9.2 Estimación de Ingresos

\begin{tabular}{|c|c|c|c|c|c|c|c|c|c|}
\hline \multicolumn{2}{|c|}{ 9.2 Estimación de Ingresos } & \multicolumn{2}{|c|}{ Si es heno o silo: } & \multirow[b]{2}{*}{$\begin{array}{l}\text { Cantidad } \\
\text { vendida }\end{array}$} & \multirow[b]{2}{*}{ Precio unitario } & \multirow[b]{2}{*}{$\begin{array}{l}\text { Ingresos por } \\
\text { venta }\end{array}$} & \multirow[b]{2}{*}{$\begin{array}{c}\text { Porcentaje } \\
\text { consumido y/o } \\
\text { intercambiado }\end{array}$} & \multirow[b]{2}{*}{\begin{tabular}{|c|} 
Valorización \\
consumido y/o \\
intercambiado
\end{tabular}} & \multirow[b]{2}{*}{ Valor total } \\
\hline Especie & $\begin{array}{l}\text { Si es pastoreo: } N^{\circ} \\
\text { cabezas } / \mathrm{há}\end{array}$ & $\begin{array}{l}\text { Cantidad } \\
\text { producida }\end{array}$ & Unidad de medida & & & & & & \\
\hline \begin{tabular}{|l|l} 
Pradera 1 \\
\end{tabular} & & & & & & & & se & 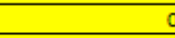 \\
\hline \begin{tabular}{|l|l} 
Pradera 2 \\
\end{tabular} & & & & & & & & ce & \\
\hline \begin{tabular}{|l} 
Pradera 4 \\
\end{tabular} & & & & & & & & 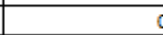 & 0 \\
\hline Total & & & & & & & & & 0 \\
\hline
\end{tabular}

$\left({ }^{*}\right)$ colocar la unidad relacionada al producto indicada en anexo 1

\begin{tabular}{|l|l|l|l|r|}
\hline $9.3 \operatorname{Costos}$ (MS) & & Maquinariay servicios & Total \\
\hline Insumos & Mano de obra familiar & Mano de obra Externa & . & \\
\hline
\end{tabular}

\subsection{Gestión}

\begin{tabular}{|l|c|l|}
\hline Actividad & (Si/No) & Drecriba \\
\hline
\end{tabular}

¿Realiza manejo orgánico?

¿̇Realiza control de malezas?

¿Realiza control de plagas y enfermedad

¿̇Lleva registros de producción?

\begin{tabular}{|l|l|l|l|}
\hline 9.5 Comercialización & Venta Local & Venta Regional & Venta Nacional \\
\hline $\begin{array}{l}\text { Porcentaji Venta } \\
\text { Directa } \%\end{array}$ & & & \\
\hline $\begin{array}{l}\text { Porcentaje Venta } \\
\text { indirecta (\%) }\end{array}$ & & & \\
\hline
\end{tabular}

Indirecta [\%]

\begin{tabular}{l|c|l|} 
& $($ si/No) & Drecriba \\
\hline & & \\
\hline es? & & \\
\hline & & \\
\hline & Venta Regional & Venta Nacional \\
\hline & & \\
\hline
\end{tabular}




\section{Annex 5. Survey of farmers in Central Chile}

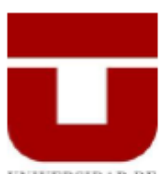

TALCA

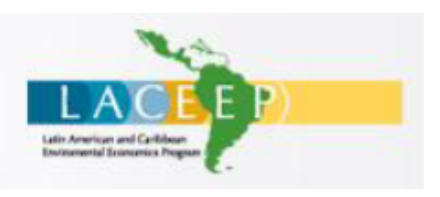

Folio

ENCUESTA A PRODUCTORES

"Impactos y estrategias de adaptación al cambio climático de diferentes sistemas agrícolas de la zona central de Chile".

Nota: Toda la información proporcionada con objeto de la presente encuesta será confidencial. El manejo de los datos será solo de tipo estadístico y NO serán facilitados a terceros. La información personal solicitada tiene por único fin verificar el proceso de recolección de información y dirimir posibles dudas posteriores respecto de algunas preguntas no contestadas por error u omisión del encuestador

\begin{tabular}{|l|l|l|}
\hline \multirow{2}{*}{$\begin{array}{l}\text { IDENTIFICACIÓN } \\
\text { Encuestador }\end{array}$} & Código Encuestador & \multicolumn{2}{|c|}{} \\
\cline { 2 - 4 } & Fecha & Firma \\
\hline
\end{tabular}

\begin{tabular}{|l|l|l|}
\hline \multirow{2}{*}{ DIGITACIÓN } & Nombre Codificador & \multicolumn{2}{|c|}{} \\
\cline { 2 - 4 } & Fecha & Firma \\
\hline
\end{tabular}

Información preliminar

\begin{tabular}{|l|l|}
\hline Comuna & Sector \\
\hline Coordenada $X$ & Coordenada $Y$ \\
\hline Nombre productor & \\
\hline Comunidad de Agua (San Clemente y Parral) & e-mail \\
\hline Teléfono & \\
\hline
\end{tabular}


Sección I. Información Básica (A contestar por el propietario o la persona que administra el predio).

1. ¿Cuántos años cumplidos tiene?

2. ¿Cuántas personas componen su grupo familiar?

3. ¿Cuántos hijos tiene?

4. Si tiene hijos. ¿Cuántos de ellos dependen económicamente de usted?

5. Con respecto a sus estudios. ¿Cuál es su nivel educacional? Marcar el número de años de estudio.

\begin{tabular}{|l|c|c|c|c|c|c|c|c|c|c|c|c|c|c|c|c|c|c|c|}
\hline 1 & 2 & 3 & 4 & 5 & 6 & 7 & 8 & 9 & 10 & 11 & 12 & 13 & 14 & 15 & 16 & 17 & 18 & 19 & + \\
\hline \multicolumn{1}{|c|}{ Educación Básica } & \multicolumn{10}{|c|}{ Educación Media } & \multicolumn{1}{|c|}{ Posgrado } \\
\hline
\end{tabular}

6. Si tiene título universitario o técnico, indique su profesión.

$$
\begin{aligned}
& \square \text { 1. Si Profesión } \\
& \square \text { 2. No }
\end{aligned}
$$

7. El ingreso principal de su hogar, ¿proviene de la agricultura?

$$
\square \text { 1. Si }
$$$$
\square^{2 \text {. No }}
$$

8. ¿Cuántos años ha trabajado en la agricultura?

9. ¿Cuántos lo ha hecho en forma independiente?

10. ¿Cuál es la situación de tenencia de su tierra?

$$
\begin{aligned}
& \square \text { 1. Propia } \\
& \square \text { 2. Arrendada } \\
& \square \text { 3. En sucesión } \\
& \square \text { 4. Otra }
\end{aligned}
$$

11. ¿Cuál es la superficie predial total?

$\square \square \square \square$ Hectáreas

12. ¿Cuántas hectáreas tiene en producción? (Cultivos, frutales, ganadería, praderas, plantaciones forestales) $\square \square \square \square$ Hectáreas

13. ¿Cuántas hectáreas están fuera de producción? (Bosque nativo, quebradas, zonas de protección, vivienda, etc.)

$$
\square \square \square \square \text { Hectáreas }
$$

14. Pertenece a alguna asociación gremial u otro tipo de institución asociada a su actividad como agricultor.

$$
\begin{aligned}
& \square \text { 1. Si ¿Cuál es el nombre de la principal? } \\
& \square \text { 2. No }
\end{aligned}
$$

\section{Sección II. Información Productiva}

15. ¿Cuáles son los rubros de su predio? Por favor, indique el porcentaje aproximado que representa cada rubro sobre el ingreso total del predio y su superficie en hectáreas para la temporada 2010-2011.

\begin{tabular}{|l|l|l|l|}
\hline $\mathrm{N}^{\circ}$ & \multicolumn{1}{|c|}{ Rubro productivo } & \% del ingreso & Superficie destinada (ha) \\
\hline $1^{\circ}$ & Huertas/Chacras & & \\
\hline $2^{\circ}$ & Cultivos anuales & & \\
\hline $3^{\circ}$ & Frutales & & \\
\hline $4^{\circ}$ & Ganaderia & & \\
\hline $5^{\circ}$ & Plantaciones forestales & & \\
\hline $6^{\circ}$ & Otros & & \\
\hline
\end{tabular}


16. Por favor, identifique los 3 principales cultivos anuales en su predio y su superficie en hectáreas

\begin{tabular}{|c|c|c|}
\hline $\mathrm{N}^{\circ}$ & Cultivo & Superficie (ha) \\
\hline 1 & & \\
\hline 2 & & \\
\hline 3 & & \\
\hline
\end{tabular}

17. Respecto de las fechas de siembra y cosecha de dichos cultivos principales, señale si han variado dentro de los últimos 20 años:

\begin{tabular}{|c|c|c|c|}
\hline $\mathbf{N}^{\circ}$ & Cultivo & Fecha de siembra & \multicolumn{1}{|c|}{ Fecha de cosecha } \\
\hline \multirow{2}{*}{1} & & $\square^{\text {1. Se ha adelantado }}$ & $\square^{\text {1. Se ha adelantado }}$ \\
& & $\square^{\text {2. Se ha atrasado }}$ & $\square^{\text {2. Se ha atrasado }}$ \\
& & $\square^{\text {3. Se ha mantenido }}$ & $\square^{\text {3. Se ha mantenido }}$ \\
\hline \multirow{2}{*}{2} & & $\square^{\text {1. Se ha adelantado }}$ & $\square^{\text {1. Se ha adelantado }}$ \\
& & $\square^{\text {2. Se ha atrasado }}$ & $\square^{\text {2. Se ha atrasado }}$ \\
& & $\square^{\text {3. Se ha mantenido }}$ & $\square^{\text {3. Se ha mantenido }}$ \\
\hline \multirow{3}{*}{3} & & $\square^{\text {1. Se ha adelantado }}$ & $\square^{\text {1. Se ha adelantado }}$ \\
& & $\square^{\text {2. Se ha atrasado }}$ & $\square^{\text {2. Se ha atrasado }}$ \\
& & $\square^{\text {3. Se ha mantenido }}$ & $\square^{\text {3. Se ha mantenido }}$ \\
\hline
\end{tabular}

18. Para el primer cultivo mencionado por favor detalle los insumos, la mano de obra, la maquinaria empleados y la producción:

\begin{tabular}{|c|c|c|c|c|}
\hline Insumo & Nombre & Dosis (ma & & sto por ha \\
\hline 1. Semillas o plantas & & $\mathrm{kg} / \mathrm{ha}$ o $\mathrm{pl} / \mathrm{ha}$ & \$/ha & \\
\hline 2. Fertilizante 1 & & $\mathrm{~kg} / \mathrm{ha}$ o l/ha & \$/ha & \\
\hline 3. Fertilizante 2 & & $\mathrm{~kg} / \mathrm{ha}$ o l/ha & \$/ha & \\
\hline 4. Herbicida & & $\mathrm{kg} / \mathrm{ha}$ o l/ha & \$/ha & \\
\hline 5. Plaguicida & & $\mathrm{kg} / \mathrm{ha}$ o l/ha & \$/ha & \\
\hline
\end{tabular}

18b. Mano de obra

\begin{tabular}{|ll|l|l|}
\hline \multicolumn{3}{|c|}{ Actividad } & Jornadas Hombre Empleadas Totales (JH) \\
\cline { 3 - 4 } & Familiar o predial & Contratada \\
\hline 1. & Preparación de terreno (arado-rastraje-cincel) & & \\
\hline 2. & Siembra & & \\
\hline 3. & Aplicación de fertilizantes & & \\
\hline 4. & Aplicación de herbicidas y plaguicidas & & \\
\hline 5. & Riego & & \\
\hline 6. & Cosecha & & \\
\hline
\end{tabular}

18c. Maquinaria

\begin{tabular}{|c|c|c|}
\hline \multirow{2}{*}{ Actividad } & Jornadas de Maquinaria Empleadas Totales (JM) & \multirow{2}{*}{ Costo Total del arriendo (\$) } \\
\hline & Arrendada & \\
\hline 1. Preparación de terreno (arado-rastraje- cincel) & & \\
\hline 2. Siembra & & \\
\hline 3. Aplicación de fertilizantes & & \\
\hline 4. Aplicación de herbicidas y plaguicidas & & \\
\hline 5. Riego (pivote-carrete) & & \\
\hline 6. Cosecha & & \\
\hline
\end{tabular}

18d. Producción

\begin{tabular}{|c|c|c|}
\hline İtem & Unidad (marcar unidad) & Valor \\
\hline 1. Producción total & $\mathrm{Kg} / \mathrm{ha}$-qq/ha- ud/ha & \\
\hline 2. Consumo familiar & $\mathrm{Kg}-\mathrm{qq}-\mathrm{ud}$ & \\
\hline 3. Precio de venta & \$/kg-\$/qq-\$/saco-\$/ud & \\
\hline
\end{tabular}


19. Para el segundo cultivo mencionado por favor detalle los insumos, la mano de obra, la maquinaria empleados y la producción

\begin{tabular}{|c|c|c|c|c|c|}
\hline \multicolumn{2}{|r|}{ Insumo } & \multirow[t]{2}{*}{ Nombre } & Dosis (marcar unidad) & \multicolumn{2}{|c|}{ Costo por ha } \\
\hline & Semillas o plantas & & $\mathrm{kg} / \mathrm{ha}$ o $\mathrm{pl} / \mathrm{ha}$ & \$/ha & \\
\hline 2. & Fertilizante 1 & & $\mathrm{~kg} / \mathrm{ha}$ o $/ \mathrm{ha}$ & \$/ha & \\
\hline 3 & Fertilizante 2 & & $\mathrm{~kg} / \mathrm{ha}$ o l/ha & \$/ha & \\
\hline 4 & Herbicida & & $\mathrm{kg} / \mathrm{ha}$ o l/ha & \$/ha & \\
\hline 5 & Plaguicida & & $\mathrm{kg} / \mathrm{ha}$ o $/ \mathrm{ha}$ & \$/ha & \\
\hline
\end{tabular}

19b. Mano de obra

\begin{tabular}{|c|c|c|}
\hline \multirow[t]{2}{*}{ Actividad } & \multicolumn{2}{|c|}{ Jornadas Hombre Empleadas Totales (JH) } \\
\hline & Familiar o predial & Contratada \\
\hline 1. Preparación de terreno (arado-rastraje-cincel) & & \\
\hline 2. Siembra & & \\
\hline 3. Aplicación de fertilizantes & & \\
\hline 4. Aplicación de herbicidas y plaguicidas & & \\
\hline 5. Riego & & \\
\hline 6. Cosecha & & \\
\hline
\end{tabular}

19c. Maquinaria

\begin{tabular}{|c|c|c|}
\hline \multirow{2}{*}{ Actividad } & Jornadas de Maquinaria Empleadas Totales (JM) & Costo Total del arriendo (\$) \\
\hline & \begin{tabular}{c|c} 
Propia & Arrendada \\
\end{tabular} & \\
\hline 1. Preparación de terreno (arado-rastraje- cincel) & & \\
\hline 2. Siembra & & \\
\hline 3. Aplicación de fertilizantes & & \\
\hline 4. Aplicación de herbicidas y plaguicidas & & \\
\hline 5. Riego (pivote-carrete) & & \\
\hline 6. Cosecha & & \\
\hline
\end{tabular}

19d. Producción

\begin{tabular}{|c|c|c|}
\hline Item & Unidad (marcar unidad) & Valor \\
\hline 1. Producción total & $\mathrm{Kg} / \mathrm{ha}-\mathrm{qq} / \mathrm{ha}-\mathrm{ud} / \mathrm{ha}$ & \\
\hline 2. Consumo familiar & Kg-qq-ud & \\
\hline 3. Precio de venta & \$/kg-\$/qq-\$/saco-\$/ud & \\
\hline
\end{tabular}

20. Para el tercer cultivo mencionado por favor detalle los insumos, la mano de obra, la maquinaria empleados y la producción:

\begin{tabular}{|c|c|c|c|c|}
\hline Insumo & Nombre & Dosis (mi & & sto por ha \\
\hline 1. Semillas o plantas & & $\mathrm{kg} / \mathrm{ha}$ o $\mathrm{pl} / \mathrm{ha}$ & \$/ha & \\
\hline 2. Fertilizante 1 & & $\mathrm{~kg} / \mathrm{ha}$ o l/ha & \$/ha & \\
\hline 3. Fertilizante 2 & & $\mathrm{~kg} / \mathrm{ha}$ o l/ha & \$/ha & \\
\hline 4. Herbicida & & $\mathrm{kg} / \mathrm{ha}$ o l/ha & \$/ha & \\
\hline 5. Plaguicida & & $\mathrm{kg} / \mathrm{ha}$ o l/ha & S/ha & \\
\hline
\end{tabular}

20b. Mano de obra

\begin{tabular}{|ll|l|l|}
\hline \multicolumn{3}{|c|}{ Actividad } & Jornadas Hombre Empleadas Totales (JH) \\
\cline { 3 - 4 } & Familiar o predial & Contratada \\
\hline 1. & Preparación de terreno (arado-rastraje-cincel) & & \\
\hline 2. & Siembra & & \\
\hline 3. & Aplicación de fertilizantes & \\
\hline 4. & Aplicación de herbicidas y plaguicidas & & \\
\hline 5. & Riego & & \\
\hline 6. & Cosecha & & \\
\hline
\end{tabular}

20c. Maquinaria

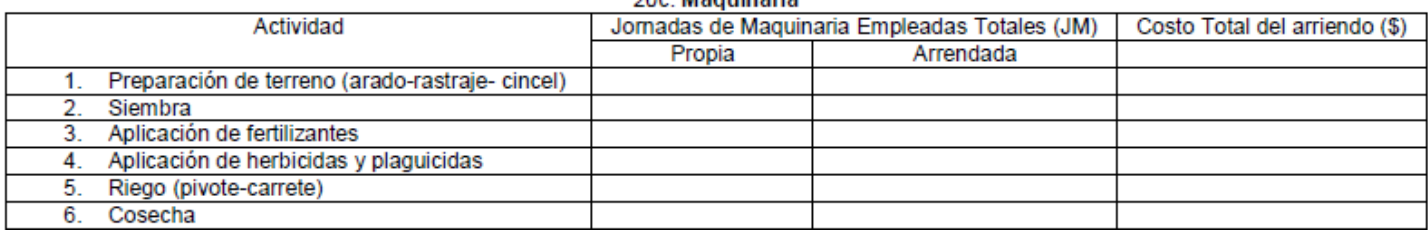

20d. Producción

\begin{tabular}{|c|c|c|}
\hline İtem & Unidad (marcar unidad) & Valor \\
\hline 1. Producción total & $\mathrm{Kg} / \mathrm{ha}-\mathrm{qq} / \mathrm{ha}-\mathrm{ud} / \mathrm{ha}$ & \\
\hline 2. Consumo familiar & $\mathrm{Kg}-\mathrm{qq}-\mathrm{ud}$ & \\
\hline 3. Precio de venta & $\$ / \mathrm{kg}-\$ / q q-\$ /$ saco-\$/ud & \\
\hline
\end{tabular}

21. ¿Cuál es el precio que Ud. pagó la última temporada por día de trabajo o jornal?

22. ¿Cuál es el precio que Ud. pagó la última temporada por día de trabajo o jornal en época de cosecha? \$/JH 


\section{Annex 6. Typology Construction}

The typology construction presented here is based on Alvarez et al. (2014). We construct the typology using four stages: 1) selection of variables, 2) data control for PCA, 3) PCA analysis and 4) hierarchical cluster of PCA results. Using this approach, we identify those variables that best describe the farm variability and group the farms into similar types. The typology was obtained from a survey that was applied in 2011 to a sample of 260 farm households and distributed proportionally to the number of farms in each commune.

\section{Variable selection and data Control}

The framework used to select variables was built on two pillars. First, it was based mainly on a structural typology, which is centred primarily in variables that describe resource endowments (Alvarez et al. 2014). We then considered different recommendations regarding farm typology construction, including the limited number of variables that users should use for typification (Kostrowicki 1977) or the factors that should be accounted for to discard some variables (Aldenderfer and Blashfield 1984; Daloğlu et al. 2014; Köbrich et al. 2003). Second, before running the PCA analysis, we check data, finding potential errors, correlations, outliers, and the variable distributions. Thus, the first variables that we chose were as follows:

Table A1: Variables from dataset ${ }^{\mathrm{a}}$

\begin{tabular}{|c|c|}
\hline Code & Variable \\
\hline Hhsize & Household size (number of members in the household) \\
\hline Farm_size & Land area (ha) \\
\hline Commune & Commune \\
\hline Hrd_ratio & Hired labour ratio (Hired/total lab) \\
\hline Ttl_Lab & Total Labour (workday/years/ha) \\
\hline Ttl_Rev & Total Revenue (\$CLP/ha) \\
\hline Ttl_Cst & Total Cost (\$CLP/ha) \\
\hline Grn_shr & Share of grain crops on total land $(\%)$ \\
\hline SV_shr & Share of spring vegetable on total land (\%) \\
\hline SC_shr & Share of spring crops on total land $(\%)$ \\
\hline Consumption & Consumption (ton/year) \\
\hline
\end{tabular}

To detect potential errors, outliers, and "strong" correlations, we use X-Y and distribution graphics. These figures demonstrate the existence of outliers in datasets of field Farm size, Total Revenue and Total Cost. To observe a more detailed perspective 
of these outliers, we create different boxplots for the variables mentioned above (Figure A1).
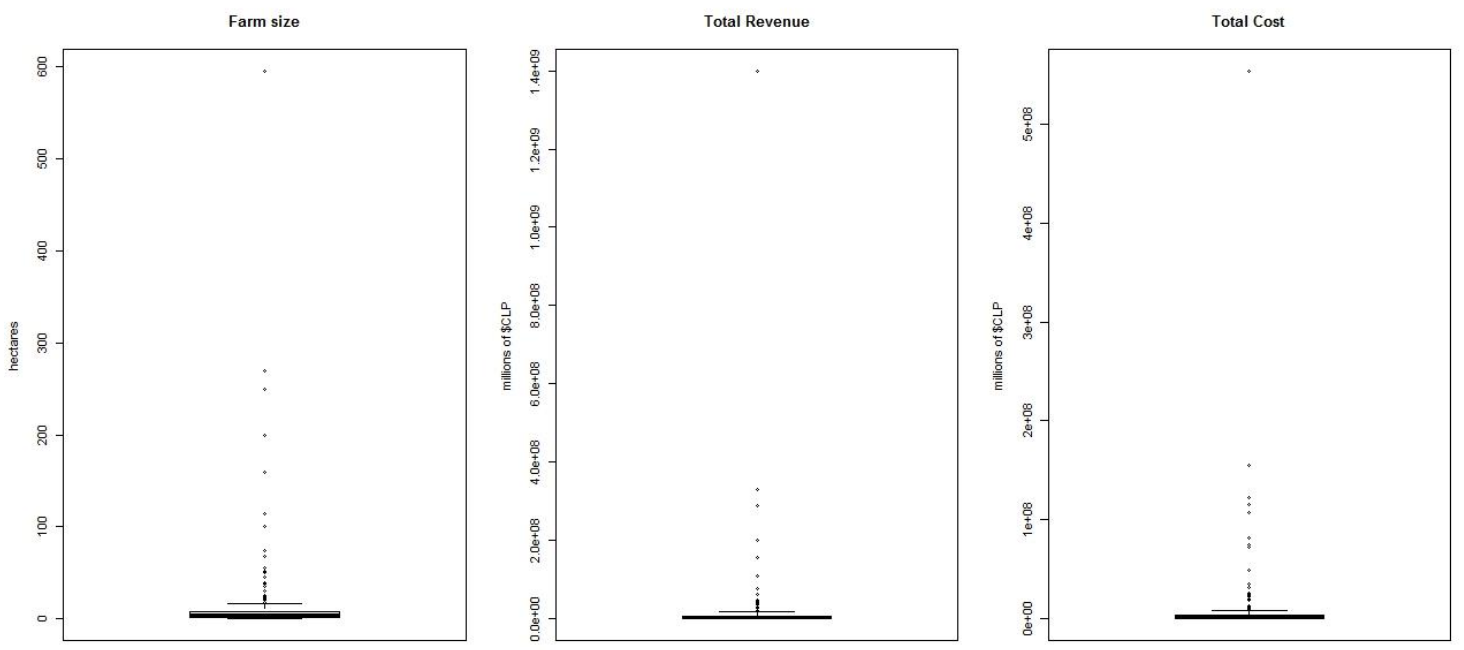

Figure A1. Boxplots for the analysis of selected variables' outliers

Following the advice of different studies (Alvarez et al. 2014; Hair 2010) we remove these outliers before the PCA due to their strong impact on the results. The following boxplots are thus obtained (Figure A2).
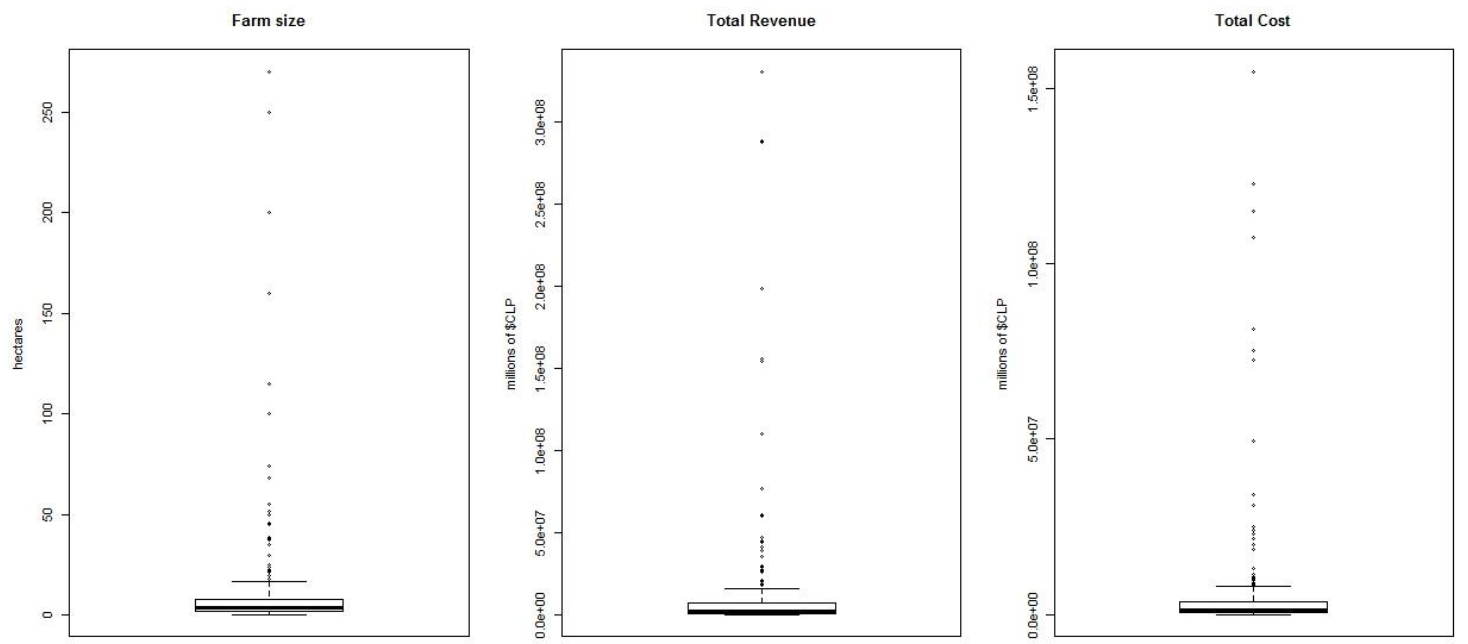

Figure A2. New boxplots for the analysis of selected variables after removing their outliers

Within the new subsets, outliers still remain. However, we are able to determine that they remain sufficiently grouped together to form a farm type. 
As a next step, it is recommended that a PCA uses quantitative variables with normal or at least symmetric distribution. Therefore, we apply different functions to the original variables that do not present a symmetric distribution.

\section{PCA Analysis}

The PCA analysis was conducted using the R-package 'ade4'. The principal components (PC) were determined by the Kaiser criterion, where all PCs with an eigenvalue higher than one were chosen. To avoid any mistake in the selection of PC, we also calculated the cumulated percentage of variability, considering as a criterion previously fixed, that the number of PC chosen must explain $60 \%$ or higher of the variability (Hair et al., 2010).

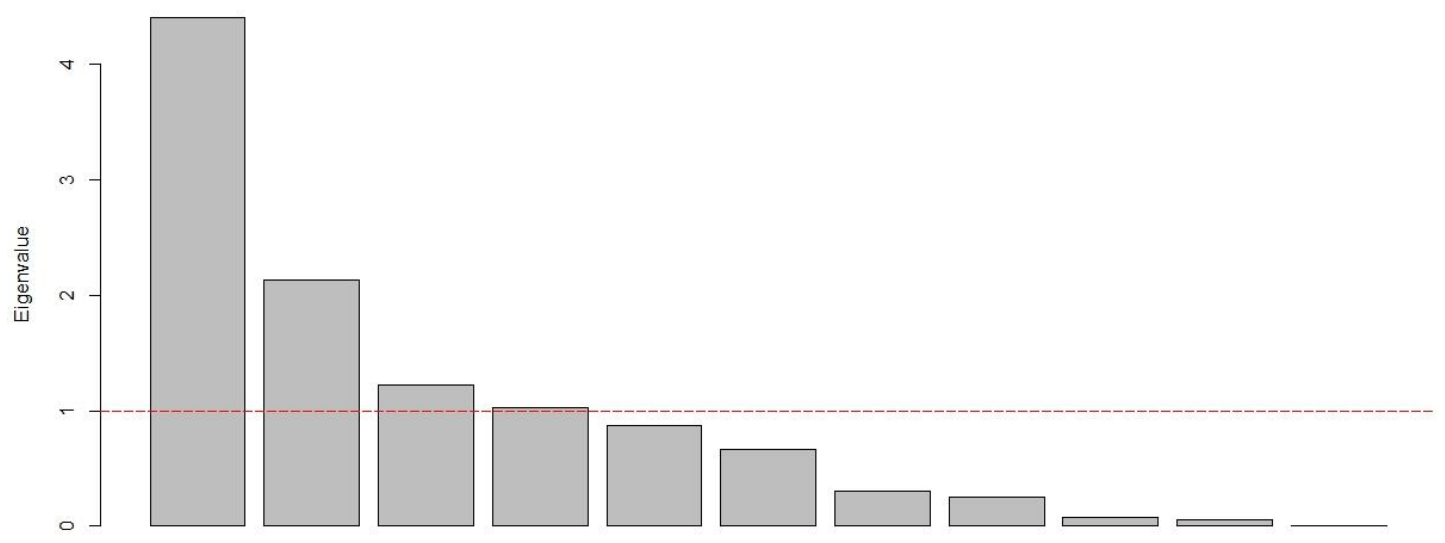

$\mathrm{PC}$

Figure A3. Barplot of eigenvalues of the principal components.

Considering Figure A3 and the cumulated percentage of variability explained by the PC, we select 4 PCs. The cumulative percentage of variability indicates that with PC1, PC2, PC3 and PC4, we can explain the $80 \%$ of the variability of the farms.

The interpretation of the PCs is based on the Table A2 (correlation matrices) and Table A3 (loadings of variables): 
Table A2: Correlation Matrices between principal components and variables.

\begin{tabular}{lcccc}
\hline & Comp 1 & Comp 2 & Comp 3 & Comp 4 \\
\hline Farm_size & $\mathbf{- 0 . 6 8 7 6}$ & $\mathbf{0 . 6 2 3 6}$ & -0.0849 & -0.0982 \\
Commune & 0.0762 & 0.4959 & 0.4119 & 0.3047 \\
Hhsize & -0.1717 & 0.0400 & -0.1056 & $\mathbf{0 . 8 8 7 6}$ \\
Hrd_ratio & $\mathbf{- 0 . 5 9 9 1}$ & 0.0137 & -0.0521 & -0.3024 \\
Ttl_lab & $\mathbf{- 0 . 6 0 2 1}$ & $\mathbf{- 0 . 6 2 9 7}$ & -0.0111 & 0.1748 \\
Ttl_Rev & $\mathbf{- 0 . 8 6 7 8}$ & 0.3942 & -0.1382 & -0.0066 \\
Ttl_Cst & $\mathbf{- 0 . 8 7 4 4}$ & 0.4050 & -0.1158 & -0.0441 \\
Grn_shr & $\mathbf{- 0 . 7 0 2 5}$ & 0.5712 & -0.3583 & 0.0165 \\
SV_shr & -0.5016 & $\mathbf{- 0 . 6 4 5 5}$ & -0.4534 & 0.0263 \\
SC_shr & -0.4970 & -0.1635 & $\mathbf{0 . 8 0 9 9}$ & -0.0431 \\
Consumption & $\mathbf{0 . 8 1 4 3}$ & 0.1022 & 0.0733 & -0.0964 \\
\hline
\end{tabular}

Table A2 shows that variables Farm size, Total Revenue, Total Cost, Total Labour and Hired ratio are negatively correlated with PC1. Further, Grain share and Consumption are positively correlated with PC1. Spring vegetables share and Total labour are negatively correlated with PC2. Spring Crops share is positively correlated with PC3. Finally, household size is positively correlated with PC4. In brief, PC1 expresses information about Farm size (regarding land and labour), PC2 and PC3 describes the relative importance of the Crop's share, and PC4 defines the family size. In this case, the variable Total Cost seems not to bring additional information for the PCA (it is correlated to Total Revenue and could provide redundancy for PC1; 0.93, Pearson's correlation)

Table A3: Loadings of variables by each component for the first run of the PCA

\begin{tabular}{lcccc}
\hline & Comp 1 & Comp 2 & Comp 3 & Comp 4 \\
\hline Farm_size & -0.3234 & $\mathbf{0 . 4 3 2 5}$ & -0.0902 & -0.0968 \\
Commune & 0.0382 & 0.3450 & 0.3920 & 0.2958 \\
Hhsize & -0.0773 & 0.0258 & -0.0857 & $\mathbf{0 . 8 7 4 0}$ \\
Hrd_ratio & -0.2829 & 0.0146 & -0.0540 & -0.3035 \\
Ttl_lab & -0.2907 & $\mathbf{- 0 . 4 3 1 6}$ & -0.0097 & 0.1725 \\
Ttl_Rev & $\mathbf{- 0 . 4 1 1 7}$ & 0.2668 & -0.1324 & -0.0015 \\
Ttl_Cst & $\mathbf{- 0 . 4 1 6 4}$ & 0.2719 & -0.1111 & -0.0386 \\
Grn_shr & -0.3388 & 0.3820 & -0.3314 & 0.0232 \\
SV_shr & -0.2451 & $\mathbf{- 0 . 4 4 8 0}$ & -0.3919 & 0.0362 \\
SC_shr & -0.2367 & -0.0925 & $\mathbf{0 . 7 2 8 2}$ & -0.0597 \\
Consumption & $\mathbf{0 . 3 8 6 4}$ & 0.0794 & 0.0634 & -0.1016 \\
\hline
\end{tabular}


Table A3 shows the loading of the variables by each component, where the higher component loadings of variables Total Revenue, Total Cost, and Consumption indicates that these variables explain the component one. Further, variables Farm size, Total Labour and Spring Vegetable share explain component 2. Spring crops share and Household size explain component three and component 4 respectively. Considering Table A2 and Table A3. The variable commune is not well represented on any of the planes PC1-PC2, PC1-PC3 and PC1-PC4. Thus, we consider deleting commune and Total Cost for the next PCA.

Therefore, we performed the second PCA without the variables communes and Total Cost. Figure A4 represents the new eigenvalues obtained from this analysis.

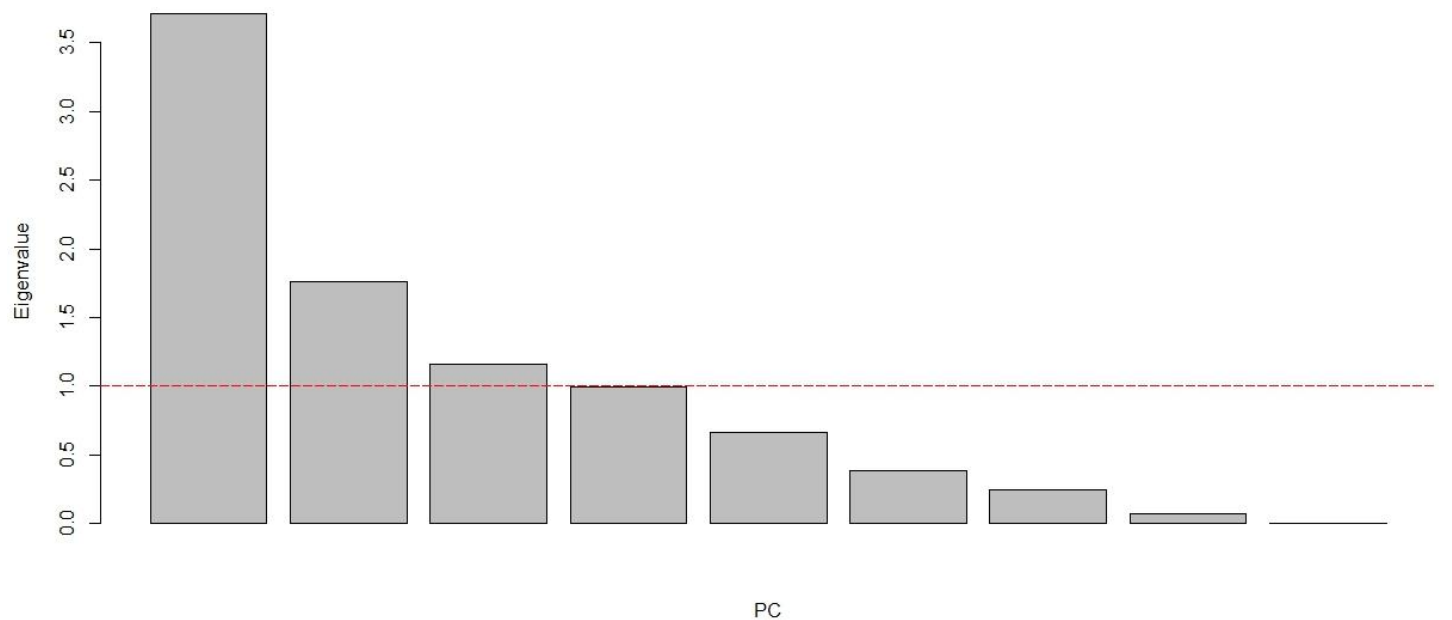

Figure A4. New barplot of eigenvalues per principal component after deletion of variables not well represented on planes, or variables that do not contribute additional information to the PCA.

PC1 and PC2 together explain $61 \%$ of the variability of the farms, and PC1, PC2 and PC3 explain 73.6\%. Here, the Kaiser criterion suggests using 3 PCs for the analysis. To interpret the meaning of each PC, we use the correlation circle (Figure A5). 

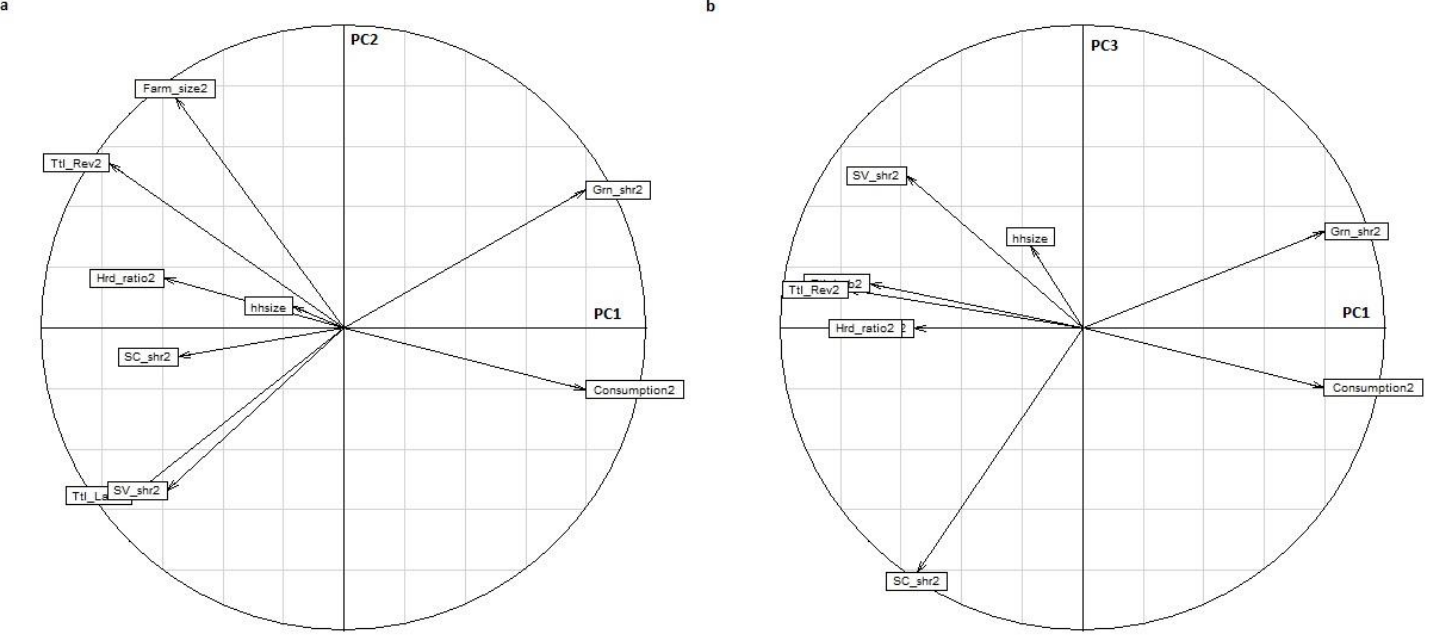

Figure A5. a. Correlation circles for principal components PC1-PC2. b. Correlation circles for the principal components PC1-PC3.

Here, the variables of Total Labour and Total Revenue are negatively correlated with PC1. Meanwhile, Grain share and Consumption are positively correlated with PC1 (Figure A5a), Farm size is positively correlated with PC2 (Figure A5a), and Spring Crops share is negatively correlated with PC3 (Figure A5b). Figure A5 also shows that the variable of household size (hhsize) is not well represented on any of the observed planes.

According to these PCA results, these discriminating variables are the best variables with which to segregate these farm-households. Thus, these are the final variables used for the further analysis (see Table 1 of the main text).

\section{Cluster analysis of PCA results}

We then apply Hierarchical clustering to the PCA results using the WARD method. The number of clusters is chosen based on the overall appearance of the dendrogram, the number of clusters and their interpretability, and the delta of the heights (Alvarez et al. 2014; Husson et al. 2010). 

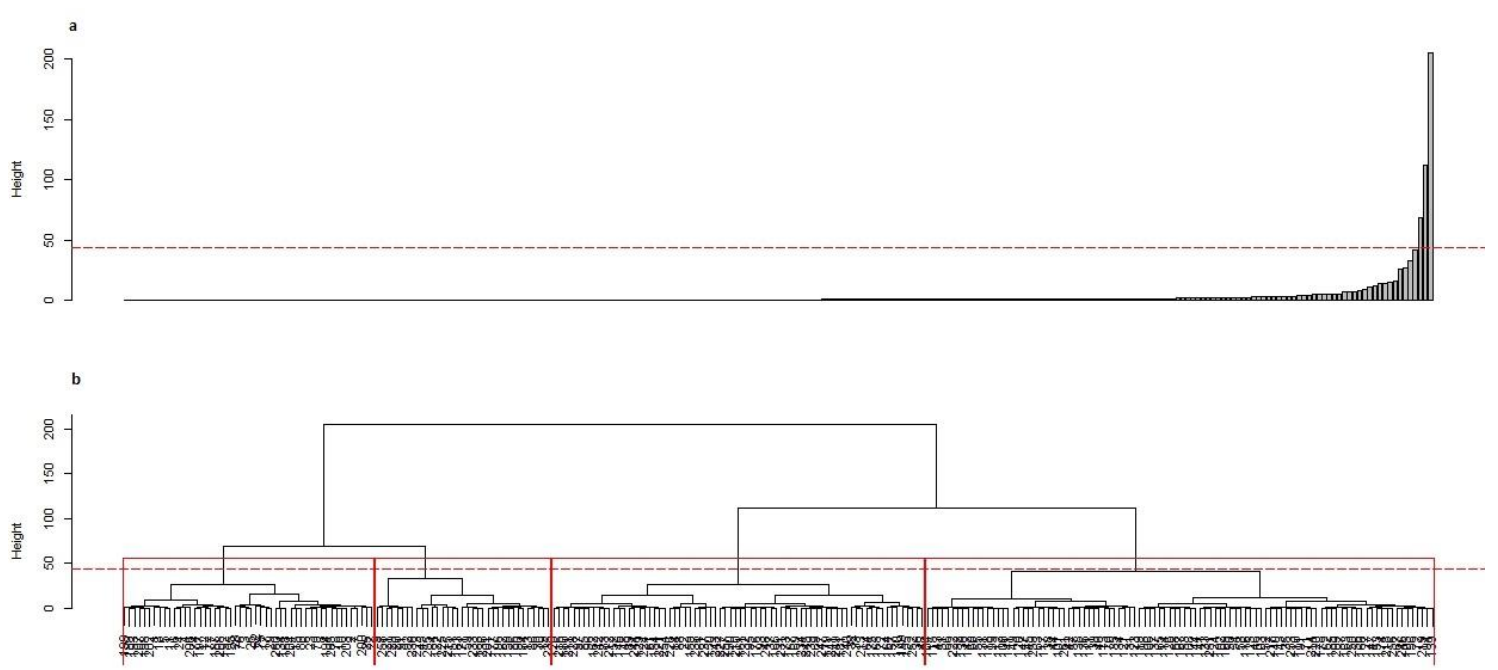

Figure A6. a. Barplot of height, associated with b. Dendrogram. Dotted line represents the selected cutoff point yielding the four-cluster solution

Figure A6 shows the height, which indicates the dissimilarity within clusters related to the number of clusters. In Figure A6a, the bar on the far right shows the maximum dissimilarity, i.e., the dissimilarity when all farms are grouped in one cluster. The heights decrease from right to left in the barplot figure, and the overall structure of the dendrogram (Figure A6b) suggests that the dendrogram can be partitioned ("cut the tree") at a height of approximately 45 (the red dotted line), leading the dendrogram to be separated into 4 clusters. Figure A7 shows the final results of the typology construction.

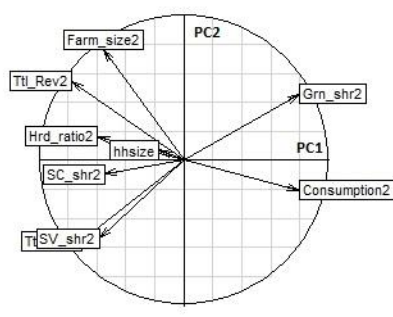

b
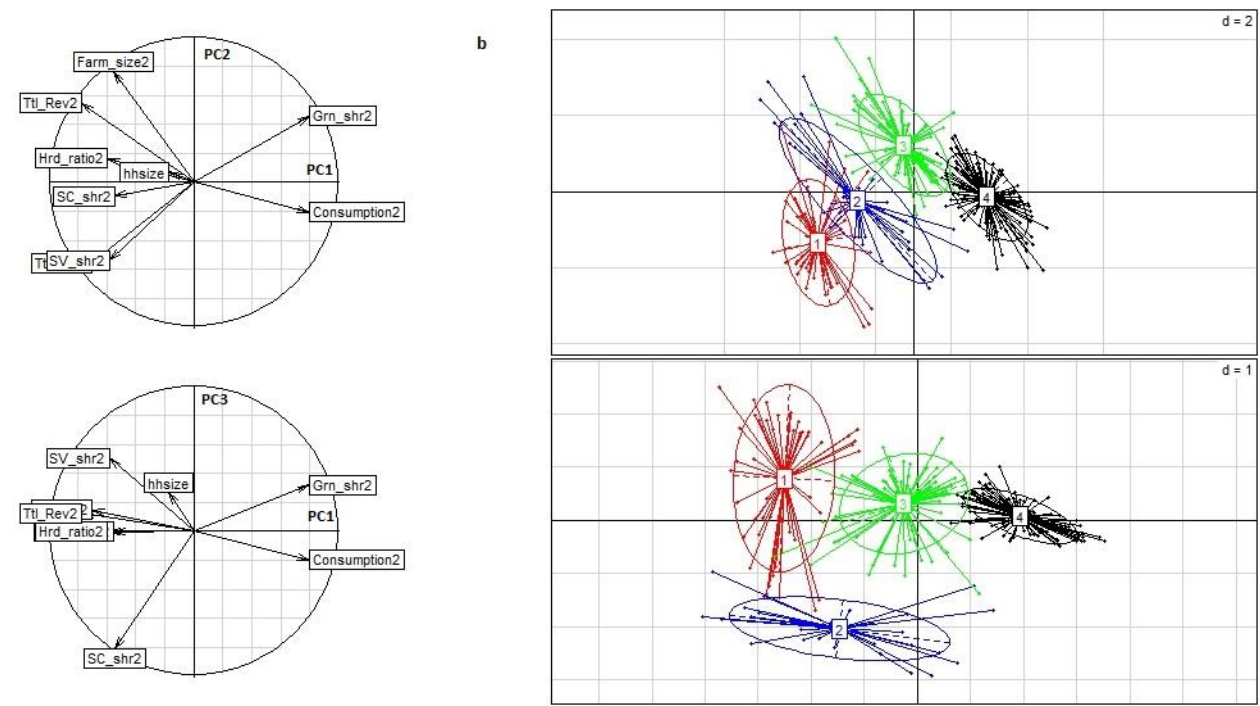

Figure A7. Results of Principal Component Analysis and the Hierarchical Cluster. column a. Correlation circles associated with column b. Cluster outputs in the planes PC1-PC2 and PC1-PC3

In the main text, a detail description of the four cluster can be found in subsection 4.4.2 


\section{References included in Annex 6}

Aldenderfer, M.S., Blashfield, R.K. (1984) Cluster analysis. Sage University paper series on quantitative applications in the social sciences 07-044.

Alvarez, S., Paas, W., Descheemaeker, K., Tittonell, P., Groot, J., (2014) Constructing typologies, a way to deal with farm diversity: general guidelines for the humid tropics, Report for the CGIAR Research Program on Integrated Systems for the Humid Tropics. Plant Sciences Group, Wageningen University, the Netherlands.

Daloğlu, I., Nassauer, J.I., Riolo, R.L., Scavia, D. (2014) Development of a farmer typology of agricultural conservation behavior in the American Corn Belt. Agricultural Systems 129, 93 102. doi: http://dx.doi.org/10.1016/j.agsy.2014.05.007

Hair, J.F., Black, W.C., Babin, B.J. (2010) Multivariate data analysis: A Global Perspective. Pearson Education.

Husson, F., Lê, S., Pagès, J. (2010) Exploratory multivariate analysis by example using R. CRC press

Köbrich, C., Rehman, T., Khan, M. (2003) Typification of farming systems for constructing representative farm models: two illustrations of the application of multi-variate analyses in Chile and Pakistan. Agricultural Systems 76, 141-157. doi: http://dx.doi.org/10.1016/S0308521X(02)00013-6

Kostrowicki, J. (1977) Agricultural typology concept and method. Agricultural Systems 2, 3345. doi: http://dx.doi.org/10.1016/0308-521X(77)90015-4 


\section{Annex 7. Household Model, Mathematical Description}

The details of the mathematical design of the household model are described in this appendix. In line with the overall design described in the main body of the paper, the objective function represented by Equation 1 is subject to several constraints described below.

As previously mentioned in the main manuscript, Farm-household expected revenue $\mathrm{R}$ is specified as the income received from all activities of a family living in the same household. It comprises of three components:

1. Agricultural income $\left(\mathrm{Z}_{\mathrm{h}}\right)$

2. Income from marketed factors of production (e.g., non-farm wages)

3. Off-agricultural farm incomes

Farm household expected income $\mathrm{R}_{\mathrm{h}}$ is calculated according to the following formulation:

$$
R_{h}=Z_{h}+\sum_{l s} L A B E A R N_{h, l s}-\sum_{j}\left(B G H T_{h, j} \times P_{h, j}\right)+e^{x i n c} c_{h}
$$

where LABEARN is the ( $\mathrm{n} \times 1)$ vector of the simulated labour income in each household $\mathrm{h}$ during labour season ls (millions of \$CLP). BGHT is the ( $\mathrm{x}$ 1) vector of bought quantities of goods $\mathrm{j}, \mathrm{P}$ is the ( $\mathrm{n} \times 1$ ) vector of prices of goods $\mathrm{j}$, and exinc is the exogenous off-farm income. It is important to highlight that labour is specified by semester to capture the seasonality of labour use.

Agricultural farm income $\left(Z_{h}\right)$ is defined as the value that farm households have earned by selling or consuming their agricultural products. Agricultural income $\left(Z_{h}\right)$ is calculated according to the following formulation:

$$
\begin{gathered}
Z_{h}=\sum_{j}\left(S_{h, j}+C_{h, j}^{s}\right) P_{h, j}+s b(h)-\sum_{a} \sum_{s}\left(\left(\alpha_{h, a, s} \times\left(X_{h, a, s}\right)^{\beta_{h, a, s} \times X_{h, a, s}}\right)\right. \\
-\sum_{l s} \text { labwage } * \operatorname{HLABOUR}_{h, l s}
\end{gathered}
$$

where $S$ is the ( $n \times 1)$ vector of sold quantities of goods $j, C^{s}$ is the (nx1) vector of selfconsumed amounts of goods, $\mathrm{X}$ is the $(\mathrm{n} \times 1)$ vector of the simulated levels of 
agricultural activities a, per system $\mathrm{s}$, in household $\mathrm{h}, \mathrm{sb}$ is the vector ( $\mathrm{n} \times 1$ ) of the subsidies, $\alpha$ and $\beta$ are cost function parameters estimated using a variant of the Positive Mathematical Programming approach, labwage is the average hired labour wage (in millions of \$CLP per work day), and HLABOUR is the ( $\mathrm{n} x 1$ ) vector of hired labour by household h in labour season ls .

\section{Resource constraints}

Land restrictions limit the total area of available land within each household as tland (ha) and the area potentially under irrigation as iland (ha), where $\operatorname{irr}_{\mathrm{h}}$ refers to the irrigated crops of each household-type, which are represented as follows:

$$
\begin{gathered}
\sum_{a} \sum_{s} X_{h, a, s} \leq \text { tland }_{h} \\
\sum_{a \in i r r_{h}} X_{h, a, s} \leq \text { iland }_{h}
\end{gathered}
$$

Water constraints indicate that the total amount of water used for irrigation at the household level cannot exceed the farm water availability FW (thousand $\mathrm{m}^{3}$ ) (Equation B5), where fir $\mathrm{h}, \mathrm{a}$ refers to the farm-gate irrigation requirements of irrigated crops (thousand $\mathrm{m}^{3} / \mathrm{ha}$ ).

$$
\sum_{a} f i r_{h, a} X_{h, a, s} \leq F W_{h} \quad \forall s=i r r_{h}
$$

Equations B5 considers the conveyance and distribution efficiency of the water network hd and the gross water delivered gwd $\left(\mathrm{m}^{3}\right)$ at the household level h (Equation B6).

$$
F W_{h}=g w d_{h} \times h d
$$

The labour constraint expresses that the total labour requirement of the production plan in a given season $\left(\sum_{a} \sum_{s}\left(\right.\right.$ labreq $\left.\left._{h, a, s} X_{h, a, s} S L R_{a, s, l s}\right)\right)$ cannot exceed the farm labour 
availability of the season, where SLR refers to the percentage share of labour requirements per activity a, per system s and during labour season ls. This labour requirement is limited to the sum of family labour use FLABOUR per year per season ls plus the hired labour use HLABOUR per year per ls.

$$
\sum_{a} \sum_{s} \text { labreq }_{h, a, s} X_{h, a, s} S L R_{a, s, l s} \leq F L A B O U R_{h, l s}+H L A B O U R_{h, l s}
$$

Equation B8 takes into account the family labour use FLABOUR plus labour hired out FOUT by a farm household $\mathrm{h}$ during the season ls. This yields the total family labour available tflab by household $\mathrm{h}$ multiplied by the percentage share of family labour availability SLA.

$$
\mathrm{FLABOUR}_{h, l s}+\mathrm{FOUT}_{h, l s}=\mathrm{tflab}_{h} \times S L A_{l s}
$$

As labour prices are defined exogenously, the farm households have the option of hiring-in labour at the market price as well as hiring it out within the Maule region. In this context, labour income LABEARN by household h corresponds to the labour hired out, FOUT by the hired-out wage rate owage, which is determined exogenously (Equation B9):

$$
\operatorname{LABEARN}_{h, l s}=\mathrm{FOUT}_{h, l s} \times \text { owage }
$$

\section{Cash constraints}

The following cash constraint states that the total value of inputs, goods and tradable factors purchased by a household is constrained by its total cash income from the market sales of goods and marketable factors, plus exogenous off-farm incomes.

$$
\begin{gathered}
\sum_{j}\left(S_{h, j} \times P_{h, j}\right)+s b_{h}+\operatorname{exinc}_{h}+\operatorname{LABEARN}_{h}= \\
\sum_{j}\left(\operatorname{BGHT}_{h, j} \times P_{h, j}\right)+\sum_{a} \sum_{s}\left(\left(\alpha_{h, a, s} \times\left(X_{h, a, s}\right)^{\beta}\right)+\text { labwage } \times H L A B O U R_{h}\right.
\end{gathered}
$$




\section{Price band and complementary slackness conditions}

Market participation decisions are modelled using three blocks of equations.

- The block for upper and lower bounds commodity prices, which considers transaction costs, capturing endogenously market participation decisions, is

$$
\begin{aligned}
& P_{h, j} \leq p_{j}^{m} t_{h, j}^{b} \\
& p_{j}^{m} t_{h, j}^{S} \leq P_{h, j}
\end{aligned}
$$

- The complementary slackness conditions, which guarantee that a farm household uses its internal shadow price if and only if does not participate in the market for goods, is

$$
\begin{gathered}
S_{h, j}\left(P_{h, j}-p_{j}^{m} t_{h, j}^{s}\right)=0 \\
B G H T_{h, j}\left(P_{h, j}-p_{j}^{m} t_{h, j}^{b}\right)=0
\end{gathered}
$$

- Finally, for each good, a farm household can be either a buyer or a seller but no both (household can also be self-sufficient, i.e., neither buying nor selling goods)

$$
S_{h, j} \times B G H T_{h, j}=0
$$

where $p_{j}^{m}$ is the ( $\left.\mathrm{n} \times 1\right)$ vector of market prices of goods and $\mathrm{t}^{\mathrm{b}}$ and $\mathrm{t}^{\mathrm{s}}$ are $(\mathrm{n} \times 1)$ vectors of multiplicative buyer and seller transaction costs, respectively.

\section{Commodity balance at the farm level}

The household model also includes a market condition that ensures commodity balance at the household level, where the sum of production and market demand for each good must be equal to the sum of consumption and market sales.

$$
Q_{h, j}+B G H T_{h, j}=S_{h, j}+C_{h, j}
$$


Where $\mathrm{Q}$ is the ( $\mathrm{n} \times 1$ ) vector of produced quantities of goods and $\mathrm{C}$ is the ( $\mathrm{n} \times 1)$ vector of consumed quantities.

\section{Household consumption}

A linear expenditure system (LES) is used to describe a household's consumption behaviour. This LES function is expressed using the following formulation:

$$
\begin{gathered}
c_{h, j} p_{h, j}=\beta_{h, j}\left(Y_{h}-\sum_{j^{\prime}=j} \gamma_{h, j} p_{h, j \prime}\right)+\gamma_{h, j} p_{h, j} \\
\left\{\begin{array}{l}
0<\beta_{h, j}<1 \\
\sum_{j} \beta_{h, j}=1 \\
\gamma_{h, j}<c_{h, j}
\end{array}\right.
\end{gathered}
$$

where $\mathrm{p}$ is the (nx1) vector of prices of goods, $\mathrm{c}$ is the (nx1) vector of the consumed quantity of goods; $\mathrm{R}$ is the farm household expected income, $\gamma$ is the minimum quantity, below which consumption cannot decrease, and $\beta$ is the marginal budget share ( $\partial \mathrm{pc} / \partial \mathrm{R})$. $\sum_{j^{\prime}=\mathrm{j}} \gamma_{\mathrm{h}, j^{\prime}} \mathrm{p}_{\mathrm{h}, \mathrm{j}^{\prime}}$ is the subsistence expenditure, and the term $\left(\mathrm{Y}_{\mathrm{h}}-\sum_{\mathrm{j}^{\prime}=\mathrm{j}} \gamma_{\mathrm{h}, \mathrm{j}^{\prime}} \mathrm{p}_{\mathrm{h}, \mathrm{j}^{\prime}}\right)$ is generally interpreted as representing "uncommitted" income, which is spent in fixed proportions of $\beta$ between commodities.

Following Louhichi et al. (2013), we estimate the $\gamma$ and $\beta$ parameters for the sampled farm households by using the Generalized Maximum Entropy (GME) method. For the GME, we used income elasticities and the Frisch parameter from the literature (Seale et al. 2003). 


\section{References included in Annex 7}

Louhichi, K., Gomez y Paloma, S., Belhouchette, H., Allen, T., Fabre, J., Blanco-Fonseca, M., Chenoune, R., Acs, S., Flichman, G. (2013) Modelling Agri-Food Policy Impact at Farmhousehold Level in Developing Countries (FSSIM-Dev). Application to Sierra Leone. Joint Research Centre. JRC Scientific and Policy Reports.

Seale, J.L., Regmi, A., Bernstein, J. (2003) International evidence on food consumption patterns. Economic Research Service, US Department of Agriculture 